\title{
Guidelines for laparoscopic (TAPP) and endoscopic (TEP) treatment of inguinal Hernia [International Endohernia Society (IEHS)]
}

\author{
R. Bittner - M. E. Arregui - T. Bisgaard - M. Dudai - G. S. Ferzli • R. J. Fitzgibbons • \\ R. H. Fortelny $\cdot$ U. Klinge $\cdot$ F. Kockerling $\cdot$ E. Kuhry $\cdot$ J. Kukleta $\cdot$ D. Lomanto $\cdot$ \\ M. C. Misra $\cdot$ A. Montgomery $\cdot$ S. Morales-Conde $\cdot$ W. Reinpold $\cdot$ J. Rosenberg $\cdot$ \\ S. Sauerland $\cdot$ C. Schug-Paß $\cdot$ K. Singh $\cdot$ M. Timoney $\cdot$ D. Weyhe $\cdot$ P. Chowbey
}

Received: 4 January 2011 / Accepted: 12 May 2011/Published online: 13 July 2011

(C) The Author(s) 2011. This article is published with open access at Springerlink.com

\section{Table of contents}

Introduction

Chapter 1 Perioperative management: what is the evidence for antibiotic and thromboembolic

\section{R. Bittner $(\square)$}

Hernia Center, Department of General,-Visceral, and Vascular Surgery, EuromedClinic, Europaallee 1, 90763 Fürth, Germany e-mail: bittnerfamilie@web.de

\section{E. Arregui}

Advanced GI surgery, Laparoscopy, Endoscopy and Ultrasound, St. Vincent Hospital and Health Care Center, 8402 Harcourt Rd. Suite 815, Indianapolis, IN 46260, USA

\section{T. Bisgaard}

Department of Surgery, Køge Hospital, University

of Copenhagen, Køge, Denmark

\section{Dudai}

Department of Surgery, Elisha Medical Center, Haifa, Israel

\section{G. S. Ferzli · M. Timoney}

Department of Surgery, Lutheran Medical Center, SUNY Health Science Center, Brooklyn, 65 Cromwell Avenue, Staten Island, NY, USA

\section{R. J. Fitzgibbons}

Department of Surgery, Creighton University, 601 North 30th Street, Suite 3700, Omaha, NE, USA

\section{R. H. Fortelny}

Department of General, Visceral and Oncological Surgery,

Wilhelminenspital, 1171 Vienna, Austria

\section{U. Klinge}

Surgical Department, University of Aachen, and Institut for Applied Medical Engineering AME Helmholtz, Pauwelstrasse, 52074 Aachen, Germany prophylaxis in laparoscopic inguinal hernia surgery?

Chapter 2 Technical key points in transabdominal preperitoneal patch plasty (TAPP)

Chapter 3 Technical key points: total extraperitoneal patch plasty (TEP) repair

\section{F. Kockerling}

Department of Surgery and Center for Minimally Invasive

Surgery, Vivantes Hospital, Neue Bergstr. 6, 13585 Berlin,

Germany

E. Kuhry

Department of Surgery, St Olavs Hospital, Trondheim, Norway

J. Kukleta

General, Visceral, Abdominal Wall Surgery, Klinik Im Park, Grossmuensterplatz 9, 8001 Zürich, Switzerland

D. Lomanto

Minimally Invasive Surgical Center, KTP Advanced Surgical

Training Center, YYL School of Medicine, National University

Hospital, Kent Ridge Wing 2, 5 Lower Kent Ridge Road,

Singapore 119074, Singapore

M. C. Misra

Division of Minimally Invasive Surgery, J P N Apex Trauma Centre, All India Institute of Medical Sciences, Angari Nagar, New Delhi 110029, India
A. Montgomery
Section of Laparoscopy and Abdominal Wall Reconstruction, Department of Surgery, University Hospital of Malmö, Malmö 20502, Sweden
S. Morales-Conde
Advanced Laparoscopic Unit of the University Hospital "Virgen del Rocío", General, Digestive and Laparoscopic Surgery Unit of the USP-"Sagrado Corazón" Clinic, University of Sevilla, Sevilla, Spain 
Chapter 4 TEP versus TAPP: which is better for the patient?

Chapter 5 Laparoscopic surgery in complicated hernia: feasibility, risks, and benefits

Chapter 6 Mesh size and recurrence: what is the optimal size?

Chapter 7 Selection of mesh material

Chapter 8 Cutting or not cutting of mesh: does it influence the recurrence rate?

Chapter 9 Mesh fixation modalities: is there an association with acute or chronic pain?

Chapter 10 Risk factors and prevention of acute and chronic pain

Chapter 11 Urogenital complications associated with laparoscopic/endoscopic hernia repair

Chapter 12 Intraperitoneal onlay mesh (IPOM) for inguinal hernia repair-still a therapeutic option?

Chapter 13 Role for open preperitoneal mesh repair in the era of laparoscopic inguinal hernia repair Chapter 14 Sportsman hernia—diagnosis and treatment

\section{Introduction}

Governments and health insurers increasingly demand transparent quality-control mechanisms. A new type of reimbursement, "pay for performance," is being discussed. Therefore, the development and implementation of guidelines constitutes an important step toward the introduction of optimal diagnostic and therapeutic concepts with the goal of improving the quality of treatment. Guidelines should define standards to help the surgeon in his or her daily work by finding the best surgical strategy for his patient.

The Guidelines are essentially evidence-based (EvidenceBased Medicine, EBM) but also allow use of "eminence"-based statements in a critical way. Already 200 years ago, P.Ch.A.

\footnotetext{
W. Reinpold

Department of Surgery, Gross-Sand Hospital Hamburg, Gross-Sand 3, 21107 Hamburg, Germany

J. Rosenberg

Department of Surgery D, Herlev Hospital, University

of Copenhagen, Copenhagen, Denmark

\section{S. Sauerland}

Institute for Research in Operative Medicine, University

of Witten/Herdecke, Cologne, Germany

C. Schug-Paß

Department of Surgery and Center for Minimally Invasive Surgery, Vivantes Hospital, Neue Bergstr. 6, 13585 Berlin, Germany
}

Louis postulated: "Thus, a therapeutic agent cannot be employed with any discrimination or probability of success in a given case, unless its general efficacy, in analogous cases, has been previously ascertained; therefore I conceive that without the aid of statistics nothing like real medicine is possible." Opponents of EBM argue that, in view of the uniqueness of the patient, clinical studies are of little value. However, despite these criticisms, it is generally accepted today that classifications, rules, laws, and scientific theories cannot be developed without identifying the common features of large patient populations or diseases; variety in itself warrants statistical methods. To answer specific questions in a particular case, the surgeon should be able to draw from pertinent, high-quality, well-documented biometric studies to choose the most appropriate therapy for his patient. However, because the studies often suffer from methodical flaws, especially from the heterogeneity of data, it needs caution and deep clinical experience when applying results of EBM to an individual case, even if elaborate meta-analytic techniques have been developed to allow for a differential evaluation of the study results.

The authors of the following guidelines are aware of these problems and are conscious of the responsibility that they undertake when describing the scientific state-of-theart in laparoscopic/endoscopic inguinal hernia repair according to the best external evidence available and when making recommendations for the individual case.

Inguinal hernia repair is the most frequent operation in general and visceral surgery worldwide. In the western countries, including the United States, more than 1.5 millions procedures are performed every year. Thus, hernia repair not only affects the individual patient but also has a significant socioeconomic relevance and an important impact on the costs for the health care system. During the third meeting of the network International Endohernia Society (IEHS) held in Stuttgart, January 2008, live demonstrations of hernia repair performed by ten surgeons from four continents showed that guidelines for standardization of operative technique, 
especially regarding teaching, are urgently needed. This prompted a discussion about this challenge, which was pursued during the meeting of AHS in Scottsdale/Arizona, 2008, with the attendance of R. Fitzgibbons, M. Arregui, F. Köckerling, and P. Chowbey. The need for guidelines was unanimously acknowledged but with a focus on technique and special problems in transabdominal preperitoneal patch plasty (TAPP) and total extraperitoneal patch plasty (TEP). The authors were aware that some overlapping or interference with the EHS Guidelines was not completely avoidable but should be limited as far as possible. Regarding this problem, the authors appreciate the valuable contributions that $\mathrm{M}$. Miserez gave during the past year.

We started the guideline development process in June 2008 by collecting the most important questions and assembling the most qualified experts in laparoscopic hernia repair. An inviting letter was sent to all well-known laparoscopic hernia specialists who have made outstanding contributions to hernia surgery published in peer-review journals to participate in a Consensus Conference organized for February 2009 in Delhi by P. Chowbey. The following questions were asked:

1. Are you willing to participate?

2. Are you interested in an active participation?

3. In your opinion what are the most important questions in endoscopic hernia surgery? (e.g., TAPP or TEP, to fix or not to fix, etc.).

4. Are you (you can create a working group) ready to answer one of these questions according to the literature and your own data? Thus, you are able to give a recommendation at the conference.

5. If yes, please inform us about the topic you want to look for.

On the basis of the answers received, 14 topics were identified as most important and 14 surgeons declared their willingness to draft the respective guideline.

In a second step, the experts were asked to: (1) search the literature regarding the topic at hand, and (2) graduation of the papers according to the Oxford hierarchy of evidence (following the advice of Dr. S. Sauerland) as outlined below consisting of the following five levels:

1A. Systematic review of RCTs (with consistent results from individual studies).

1B. RCTs (of good quality).

2A. Systematic review of $2 \mathrm{~B}$ studies (with consistent results from individual studies).

2B. Prospective comparative studies (or RCT of poorer quality).

2C. Outcome studies (analyses of large registries, population-

based data, etc.).

3. Retrospective, comparative studies, case-control studies.

4. Case series (i.e., studies without control group).

5. Expert opinion, animal or lab experiments.
(3) For the recommendations, use the following grading scale:

A Consistent level 1 studies $=>$ strict recommendations ("standard"; "surgeons must do it").

B Consistent level 2 or 3 studies or extrapolations from level 1 studies => less strict wording ("recommendation"; "surgeons should do it").

C Level 4 studies or extrapolations from level 2 or 3 studies $=>$ vague wording ("option"; "surgeons can do it").

D Level 5 evidence or troublingly inconsistent or inconclusive studies at any level $=>$ no recommendation at all, describe options.

However, there often is a need to upgrade or downgrade a recommendation, because the outcome is so important or the clinical preference is so strong. This is possible but needs to be explained in the commentary text, and

(4) Prepare a paper to present at the Consensus Conference in Delhi.

In Delhi (Consensus Conference and fourth meeting of the International Endohernia Society (IEHS), February 18-21, 2009), the papers were discussed first in the round of experts and one day later during the plenary session attended by several hundreds of participants. During the following months, the authors drafted the first version of their specific chapter, including all the suggestions they had received during the conference. These first versions had been sent to our biometric advisor, Dr. S. Sauerland, for review and then were distributed to all the other experts for critics, remarks, and supplements. During these weeks, countless mails and revisions of papers were exchanged to achieve definitive guidelines that all experts could agree upon. In addition, two meetings that brought together most of the authors and the steering committee took place in September 2009 during the AHS/EHS/APHS meeting in Berlin and in December 2009 in Stuttgart respectively.

The guidelines focus on technique and perioperative management of laparoscopic/endoscopic inguinal hernia repair. They are not intended as competing alternatives to the EHS guidelines, although there is some overlap, especially regarding risk factors for pain and selection of mesh. The advantages of the guidelines presented here are: (1) Papers published until 01.02.2009 could be included, therefore, literature used here is more up to date; (2) The authors come from Europe, America, and Asia; therefore, the guidelines are, effectively, global; (3) The authors use the Oxford hierarchy of evidence comprising five levels; thus, big case series could be included, all together giving a more realistic representation of generally used practice.

Steering Committee

Prof. Reinhard Bittner, MD. Professor of Surgery, Dr.h.c. mult., FRCS; visceral surgeon, em. Director, 
Department of Visceral and General Surgery, Marienhospital Stuttgart. Seniordirector, Center of Minimally Invasive Surgery, Bethesda Krankenhaus Stuttgart. More than 350 original articles and more than 600 scientific lectures. Approximately 50 live demonstrations of TAPP, Cholecystectomy, Colon Resection in 15 countries in Europe and Asia. Former President of the German Society for Visceral and General Surgery. Former President of the German Association of Minimal Surgery. Vice-President and Former Congress President of the German Hernia Society.

Dr. Jan Kukleta, MD. General, visceral, abdominal wall surgeon. Klinik im Park, Zürich, Switzerland. Director of the Endoscopic Training Center Zürich. Lecturer at the ESI Hamburg and Elancourt Paris. More than 50 hernia-specific contributions at international meetings.

Dr. Wolfgang Reinpold, MD. General surgeon, Director of the Department of Surgery, Gross Sand Hospital Hamburg; Director of the Hernia Center in Hamburg Wilhelmsburg. Special interest: risk factors for pain and pain treatment after hernia repair. One randomized and seven prospective studies on pain and new techniques in inguinal and incisional hernia repair, whether open or laparoscopic. More than 30 hernia specific presentations at international meetings. Congress President elect of the German Hernia Society.

Working Group

Maurice E. Arregui, MD, FACS. Department Chair, General Surgery, St. Vincent Hospital, Indianapolis, Indiana, USA. Former President of the American Hernia Society. Co-Editor of Surgical Laparoscopy, Endoscopy, and Percutaneous Techniques. 97 Original Articles in Peer Review Journals. 43 book chapters.

Thue Bisgaard, MD. Associated Professor, Chief Surgeon, Department of Surgery, Koge Hospital, University of Copenhagen. 52 publications in peer-reviewed journals. Three book chapters. Assistant editor: Ugeskrift for Laeger and Danish Medical Bulletin. Member of steering committee of the Danish National Hernia Database, chairman of the ventral hernia database.

Pradeep Chowbey, MD, Dr.h.c., FACS. Director of Minimal Access, Metabolic, and Bariatric Surgery, Max Healthcare Institute Ltd., Saket, New Delhi, India. Honorary Surgeon to the President of India. Surgeon to His Holiness Dalai Lama. Founder President of the AsiaPacific Hernia Society. Former President of the Obesity \& Metabolic Surgery Society of India. Trustee \& Former President of the Indian Association of Gastrointestinal Endo-Surgeons. President elect of the Asia Pacific Metabolic \& Bariatric Surgical Society. 75 original articles. Two books. Educational set of 15 CD-ROMs. Editor: Journal of Minimal Access Surgery. Editorial Board: Hernia. Obesity Journal. Indian Journal of Surgery. Journal of Society of Endoscopic and Laparoscopic Surgeons of Asia.
Moshe Dudai, MD, FACS. Assistant Professor of Surgery, USUHS Bethesda, USA. Consultant of Elisha Medical Center in Haifa, Israel. President of European Association of Video Surgeons. Video Editor of the Journal of Surgical Laparoscopy Endoscopy \& Percutaneous Techniques. 14 publications. Three book chapters. 268 scientific lectures.

Prof. George S. Ferzli, MD, FACS. Professor of Surgery, SUNY Health Science Center, Brooklyn, NY, USA. Chairman of the Department of Surgery at Lutheran Medical Center. Director of the Medical Fellowship Program. More than 100 original articles in peer-reviewed journals. More than 10 chapters in medical textbooks.

Prof. Robert J. Fitzgibbons, MD, FACS. Harry E. Stuckenhoff Professor of Surgery. General Surgeon. Chief of the Division of General Surgery and Associated Chairman, Department of Surgery Creighton University School of Medicine, Omaha, Nebraska, USA. Former President of the American Hernia Society. Former President of the Society of Laparoendoscopic Surgeons. Member of Committee on emerging technology for the American College of Surgeons. 111 original articles in peerreviewed journals. Six books. 77 book chapters. Seven editorials. More than 400 scientific lectures.

Dr. René Fortelny, MD. Univ.-Lector. Chief Resident, 2nd Department of Surgery, Wilhelminenspital, Vienna, Austria. General, visceral and abdominal wall surgeon, Head of the Hernia Center at the Wilhelminenspital, Head of the Experimental Hernia Group at the Ludwig Boltzmann Institute for Experimental and Clinical Traumatology, Austria, Vienna. Former President of the Austrian Society for Minimal Invasive Surgery. President elect of the Austrian Hernia Society. 22 publications in peer-reviewed journals. 45 scientific lectures. 25 live demonstrations in hernia repair.

Dr. Uwe Klinge, MD. General and Visceral Surgeon. Principal Investigator of the Surgical Department, University of Aachen, and Institute for Applied Medical Engineering AME Helmholtz. Special fields of research: Biocompatibility of meshes. Visualization of meshes. Wound healing. 163 publications cited in PubMed, 53 book chapters; 127 invited lectures.

Esther Kuhry, MD, PhD. General Surgeon. St. Olavs Hospital, Trondheim, Norway. Advisor for the Research and Development department. Member of the Cochrane Colorectal Cancer Group. 12 papers in peer-reviewed journals. More than 30 scientific lectures.

Prof. Ferdinand Köckerling, MD. Professor of Surgery. Chairman of the Department of Surgery and Center of Minimally Invasive Surgery at the Vivantes Hospital in Berlin, Teaching Hospital of Charité Medical School. Former President of the German Society for Minimally Invasive Surgery. Former President of the German Society for General and Visceral Surgery. Former Congress President of the German Hernia Society. Editorial Board: Surgical Endoscopy; 
Langenbeck's Archives of Surgery. 173 papers cited in PubMed. More than 400 presentations in national and international conferences.

Davide Lomanto, MD, PhD, FAMS. Associate Professor, Senior Consultant, Director of the Minimally Invasive Surgical Center; Director of the KTP Advanced Surgical Training Center; YYL School of Medicine, National University of Singapore. President of Asia-Pacific Hernia Society. General Secretary of the Asia Pacific Bariatric Surgery Society. Editorial Board: Asian Journal of LaparoEndoscopic Surgery. Chinese Journal of Hernia and Abdominal Wall Surgery. 85 original articles in peerreviewed journals; 14 book chapters; 3 books; 184 scientific lectures. Instructor/mentor in 113 live surgery workshops.

Prof. Mahesh Chandra Misra, MD. Head of the Department of Surgical Disciplines and Chief; J P N Apex Trauma Center, All India Institute of Medical Sciences, New Delhi, India. General, Visceral, and Trauma Surgeon. 70 papers in peer-reviewed journals; 50 scientific lectures; 25 live surgery demonstrations.

Salvador Morales-Conde, MD. Chief of the Advanced Laparoscopic Unit of the University Hospital "Virgen del Rocío" (Sevilla, Spain). Head of the General, Digestive and Laparoscopic Surgery Unit of the USP-"Sagrado Corazón" Clinic (Sevilla, Spain). Associate Professor of the University of Sevilla (Spain). Director of the National program of training on Laparoscopic Surgery of the Spanish Association of Surgery. President of the Spanish Society of Abdominal Wall Surgery. Secretary of the Spanish Society of Endoscopic Surgery. Member of the Board of European Hernia Society. Authors of several papers and chapters of books and of the book entitled, Laparoscopic Ventral Hernia Repair.

Agneta Montgomery, MD, PhD. Associated Professor. Head of the Laparoscopy and Abdominal Wall Reconstruction Section. Department of Surgery, University Hospital of Malmö, Sweden. Former President of the Swedish Society of Laparoscopic Surgery. Secretary of the Swedish Surgical Society. Former President of the European Society for Surgical Research. Editorial Board: British Journal of Surgery, Scandinavian Journal of Surgery. Hernia. 42 original articles in peer-reviewed journals; 10 book chapters; 70 invited scientific lectures; 13 arrangements of symposia.

Prof. Jacob Rosenberg, MD, D.Sc., FRCS, FACS. Professor, Chief Surgeon, Department of Surgery D, Herlev Hospital, University of Copenhagen. Chief Editor: Ugeskrift for Laeger and Danish Medical Bulletin. 264 articles in peerreviewed journals; 28 editorials; 44 book chapters; 7 textbooks; 190 scientific lectures; taught 133 postgraduate courses. President of the Danish National Hernia Database.

Priv. Doz. Dr. Stefan Sauerland, MD, MPH. Head of the Department of Non-Drug Interventions, Institute for Quality and Efficiency in Healthcare, Cologne, Germany. Speciality: development of evidence-based methodology in Germany. Coordination of various clinical trials and clinical practice guidelines. More than 110 original articles in peer-reviewed journals and more than 100 scientific lectures. 2005 Cochrane Prize.

Dr. Christine Schug-Paß, MD. General Surgeon. Department for Surgery. Center for Minimally Invasive Surgery. Vivantes Klinikum Spandau, Berlin, Germany. 18 original articles in peer-reviewed journals; 26 book contributions; 70 scientific lectures.

Kirpal Singh, MD. General Surgery with Advanced Laparoscopy \& Endoscopy, St. Vincent Hospital, Indianapolis, Indiana, USA. Fellow of Maurice Arregui 2002-2004. One paper in a peer-reviewed journal.

Michael Timoney, MD. Attending Surgeon/Director of Quality Assurance, Lutherian Medical Center, Brooklyn, New York, USA. Five papers and abstracts in peerreviewed journals and one correspondence in New England Journal of Medicine.

Priv. Doz. Dr. Dirk Weyhe, MD, PhD. General and Visceral Surgeon, Head of the Department of Surgery, Pius Hospital Oldenburg, Germany. Speciality: biocompatibility of synthetic materials. 50 publications in peer-reviewed journals; 2 book contributions; 99 scientific lectures.

In summary, the guidelines have been developed by leading hernia surgeons from Europe, America, and Asia, working in high spirits and in an atmosphere of deep friendship. The result is a truly global achievement pointing to the future. We thank all of the contributors for their tireless efforts and their unwavering dedication to hernia surgery without any remuneration or compensation even for traveling expenses.

If you do a PubMed literature research using the term "hernia surgery," you will find 29,939 publications. The Guidelines should assist the surgeon in his clinical practice to make the right decision and to improve his technical performance. For validation and agreement, every expert received at least twice all of the chapters written by the other authors. All comments and critics were seriously discussed with the respective author and, if necessary, the statements and recommendations were revised accordingly. In addition, the steering committee carefully reviewed every paper.

The Guidelines are valid until December 2013. The update meeting will be organized in due time by the first and last authors. 
Chapter 1: Perioperative management: what is the evidence for antibiotic and thromboembolic prophylaxis in laparoscopic inguinal hernia surgery?

Agneta Montgomery

Department of Surgery, University Hospital Skåne, Malmö, Sweden

Is antibiotic prophylaxis routinely indicated for an elective laparoscopic inguinal hernia operation?

Is thromboembolic prophylaxis routinely indicated for an elective laparoscopic inguinal hernia operation?

Search terms: "Antibiotic prophylaxis" AND "laparoscopy" AND "inguinal hernia"; "Antibiotic prophylaxis" AND "TEP" AND "TAPP"; "Antibiotic prophylaxis" AND "randomized studies" AND "inguinal hernia"; "Thromboembolic prophylaxis" AND "laparoscopy" AND "inguinal hernia"; "Thromboembolic prophylaxis" AND "TEP" AND "TAPP"; "Thromboembolic prophylaxis" AND "randomized studies" AND "inguinal hernia."

\section{Statements}

Level 5 There is insufficient evidence for routine antibiotic prophylaxis in laparoscopic hernia surgery.

Level 5 There is insufficient evidence for routine thromboembolic prophylaxis in laparoscopic hernia surgery.

\section{Recommendations}

Grade D Antibiotic prophylaxis for elective laparoscopic inguinal hernia repair cannot be universally recommended.

Grade D It is recommended that antibiotic prophylaxis should be considered in the presence of risk factors for wound and mesh infection based on patient (advanced age, corticosteroid usage, immunosuppressive conditions and therapy, obesity, diabetes, and malignancy) or surgical complications (contamination, long operation time, drainage, urinary catheter).

Grade D It is recommended that thromboembolic prophylaxis is given according to usual routines in patients with risk factors.

\section{Antibiotic prophylaxis}

Antibiotic prophylaxis in inguinal hernia surgery is controversial. The overall infection rate is low, with a mean value of $1-4 \%$ [1-4]. An infectious rate $<2 \%$ is regarded as a clean operation. Repair for inguinal hernia is a highvolume operation. Antibiotic prophylaxis may reduce wound infection rates with an impact on patients' satisfaction, wound care, and sick leave, but it also involves risks of toxic, allergic side effects, bacterial resistance, and higher costs. There also has been a discussion on risk factors used to select the best candidates for antibiotic prophylaxis. Age $>75$ years, obesity, and urinary catheter were heavy risk factors for global infectious complications in one study [5]. Other known risk factors for infectious complications are hernia recurrence, diabetes, immunosuppressant, corticosteroid usage, and malignancy.

RCT studies as well as systematic reviews and metaanalyses on antibiotic prophylaxis versus placebo were identified. To analyze the wound infection rate in a large population, the Swedish National Hernia register was searched for the years 1992-2006 [1]. The five largest RCTs between open and laparoscopic hernia repair, having wound infection as a secondary endpoint, also were analyzed [6-10], as well as large case series reporting on antibiotic prophylaxis and infectious complications.

A total of five systematic reviews or meta-analyses comparing antibiotic prophylaxis versus placebo were identified. Sanchez-Manuel and Seco-Gil [11] reported in the Cochrane Database system in 2004 and updated the results in 2007 [4]. Three different systematic reviews and meta-analyses were performed in 2005, 2006, and 2007 $[3,12,13]$. Almost the same studies are referred to in these publications adding some new references each time. A total of 12 randomized studies are presented in the latest Cochrane Publication [4], involving only open surgery.

Until now, a total of 14 RCTs comparing antibiotic prophylaxis versus placebo in inguinal hernia surgery were identified, of which there was only 1 about laparoscopic repair and the remaining 13 were about open repair (Table 1).

The endoscopic RCT by Schwetling and Bärlehner [14] has an incorrect randomization, lacks a definition of wound infection, and is heavily underpowered with only 40 patients in each arm. It does not allow any conclusions to be made and is not included in the Cochrane review.

In the remaining studies on open hernia repair, a total of 4,128 patients are included in the latest report from the Cochrane database by Sanchez-Manuel and Seco-Gil [4]. The wound infection rate was $2.9 \%$ in the prophylaxis group and $3.9 \%$ in the nonprophylaxis group with no statistical difference. There is a huge variation in infection rate between the studies both in the prophylaxis group (0-8.8\%) and nonprophylaxis group (0-8.9\%). A subgroup analysis between no mesh and mesh was performed. In the no-mesh group, an infection rate of $3.5 \%$ was seen in the prophylaxis and $4.9 \%$ in the placebo with no statistical difference. In the mesh group, the infection rate was $1.4 \%$ in the prophylaxis and $2.9 \%$ in the placebo, also with no statistical difference.

Only one further randomized, controlled study on open hernia surgery has been presented after the latest Cochrane report [15] (Table 1). Wound infection is registered as a secondary endpoint in large RCTs on laparoscopic versus 
Table 1 RCT comparing prophylaxis versus nonprophylaxis antibiotics in inguinal hernia surgery

\begin{tabular}{|c|c|c|c|c|c|c|c|}
\hline Author & $\begin{array}{l}\text { Prophylaxis } \\
\text { Total } n\end{array}$ & $\begin{array}{l}\text { Infection prophy } \\
\text { laxis }(\%)\end{array}$ & $\begin{array}{l}\text { Nonprophylaxis } \\
\text { Total } n\end{array}$ & $\begin{array}{l}\text { Infected } \\
\text { nonprophylaxis }(\%)\end{array}$ & $\begin{array}{l}\text { RRA CI } \\
95 \%\end{array}$ & NNT & $\begin{array}{l}\text { Level of } \\
\text { evidence }\end{array}$ \\
\hline \multicolumn{8}{|c|}{ Open hernia surgery included in Cochrane } \\
\hline Evans et al. (1973) [16] & 48 & 2.1 & 49 & 4.1 & $\begin{array}{c}2(-4.9 \\
8.9)\end{array}$ & 50 & $3 b$ \\
\hline $\begin{array}{l}\text { Anderson et al. (1980) } \\
\text { [17] }\end{array}$ & 137 & 3.6 & 150 & 4 & $\begin{array}{l}0.4(-4.1 \\
4.7)\end{array}$ & 285 & $2 b$ \\
\hline Platt et al. (1990) [18] & 301 & 1.3 & 311 & 1.9 & $\begin{array}{l}0.6(-1.4 \\
2.6)\end{array}$ & 167 & $1 b$ \\
\hline $\begin{array}{l}\text { Lazhortes et al. (1992) } \\
\text { [19] }\end{array}$ & 155 & 0 & 153 & 4.6 & $\begin{array}{l}4.6(1.2, \\
7.9)\end{array}$ & 22 & $2 b$ \\
\hline Taylor et al. (1997) [20] & 283 & 8.8 & 280 & 8.9 & $\begin{array}{l}0.1(-4.6 \\
\quad 4.7)\end{array}$ & 1057 & $1 b$ \\
\hline Morales et al. (2000) [21] & 237 & 1.7 & 287 & 2.1 & $\begin{array}{l}0.4(-1.9 \\
2.7)\end{array}$ & 248 & $1 \mathrm{~b}$ \\
\hline Yerdel et al. (2001) [22] & 136 & 0.7 & 133 & 9 & $\begin{array}{l}8.3(3.2 \\
13.4)\end{array}$ & 12 & $2 b$ \\
\hline Oteiza et al. (2004) [23] & 124 & 0.8 & 123 & 0 & $\begin{aligned}-0.8(- \\
2.4,0.7)\end{aligned}$ & 124 & $2 b$ \\
\hline $\begin{array}{l}\text { Aufenacker et al. (2004) } \\
\text { [24] }\end{array}$ & 475 & 1.7 & 472 & 1.9 & $\begin{array}{l}0.2(-1.5 \\
1.9)\end{array}$ & 449 & $1 \mathrm{~b}$ \\
\hline Celdan et al. (2004) [25] & 50 & 0 & 49 & 8.1 & $\begin{array}{l}8.2(0.5 \\
15.8)\end{array}$ & 12 & $2 b$ \\
\hline Pessaux et al. (2005) [5] & 2008 & 3.4 & 394 & 5.1 & $\begin{array}{l}1.7(-0.6, \\
4)\end{array}$ & 59 & $2 b$ \\
\hline Perez et al. (2005) [26] & 174 & 1.7 & 176 & 3.4 & $\begin{array}{l}1.7(-1.6, \\
5)\end{array}$ & 59 & $2 b$ \\
\hline Total & 4,128 & 2.9 & 2577 & 3.9 & $1.1(0.2,2)$ & 92 & \\
\hline \multicolumn{8}{|c|}{ Laparoscopic hernia surgery not included in Cochrane } \\
\hline $\begin{array}{l}\text { Schwetling and Bärlehner } \\
\text { (1998) [14] }\end{array}$ & 40 & 0 & 40 & 0 & $n s$ & & $2 b$ \\
\hline \multicolumn{8}{|c|}{ Open hernia surgery not included in Cochrane } \\
\hline $\begin{array}{l}\text { Tzovaras et al. (2007) } \\
\text { [15] }\end{array}$ & 193 & 2.6 & 193 & 4.4 & $p=0.4$ & & $2 b$ \\
\hline
\end{tabular}

Table 2 RCT comparing laparoscopic versus open inguinal hernia surgery with infectious complications as a secondary endpoint

\begin{tabular}{|c|c|c|c|c|c|c|c|c|}
\hline Study & Name, country & $\begin{array}{l}\text { Antibiotic } \\
\text { prophylaxis }\end{array}$ & Total & Lap group & $\begin{array}{l}\text { Lap infect. } \\
(\%)\end{array}$ & Open group & $\begin{array}{l}\text { Open infect. } \\
(\%)\end{array}$ & $n$ \\
\hline Liem et al. (1997) [6] & $\begin{array}{l}\text { Coala, } \\
\text { Netherlands }\end{array}$ & $?$ & 994 & 487 TEP & 0 & 507 Optional & 1.2 & 0.03 \\
\hline MRC 1999 [7] & MRC, UK & $?$ & 928 & $\begin{array}{l}468 \text { TEP, } \\
\text { TAPP }\end{array}$ & 2.8 & 460 Optional & 3.1 & NS \\
\hline $\begin{array}{l}\text { Berndsen et al. (2002) } \\
\text { [8] }\end{array}$ & $\begin{array}{l}\text { SMIL I, } \\
\text { Sweden }\end{array}$ & No & 1,042 & 518 TAPP & 0.8 & 524 Shouldice & 0.8 & NS \\
\hline $\begin{array}{l}\text { Neumayer et al. (2004) } \\
\text { [9] }\end{array}$ & AV, USA & $?$ & 1,983 & $\begin{array}{l}989 \text { TEP, } \\
\text { TAPP }\end{array}$ & 1 & $\begin{array}{l}994 \\
\text { Lichtenstein }\end{array}$ & 1.4 & NS \\
\hline $\begin{array}{l}\text { Eklund et al. (2006) } \\
\text { [10] }\end{array}$ & $\begin{array}{l}\text { SMIL II, } \\
\text { Sweden }\end{array}$ & No lap yes open & 1,371 & 665 TEP & 1.4 & $\begin{array}{l}706 \\
\text { Lichtenstein }\end{array}$ & 0.7 & 0.21 \\
\hline Total & & & 6,318 & 3,127 & 1.2 & 3,191 & 1.3 & \\
\hline
\end{tabular}

$?=$ Whether antibiotic prophylaxis was given is not reported

$N S$ not significant, Lap laparoscopic, infect infection, TAPP laparoscopic transabdominal preperitoneal repair, TEP laparoscopic totally extraperitoneal repair 
open operation, but only two of five mention antibiotic prophylaxis (Table 2). The infection rate varies between $0-2.8 \%$ in the laparoscopic group and $0.7-3.1 \%$ in the open group. There are significantly more infections reported in the open group in one study, whereas all other studies show no difference between groups, including the two studies that report the administration of antibiotics.

Five TAPP case series, including more than 1,000 patients each, reported on wound and/or mesh infections [27-31]. Four studies are from the same institution. Antibiotic prophylaxis was given to all patients and commented about in only one study [31]. No large TEP series was identified. Schmedt et al. [28] reported $0.07 \%$ infections in 4188 unilateral TAPP procedures and $0 \%$ in 1,336 bilateral procedures. Kapiris et al. [29] reported $0.11 \%$ mesh infections in 3,017 patients, and Leibl et al. [30] reported 3 cases $(0.001 \%)$ in 2,700 patients. Bittner et al. [31] reported $0.1 \%$ mesh infections and $0 \%$ wound infections in 8,050 TAPP procedures in a total of 6,479 patients.

The Swedish National Inguinal Hernia Register recorded the wound infections between 1992 and 2006. The incidence was $1.4 \%$ in 28,220 patients recorded to have received antibiotic prophylaxis. The infection rate also was $1.4 \%$ in the nonprophylactic group, consisting of 104,354 patients [1]. There is no specific analysis on the laparoscopic patients representing approximately $8 \%$ of the patients who underwent surgery.

Pessaux et al. [5] has converted predictive risk factors for infection, such as age older than 75 years, obesity, and urinary catheter, into a global infection complication score. Low-risk patients had an infection rate of $2.7 \%$ and highrisk patients of $14.3 \%(p<0.001)$ [5].

\section{Thromboembolic prophylaxis}

Because thromboembolic complications have been very rarely reported after inguinal hernia surgery, there has been a heated debate about whether thromboembolic prophylaxis is needed at all in the absence of risk factors. Moreover, the laparoscopic techniques might involve risks from altered venous flow due to pneumoperitoneum and the Trendelenburg position.

No RCT or case-controlled studies about laparoscopic versus open hernia repair or case series were identified on thromboembolic prophylaxis.

To analyze the current practice in thromboembolic prophylaxis for inguinal hernias in the United Kingdom, 200 questionnaires were sent to endoscopic surgeons of Great Britain with a respondent's rate of $72 \%$. Risk stratification was $10 \%$ for laparoscopic and $14 \%$ for open procedures [32].

In one case-controlled study on laparoscopic cholecystectomy in 569 patients where only 18 patients received DVT prophylaxis, a postoperative clinical control showed no symptoms of DVT or pulmonary embolism [33]. An expert opinion discussing pros and cons for thromboembolic prophylaxis also has been published [34].

References (in parentheses graduation of evidence)

1. Swedish National Hernia Register; www.incanet.se

2. Schmedt CG, Sauerland S, Bittner R (2005) Comparison of endoscopic procedures vs Lichtenstein and other mesh techniques for inguinal hernia repair: a meta-analysis of randomized controlled trials. Surg Endosc 19:605-615. (1A)

3. Sanabria A, Dominquez LC, Valdivieso E, Gomez G (2007) Prophylactic antibiotics for mesh inguinal hernioplasty: a meta-analysis. Ann Surg 245:392-396. (1A)

4. Sanchez-Manuel FJ, Seco-Gil JL (2007) Antibiotic prophylaxis for hernia repair. Cochrane Database Syst Rev 3:CD003769. doi:10.1002/14651858.CD00 3769.pub3. (1A)

5. Pessaux P, Lermite E, Blezel E, Msika S, Hay J-M, Flamant Y, Deepak V, Arnaud JP (2006) Predictive risk score for infection after inguinal hernia repair. Am J Surg 192:165-171. (2B)

6. Liem MS, van der Graaf Y, van Steensel CJ, Boelhouwer RU, Clevers GJ, Meijer WS, Stassen LP, Vente JP, Weidema WF, Schrijvers AJ, van Vroonhoven TJ (1997) Comparison of conventional anterior surgery and laparoscopic surgery for inguinal hernia repair. N Engl J Med 336:1541-1547. (1B)

7. The MRC Laparoscopic Groin Hernia Trial Group (1999) Laparoscopic versus open repair of groin hernia: a randomized comparison. Lancet 354:185190. (1B)

8. Berndsen F, Arvidsson D, Enander LK, Leijonmark CE, Wingren U, Rudberg C, Smedberg S, Wickbom G, Montgomery A (2002) Postoperative convalescence after inguinal hernia surgery: prospective randomized multicenter study of laparoscopic versus Shouldice inguinal hernia repair in 1042 patients. Hernia 6: 56-61. (1B)

9. Neumayer L, Giobbe-Hurder A, Jonasson O, Fitzgibbons R Jr, Dunlop D, Gibbs J, Reda D, Henderson W (2004) Open mesh versus laparoscopic mesh repair of inguinal hernia. N Engl J Med 350: 1819-1827. (1B)

10. Eklund A, Rudberg C, Smedberg S, Enander LK, Leijonmark CE, Österberg J, Montgomery A (2006) Short-term results of a randomized clinical trial comparing Lichtenstein open repair with totally extraperitoneal laparoscopic inguinal hernia repair. Br J Surg 93:1060-1068. (1B)

11. Sanchez-Manuel FJ, Seco-Gil JL (2004) Antibiotic prophylaxis for hernia repair. Cochrane Database Syst Rev 4:CD003769. (1A) 
12. Biswas $S$ (2005) Elective inguinal hernia repair with mesh: is there a need for antibiotic prophylaxis? A review. World J Surg 29:830-836. (2A)

13. Aufenacker TJ, Koelemay MJW, Gouma DJ, Simons MP (2006) Systematic review and meta-analysis of the effectiveness of antibiotic prophylaxis in prevention of wound infection after mesh repair of abdominal wall hernia. Br J Surg 93:5-10. (1A)

14. Schwetling R, Bärlehner E (1998) Is there an indication for general antibiotic prophylaxis in laparoscopic plastic hernia repair with implantation of alloplastic tissue? Zentralbl Chir 123:193-195. (2B)

15. Tzovaras G, Delikoukos S, Christodoulides G, Spyridakis M, Mantzos F, Tepetes K, Athanassiou E, Hatzitheofilou C (2007) The role of antibiotic prophylaxis in elective tension-free mesh inguinal hernia repair: results of a single-centre prospective randomized trial. Int J Clin Pract 61:236-239. (2B)

16. Evans C, Pollock AV (1973) The reduction of surgical wound infections by prophylactic parental cephaloridine. A controlled clinical trial. Br J Surg 60:434-437. (3B)

17. Andersen JR, Burchart F, Larsen HW, Roder O, Andersen B (1980) Polyglycolic acid, silk, and topical ampicillin. Their use in hernia repair and cholecystectomy. Arch Surg 115:293-295. (2B)

18. Platt R, Zaleznik DF, Hopkins CC, Dellinger EP, Karchmer AW, Bryan CS, Burke JF, Wikler MA, Marino SK, Holbrook KF (1990) Perioperative antibiotic prophylaxis for herniorrhaphy and breast surgery. N Engl J Med 322:153-160. (1B)

19. Lazorthes F, Chiotasso P, Massip P, Materre JP, Sarkissian M (1992) local antibiotic prophylaxis in inguinal hernia repair. Surg Gynecol Obstet 175:569-570. (2B)

20. Taylor EW, Byrne DJ, Leaper DJ, Karran SJ, Kennedy Browne M, Mitchell KJ (1997) Antibiotic prophylaxis and open groin hernia repair. World $\mathbf{J}$ Surg 21:811-815. (1B)

21. Morales R, Carmona A, Pagain A, Garcia Menéndez C, Bravo R, Hernández MJ (2000) utility of antibiotic prophylaxis in reducing wound infection in inguinal or femoral hernia repair using polypropylene mesh. Cir Esp 67:51-59. (1B)

22. Yerdel MA, Akin EB, Dolalan S, Turkcapar AG, Pehlivan M, Cecim IE, Kuterdem E (2001) Effect of single-dose prophylactic ampicillin and sulbactam of wound infection after tension-free inguinal hernia repair with polypropylene mesh. The randomized doubleblind, prospective trial. Ann Surg 233:26-33. (1B)

23. Oteiza F, Ciga MA, Ortiz H (2004) Antibiotic prophylaxis in inguinal hernioplasty. Cir Esp 75:69-71. (2B)

24. Aufenacker TJ, van Geldere D, van Mesdag T, Bossers AN, Dekker B, Scheije E, van Nieuwenhuizen R, Hiemstra E, Maduro JH, Juttmann JW, Hofstede D, van
Der Linden CT, Gouma DJ, Simons MP (2004) The role of antibiotic prophylaxis in prevention of wound infection after Lichtenstein open mesh repair of primary inguinal. A multicenter double-blind randomized controlled trial. Ann Surg 240:955-961. (1B)

25. Celdran A, Frieyro O, de la Pinta JC, Souto JL, Esteban J, Rubio JM, Senaris JF (2004) The role of antibiotic prophylaxis on wound infection after mesh hernia repair under local anesthesia on a ambulatory basis. Hernia 8:20-22. (2B)

26. Perez AR, Roxas MF, Hilvano SS (2005) A randomized double-blind, placebo-controlled trial to determine effectiveness of antibiotic prophylaxis for tension-free mesh herniorrhaphy. J Am Coll Surg 200:393-397. (2B)

27. Bittner R, Kraft K, Schmedt CG, Schwarz J, Leibl B (1998) Risk and benefits of laparoscopic hernioplasty (TAPP): 5 year of experience in 34000 hernia repairs. Chirurg 69:854-858. (4)

28. Schmedt CG, Daubler P, Leibl B, Kraft K, Bittner R (2002) Simultaneous bilateral laparoscopic inguinal hernia repair. An analysis of 1336 consecutive cases at a single center. Surg Endosc 16:240-244. (4)

29. Kapiris SA, Brough WA, Ryston CMS, O'Boyle C, Sedman PC (2001) Laparoscopic transabdominal preperitoneal (TAPP) hernia repair. A 7-year twocentre experience in 3017 patients. Surg Endosc 15:972-975. (4)

30. Leibl B, Schmedt CG, Schwarz J, Daubler P, Kraft K, Kraft K, Schlossnickel B, Bittner R (1998) A single institution's experience with transperitoneal laparoscopic hernia repair. Am J Surg 175:446-452. (4)

31. Bittner R, Schmedt CG, Schwarz J, Kraft K, Leib BJ (2002) Laparoscopic transperitoneal procedure for routine repair of groin hernia. Br J Surg 89:1062-1066. (4)

32. Anwar S, Scott P (2003) Current practice for anticoagulation prophylaxis in inguinal hernia surgery: a questionnaire survey. N Z Med J 116:U583. (4)

33. Blake AM, Toker SI, Dunn E (2001) Deep venous thrombosis prophylaxis is not indicated for laparoscopic cholecystectomy. JSLS 5:215-219. (4)

34. Zacharoulis D, Kakkar AK (2003) Venous thromboembolism in laparoscopic surgery. Curr Opin Pulm Med 9:356-361. (5)

\section{Chapter 2: Technical key points in transabdominal preperitoneal patch plasty (TAPP)}

Jan F. Kukleta, Reinhard Bittner

Klinik Im Park Zurich, CH/Stuttgart, D

Search terms: TAPP, TEP, inguinal hernia, groin hernia, femoral hernia, technique, endoscopic repair, RCT, clinical 
trial, systematic review, meta-analysis, outcome studies, individual experience report and specific terms associated with the technical key element described below.

The available external evidence (EB) is presented separately from the experience reports (ER) and from personal experience (PE).

\section{General considerations}

What are the important technical key points in transabdominal preperitoneal groin hernia repair? How far (in what way) do the individual steps influence the patient's outcome?

Statements

Level 5 The level of evidence for the different technical key points is very heterogeneous.

Level 5 The supposed consensus on the technical requirements for TAPP is not well supported by the literature.

\section{Recommendations}

\begin{tabular}{|c|c|}
\hline Grade D & $\begin{array}{l}\text { To standardize particular technical steps in TAPP } \\
\text { is a complex task; thus, it is recommended to adhere } \\
\text { strictly to the principles of minimally invasive } \\
\text { techniques and to structure teaching and training. }\end{array}$ \\
\hline Grade D & $\begin{array}{l}\text { Specialized centers or high-volume teaching institutions } \\
\text { are recommended. }\end{array}$ \\
\hline
\end{tabular}

\section{Introduction}

The learning curve of TAPP groin hernia repair is longer than in open procedures. To facilitate teaching and learning, it is necessary to analyze and structure the procedure and emphasize the importance of various surgical steps for the success of the treatment. The standardization of specific steps, which are supported by evidence-based principles or by positive experience reports, should help to reproduce the best achievable results.

Several RCTs and prospective clinical studies have demonstrated that TAPP repair has a strong potential for achieving patient-oriented positive outcomes [1-9]. However, other studies have shown that, despite using a "similar" technique, the expected results could not be reached [10]. The reason for the obvious differences of published results seems to be the individual interpretation of the surgical technique and its performance. Therefore, strict standardization of the technique according to the best available evidence is recommended.

\section{Results}

EBM data on technical key points of TAPP repair per se are not available and are not expected due to the complexity of the whole procedure (heterogeneity and importance of the particular technical steps). Therefore, the TAPP procedure was divided into several parts (phases), and each is evaluated separately.

\section{Preparation of the patient \\ Is preoperative bladder emptying of importance? When is the urinary bladder catheter recommended? Statements}

\begin{tabular}{cc}
\hline Level 4 & $\begin{array}{l}\text { If the patient does not empty his/her urinary bladder, } \\
\text { the operation may be more difficult with a higher } \\
\text { riskof bladder injury. } \\
\text { Perioperative catheterisation of urinary bladder } \\
\text { is very rarely necessary. }\end{array}$ \\
\hline
\end{tabular}

\section{Recommendations}

Grade D It is recommended that the patient empty his/her bladder before the operation.

Grade D Restrictive per- and postoperative intravenous fluid administration reduces the risk of postoperative urinary retention.

Grade D If you expect technical difficulties (e.g., after prostatic surgery, scrotal hernia) or an extended operating time, consider using a urinary catheter during the intervention.

Full urinary bladder can increase substantially the technical difficulty of TAPP repair $[4,11]$. To diminish the risk of bladder injury, the bladder should be emptied before surgery. Predisposing factors for an injury are a full bladder or a previous exposure of the retropubic space particularly after prostate interventions, irradiation, or TAPP [12] (see Chap. 11, Fitzgibbons). An early stage of the learning curve in endoscopic hernia repair might be another reason [13]. With adequate experience, TAPP is a safe procedure even after radical prostatectomy [14].

The incidence of urinary retention was $0.37 \%(33 / 8,991$ patients) with local anaesthesia, $2.42 \%$ (150/6,191 patients) with regional anaesthesia, and 3.0\% (344/11,471 patients) with general anesthesia [15]. The inhibitory effect of general anaesthesia on bladder function would explain the increased incidence of postoperative urinary retention.

The volume of intravenous postoperative fluid administered is a significant risk factor for urinary retention [16].

Urinary retention prolongs hospitalization and predisposes the patient to urinary tract infection. Atony of the bladder results from unrecognized overdistension of the bladder and consequent damage to the detrusor muscle. With increasing emphasis on cost-effectiveness and early discharge of patients, the avoidance of urinary retention is of utmost importance [17] (see Chap. 11, Fitzgibbons).

Preperitoneal placement of mesh with the TEP technique was found not to cause urinary retention by outflow obstruction or alteration of the bladder contractility [17]. In a report of 8,050 TAPP repairs from Bittner et al., the incidence of urinary retention is very low at $0.5 \%$ [2]. This may be due to the patient being imperatively ordered to evacuate his/her urinary bladder just before being brought to the operating room, short operating times, and very restrictive fluid administration by anesthesiologists. 
Does preoperative hair removal increase the risk of surgical site infection (SSIs)?

\section{Statements}

\begin{tabular}{ll} 
Grade 1A & $\begin{array}{l}\text { There is no evidence for a difference in surgical } \\
\text { site infections SSI between hair removal or no } \\
\text { removal before surgery. }\end{array}$ \\
Grade 1A & $\begin{array}{l}\text { Shaving causes significantly more SSIs than hair } \\
\text { clipping. }\end{array}$ \\
Grade 1A & $\begin{array}{l}\text { There is no difference in SSIs when hair is shaved } \\
\text { or clipped 1 day before surgery or on the day of surgery. }\end{array}$ \\
\hline
\end{tabular}

\section{Recommendations}

\begin{tabular}{ll}
\hline Level A & Clipping results in fewer SSIs than razor shaving. \\
Level A & Hair can be removed even the day before surgery.
\end{tabular}

Level A Hair can be removed even the day before surgery.

Specific studies in hernia surgery are not available, but studies in general surgery have demonstrated no difference in SSIs among patients who have had hair removed before surgery and those who have not [18]. Clipping results in fewer SSIs than razor shaving using a razor. Three trials involving 3,193 people compared shaving with clipping and found that there were statistically significantly more SSIs when hair is shaved rather than clipped (relative risk (RR), 2.02; 95\% confidence interval (CI), 1.21-3.36) [18-20].

There is insufficient evidence regarding depilatory cream compared with razor shaving. Three trials involving 625 people compared hair removal using depilatory cream or razors with no hair removal and found no statistically significant difference between the groups in terms of surgical site infections. Seven trials involving 1,420 people compared shaving with removing hair using a depilatory cream but found no statistically significant difference between the two groups in SSI rates [20].

There is no difference in SSIs when hair is shaved or clipped 1 day before surgery or on the day of surgery [21]. A significant drawback of these studies is that the evidence does not derive from studies in laparoscopic hernia repair.

\section{Information before surgery}

\section{Statements}

Level 2B Chronic pain may develop after inguinal hernia repair. Level 5 In a significant number of cases, unsuspected hernias are found on the contralateral side at surgery.

\section{Recommendations}

Grade B The patient should be informed about the possibility of a negative outcome (chronic pain).

Grade D The patient with unilateral groin hernia should be asked to give his/her consent to allow simultaneous repair if a contralateral occult hernia is found and he/she wishes it.
The informed consent of the patient is an important part of any surgical act. The patient must be provided with information not only on the details of the procedure or on the different operative methods but also be informed of the possibility of a negative outcome [22]. Correct information helps to prevent unfulfilled expectations. Unexpected bilaterality is reported in $10-25 \%$ [23-26]. Up to $28.6 \%$ of these patients will progress to a symptomatic hernia within 1 year [26].

Establishing pneumoperitoneum

Which is the safest and most effective method of establishing pneumoperitoneum and obtaining access to the abdominal cavity?

\section{Statements}

Level 1A There is no definitive evidence that the open entry technique for establishing pneumoperitoneum is superior or inferior to the other techniques currently available.

Level 1B In thin patients (BMI <27), the direct trocar insertion is a safe alternative to the Veress needle technique.

Level 2C Establishing pneumoperitoneum to gain access to the abdominal cavity represents a potential risk of parietal, intra-abdominal, and retroperitoneal injury.

Patients after previous laparotomy, obese patients, and very thin patients are at a higher risk.

Level 3 Waggling of the Veress needle from side to side must be avoided, because this can enlarge a $1.6-\mathrm{mm}$ puncture injury to an injury of up to $1 \mathrm{~cm}$ in viscera or blood vessels.

Level 4 The various Veress needle safety tests or checks provide insufficient information on the placement of the Veress needle.

The initial gas pressure when starting insufflation is a reliable indicator of correct intraperitoneal placement of the Veress needle.

Left upper quadrant (LUQ, Palmer's) laparoscopic entry may be successful in patients with suspected or known periumbilical adhesions or history or presence of umbilical hernia, or after three failed insufflation attempts at the umbilicus.

\section{Recommendations}

Grade A When establishing pneumoperitoneum to gain access to the abdominal cavity, extreme caution is required.

Be aware of the risk of injury.

The open access should be utilized as an alternative to the Veress needle technique, especially in patients after previous open abdominal surgery.

Grade C The technique of access should be adapted in case of obesity, previous intra-abdominal surgery, and abdominal wall hernias.

To create pneumoperitoneum to gain access to the abdominal cavity has a risk of injury. The safest and most efficient method of access is still controversial.

There are four ways to obtain access to the abdominal cavity: (1) Open access (Hasson); (2) Veress needle to create pneumoperitoneum and trocar insertion without visual control; (3) Direct trocar insertion (without previous pneumoperitoneum); and (4) Visual entry with or without previous gas insufflation. 
Among general surgeons and gynecologists, the most popular method is the Veress needle [27]. To increase the safety and minimize the morbidity of this method, several safety tests were proposed by Semm [7, 28]. The literature does not always support the use of these tests because they provide very little useful information on the placement of the needle [29]. The intraperitoneal pressure initially induced by the gas insufflations seems to be more important to control the correct placement of the Veress needle [30]. If the pressure is initially higher than $2-3 \mathrm{mmHg}$, then the needle is not placed correctly.

Therefore, it might not be necessary to perform various safety checks when inserting the Veress needle, but their routine use may still remind the surgeon of the risk of injury involved in this procedure; however, waggling of the Veress needle from side to side must be avoided, because this can enlarge a 1.6-mm puncture injury to an injury of up to $1 \mathrm{~cm}$ in viscera or blood vessels [29]. The angle of the Veress needle insertion should vary according to the BMI of the patient: from 45 degrees in nonobese to 90 degrees in obese patients.

Although the open approach seems to be the safest, it does not eliminate the entire risk of injury [31] (Level 2C). In 12,919 cases, its morbidity was in 12,919 cases: Hasson $0.09 \%$, Veress + first trocar $0.18 \%$ and optical trocar $0.29 \%$.

When using open approach palpation through the peritoneal aperture, to exclude adhesions is mandatory before inserting a blunt canula [32]. There is no evidence that the open entry technique is superior or inferior to the other entry techniques currently available. One RCT recommends open access as a standard for laparoscopic operations, but the number of only randomized 50 patients is too small to allow definite conclusions [33].

There is an upcoming trend to direct trocar insertion without previous gas insufflation $[34,35]$. The benefit, it is argued, is to diminish the potential morbidity of the Veress needle and to create pneumoperitoneum faster. The new designs of blunt tip trocars promise to decrease the number of minor injuries (subcutaneous, preperitoneal gas insufflation, needle tip injuries intra- and retroperitoneally) while maintaining the incidence of major injuries equally low as the Veress needle. Direct insertion of the trocar is associated with less insufflation-related complications, such as gas embolism, and faster than the Veress needle technique.

The visual entry trocars may offer an advantage over traditional trocars, because they allow a clear optical entry, but this advantage has not been fully explored. They also minimize the size of the entry wound and reduce the force necessary for insertion, but they are not superior to other trocars because they do not avoid visceral and vascular injury.

The 2002 EAES clinical practice guideline on the pneumoperitoneum did not make any strong recommendation favoring one technique over the other [36]; however, the use of either technique may have advantages in specific patient subgroups (Recommendation B).

A systematic review of the safety and effectiveness of methods used to establish pneumoperitoneum in laparoscopic surgery (2003) could not demonstrate any significant difference to support one method of choice [37].

The method of approach has to be adapted to patient's condition in case of expected increased risk of injury (BMI, previous surgery, position of scars, suspicion of adhesions, etc.). Implementation of the available evidence should optimize the decision-making process in choosing a particular technique to enter the abdomen during laparoscopy [29].

After an unsuccessful attempt in the umbilical region, preferably with safety tests or having a high intraperitoneal pressure when starting gas insufflations [30], "Palmer's" point in left hypochondrium can be chosen [29]. If in any doubt, the Hasson approach is recommended. The use of visual entry trocars outside of potential danger areas may increase the safety of trocar insertion.

Trocar choice, placement and positioning

What kind of trocars should be used?

Is there any relation between trocar type and risk of injury and/or trocar hernias?

\section{Statements}

Level 1B The radially dilating trocars cause less acute injuries (bleeding at trocar site) and less chronic tissue damage (trocar hernias).

Level 2B Visual entry trocars are not superior to other trocars, because they do not avoid visceral and vascular injury.

Level 2B The visual entry cannula trocars have the advantage of minimizing the size of the entry wound and reducing the force necessary for insertion under visual control.

\section{Recommendations}

Grade A

Cutting trocars should be avoided.

\section{Discussion}

Instrumentation has improved to the point that the principles of minimally invasive surgery can be put into practice. The design of dilating instead of cutting trocars contributed significantly to decrease the risk of port-site bleeding and development of port-site hernias [1, 4, 29, 38-40]. Bittner et al. found significant differences in incidence of trocarrelated parietal hemorrhage (cutting trocar 1.76 vs. $0.056 \%$ conical trocar, $p>0.0001$ ) and incidence of trocar hernias (cutting trocar 1.27 vs. $0.037 \%$ conical trocar, $p>0.0001$ ) [4]. The equal effect on incisional pain of both trocar types found in patients after laparoscopic cholecystectomy is no reason to continue to cutting trocars [41].

In TAPP, three trocars are usually placed at the umbilical level (optic and two working ports); all working ports are inserted under direct vision. The parietal, intraabdominal, and retroperitoneal vascular injuries are preventable 
with good anatomical orientation and cautious pressurecontrolled trocar insertion.

The optimal trocar positioning respects the rules of triangulation to facilitate and improve the workflow ergonomics. Consider the proximity of bony structures as potential inhibitors of instrumentation freedom.

\section{Assessment of defect, contralateral site, exploration of abdominal cavity}

Is clinical examination of hernias efficient enough?

What is the role of TAPP and other techniques in reliable assessment?

\section{Statements}

Level 1B A significant proportion of incidental defects will progress to a symptomatic hernia if left untreated.

Level 2B Clinical examination is accurate only in $75-89 \%$ of patients. The sensitivity of ultrasound is clearly higher than a mere physical examination.

Level 2B TAPP enables rapid evaluation of the "contralateral groin" (clinically unsuspected) hernia.

Level 2C TAPP is beneficial in avoiding unnecessary explorations and repairs of the contralateral side.

\section{Recommendations}

\begin{tabular}{cc}
\hline Grade A & The patient with unilateral hernia should be informed \\
about the possibility of having undiagnosed \\
contralateral hernia. \\
The patient should be informed about advantages \\
and disadvantages of simultaneous repair. \\
In case of clinical uncertainty diagnosing the hernia, \\
an ultrasound examination should be done. \\
If the patient agrees, the incidental contralateral \\
defect should be repaired simultaneously. \\
In case of diagnostic uncertainty (inguinal pain, \\
inconclusive clinical evaluation, recurrence, occult \\
hernia) despite extensive use of the diagnostic \\
tools-ultrasound, CT scan, MRT-TAPP may be \\
the approach of choice. \\
When at laparoscopy no hernia opening is visible \\
in patients with strong clinical suspicion of hernia, \\
a preperitoneal exploration is indicated.
\end{tabular}

The accuracy of a clinical groin examination is limited. The incidence of occult contralateral hernia found at the time of unilateral hernia repair using TAPP or TEP is up to $25 \%[23,24]$.

For definitive proof of the presence of a hernia, the sensitivity of ultrasound is clearly higher than a mere physical examination. The final and definitive classification of hernias can only be made intraoperatively; at best, the results of an ultrasound examination can help to orientate the surgeon. The TAPP enables rapid assessment [24]. In conventional hernia surgery or with the total extraperitoneal (TEP) method, this kind of evaluation is impossible or at least problematic.

In case of a missing hernia sac, most cord lipomas can be visualized when external pressure is applied over the groin. When no hernia is found in patients with strong hernia suspicion (positive clinical examination, positive ultrasound finding), the preperitoneal exploration is still indicated to rule out other pathologies of inguinal canal or preperitoneal lipomas in the femoral canal.

A significant proportion of incidental defects will progress to a symptomatic hernia if left untreated (28\% within 15 months). Therefore, incidental hernias should be simultaneously repaired if the patient has agreed [26]; $11 \%$ of clinically unrecognized hernias were repaired at the time of surgery.

TAPP herniorrhaphy is beneficial to avoid unnecessary explorations and allow timely repairs in patients with occult inguinal hernias [25, 42]. Although the reported incidence of chronic pain after TAPP repair is very low, the simultaneous repair of the healthy contralateral groin "in advance" is not justified unless a "significant collagen deficiency" is suspected.

\section{Anatomical landmarks, peritoneal incision, extent of dissection}

Statements

Level 5 There is not enough data available on the influence of the particular steps of the surgical technique and the individual performance on the outcome.

Level 5 Taking down adhesion between omentum or bowel to the peritoneum of groin or to the hernia sac is mostly not necessary. It carries additional risk of intestinal injury.

\section{Recommendations}

Grade D A meticulous operative technique and the adequate extent of preperitoneal anatomical dissection (whole pelvic floor) belong to the most important key points of TAPP repair.

Grade D Reduction of the hernia sac inclusive adherent content if excising should be done en bloc.

In the majority of cases, the anatomical points of primary orientation are visible or demonstrable by external palpation: the medial umbilical ligament (MUL), the lower epigastric vessels (the lateral umbilical ligament), the deep (inner) inguinal ring, the anterior superior iliac spine (ASIS), and the spermatic structures (vas deferens and spermatic vessels) or the round ligament. The other important structures (secondary orientation) become visible during the preperitoneal dissection: the ileopubic tract, the symphysis pubis, Cooper's ligament, and the femoral canal.

In case of local omental or intestinal adhesions to the peritoneum of the groin, it is not recommended to perform adhesiolysis in general, unless it obstructs the overview. In sliding hernias or even irreducible hernias, neither adhesiolysis nor reduction is mandatory, but the straightforward preperitoneal dissection should be performed. This facilitates the mobilization of hernia content within the sac and helps to avoid intestinal injury. In strangulated hernias, the 
preperitoneal dissection allows to visualize the safe position of a relaxing incision of the hernia ring if necessary $[1,4]$.

\section{Surgical strategy}

No studies have compared different positions of the patient and the operating table or the positioning of the surgeons. However, there is a general agreement that the patient is kept in the supine position on the operating table, which is in head-down position during the operation and slightly (approximately $15^{\circ}$ ) turned toward the surgeon $[1,4]$. The operating surgeon and the camera assistant stay on opposite sides of the hernia.

1. The peritoneal incision is placed $3-4 \mathrm{~cm}$ above all possible defects from ASIS to MUL (not vice versa ER, PE), which does not have to be transected. If more space is needed, a cranial extension of the peritoneal incision parallel to MUL may be helpful.

2. A complete anatomical dissection of the whole pelvic floor is necessary for a flat and wrinkle-free placement of the mesh.

3. The extent of dissection reaches medially $1-2 \mathrm{~cm}$ beyond the symphysis pubis to the contralateral side, cranially $3-4 \mathrm{~cm}$ above the transversalis arch or any direct defect, laterally to ASIS, and caudally minimally 4-5 cm below the ileopubic tract at the level of psoas muscle and 2-3 cm below the Cooper's ligament at the level of superior arch of the pubic bone.

4. The resulting preperitoneal space has to accommodate a mesh of adequate size (at least $10 \times 15 \mathrm{~cm}^{2}$ ) (PE).

5. The level of the dissection plane within the avascular "spin-web" space between the internal and external layer of peritoneum is crucial. The objective is to retract all peritoneal sack and corresponding pre-, extra-, and retroperitoneal fat tissue from the hernia orifices down to the middle of psoas muscle (=parietalization) [1, 3, 4, 7]. The preservation of the spermatic fascia and of the lumbar fascia protects the fragile parietal structures (vas deferens, vessels and the nerves) [43].

\section{Indirect hernias}

Statements

Level 2C Cord lipomas or lipomas in the femoral canal may imitate primary hernia, hernia recurrence, or become symptomatic in later course.

Level 4 Complete reduction of the hernia sac does not increase the incidence of sero-hematomas if careful dissection and control of hemostasis are done.

Level 5 Complete reduction of the hernia sac may eliminate the occurrence of chronic seroma/"pseudo-hydrocele."

\section{Recommendations}

Grade B Lipomas of spermatic cord/round ligament and the preperitoneal lipomas of direct and femoral sacs should be removed.

Grade D In case of unclear anatomy, first identify spermatic vessels.

\begin{tabular}{l}
\hline Grade D If dense adhesions to the cord structures are present \\
in a long hernia sac, the sac may be exceptionally \\
transected at the level of inner inguinal ring \\
to prevent injury.
\end{tabular}

Large and/or deep indirect sacs may prolong the operating time, but complete retraction is possible in almost every case. Delicate dissection and ongoing control of hemostasis do not increase the incidence of scrotal hematoseromas [44] but eliminate the formation of chronic seroma/pseudo-hydrocele. The transection of a difficult indirect sac was suggested to prevent possible damage to the spermatic cord and decrease the incidence of scrotal hematomas. Bittner et al. [2] reported low rates of orchitis $(0.1 \%)$ and testicular atrophy $(0.05 \%)$ despite nearly always complete reduction of the sack.

In difficult conditions, in the presence of large and deep sacs, after temporary strangulations or in complicated recurrences, the following strategy is recommended: identify the spermatic vessels far latero-caudally first before starting the dissection along the vessels towards the inguinal canal and to the top of the indirect sac. In this manner, damage to the spermatic vessels can be safely prevented [1, 4].

Quite often, substantial funicular lipomas or pre-/or retroperitoneal fat prolapse into the enlarged hernia orifices ring [45-48]. They should be retracted and eventually resected, because they may become symptomatic or mimic a recurrent hernia [49]. An overlooked lipoma is one of the known reasons for "recurrence" [50]. Although the published data provide low evidence, the search for and exclusion of such masses is integral part of the endoscopic hernia repair $[51,52]$.

\section{Direct hernias}

\section{Statements}

Level 2B The incidence of seromas in direct hernias can be significantly reduced when the lax transversalis fascia is inverted.

Level 2C Seroma is a common early postoperative minor complication in endoscopic preperitoneal hernia repair.

\section{Recommendations}

\begin{tabular}{cc}
\hline Grade B & $\begin{array}{c}\text { In voluminous direct hernias, the extended transversalis } \\
\text { fascia should be inverted. }\end{array}$ \\
\hline
\end{tabular}

A prospective nonrandomized study demonstrates significantly lower incidence of postoperative seromas in the group of patients with direct hernias and transversalis fascia inversion, without increase of postoperative pain despite the use of invasive fixation with tacks to the 
Cooper's ligament [53]. In some expert reports, fixation with sutures is recommended as a less expensive alternative. A cautious use of superficial electrocoagulation to obliterate blood, and lymphatic vessels, also has been suggested to reduce seroma formation [1, 4].

\section{Mesh choice, mesh size, mesh slit, mesh fixation}

The mesh issues (type, size, slited/nonslited, and fixation) are technical key points of paramount importance. The details will be analyzed and discussed in another chapter.

\section{Peritoneal closure \\ Statements}

\begin{tabular}{cc}
\hline Level 3 & $\begin{array}{c}\text { Incomplete peritoneal closure or its breakdown in } \\
\text { endoscopic preperitoneal hernia repair increases } \\
\text { the risk of bowel obstruction. } \\
\text { TAPP procedure presents a higher statistical risk of } \\
\text { small-bowel obstruction than TEP. } \\
\text { The most appropriate peritoneal closure is achieved } \\
\text { by running absorbable suture. } \\
\text { Running suture seems to cause less pain compared } \\
\text { with clip/tack closure. }\end{array}$ \\
Level 5 5 & $\begin{array}{l}\text { The closure of entrance of indirect sacs may reduce } \\
\text { the risk of internal hernia with consecutive } \\
\text { incarceration, strangulation, or small-bowel } \\
\text { obstruction. }\end{array}$ \\
\hline
\end{tabular}

\section{Recommendations}

\begin{tabular}{cc}
\hline Grade C & $\begin{array}{c}\text { A thorough closure of peritoneal incision or peritoneal } \\
\text { tears should be done. }\end{array}$ \\
Grade D & $\begin{array}{c}\text { The peritoneal closure can be accomplished by running } \\
\text { suture. }\end{array}$ \\
\hline
\end{tabular}

The bowel obstruction can develop due to adhesions between omentum or epiploic appendices and suture line, between the mesh and the intestines, e.g., by inadequate closure of a peritoneal lesion [54-56]. The peritoneal opening must be thoroughly closed to prevent contact of viscera with the prosthetic mesh material and to reduce the risk of bowel obstruction. The closure can be achieved with staples, tacks, running suture, or glue. These last two methods are more time-consuming but less painful $[1,4]$ (see Chap. 9). Rare cases of bowel obstruction in port-site hernias also have been described, especially after TAPP.

The reduction of intra-abdominal pressure (e.g., $8 \mathrm{mmHg}$ or less) facilitates the peritoneal closure during the running suture, especially in difficult cases $[1,4]$. Several anecdotic reports on small-bowel obstruction both in TAPP [6] and TEP repairs have been published $[57,58]$. The data from Swedish National Inguinal Hernia Register show higher incidence of late postoperative bowel obstruction after TAPP than after TEP [54].

Theoretically, the deep indirect sacs could cause internal hernia. Therefore, the author closes the internal orifice of the sac to eliminate the incarceration risk (author's personal experience).

\section{Port-site closure Statements}

Level 3 Use of 10-mm trocars or larger may predispose to hernias, especially in the umbilical region or in the oblique abdominal wall.

\section{Recommendations}

Grade C Trocar sites with fascial defects of $10 \mathrm{~mm}$ or larger can be closed.

Port-site hernia is a late postoperative complication predominantly reported in TAPP repair. Although, according to general opinion, only $10 \mathrm{~mm}$ and bigger trocar site defects should be closed, the development of incisional hernia with consequences was described even with 3-5-mm trocars [59-65].

A review of 63 reports (24 case reports, 27 original articles, 7 technical notes, and 5 review articles) was published in 2004 [66]. The evidence level of these reports varies from 1 to 3 . Recommendation B concerns the closure of trocars of $10 \mathrm{~mm}$ or bigger.

A difference should be made between the periumbilical closure and the closure of the working ports. Again, it should be differentiated according the defects through the rectus muscle and through the weaker oblique abdominal wall. A pre-existent umbilical hernia/weakness must be treated like a primary hernia (author's personal experience).

It is the author's opinion that it is important to close the peritoneum in lateral working ports $\geq 10 \mathrm{~mm}$, because trocar hernias do not occur in TEP (peritoneum under working ports remains intact) (PE).

Pain control

Statements

Level 5 Additional use of local anaesthetic positively influences postoperative pain in TEP and TAPP. Infiltration of trocar wounds with long-acting local anaesthetic in TAPP improves patient's well-being and accelerates return to ambulation.

\section{Recommendations}

Grade D To improve postoperative pain control, trocar wounds can be infiltrated by local anesthetics.

Efficient pain control after hernia repair is a pillar of success. A significant reduction of postoperative pain through preemptive use of Bupivacaine was described in TEP [67]. Such effect was not reported in TAPP yet, although routine infiltration of the wound after hernia repair provides extra pain control and limits the use of analgesics. Additional use of local anesthetics positively influences postoperative pain in TAPP. Infiltration of trocar wounds with long-acting local anesthetic in TAPP 
improves patient's well-being and accelerates return to ambulation (PE).

\section{Conclusion on technical key points in TAPP repair}

The multitude of data published on this subject presents different levels of evidence, but particular technical key points are well investigated [68, 69]. Some expert opinions lack supporting data, but some steps of the TAPP technique are clearly supported by strong levels of evidence. The grade of recommendations varies from A to $\mathrm{D}$. The proven technical key points should become the pillars of the standardized TAPP repair, transferred to the wide surgical community and emphasized in the teaching and learning environment to guarantee the best possible outcomes.

References (in parentheses graduation of evidence)

1. Bittner R, Schmedt CG, Leibl BJ (2003) Transabdominal pre-peritoneal approach in LeBlanc KA. Laparoscopic hernia surgery. London: Arnold Publisher; pp 54-64. (2C)

2. Bittner R, Schmedt CG, Schwarz J, Kraft K, Leibl BJ (2002) Laparoscopic transperitoneal procedure for routine repair of groin hernia. Br J Surg 89:1062-1066. (2C)

3. Bittner R, Kraft K, Schmedt CG, Leibl BJ (2000) Technik der laparoskopischen Hernioplastik (TAPP). Chir Gastroenterol 16:98-103. (4)

4. Bittner R, Leibl BJ, Ulrich M (2006) Chirurgie der Leistenhernie, Karger, Freiburg. (2C)

5. Leibl BJ, Kraft K, Schmedt CG, Bittner R (2001) Access techniques for endoscopic surgery-types of trocars, ports and cannulae-an overview. Min Invas Ther Allied Technol 10:5-10. (3)

6. Lovisetto F, Zonta S, Rota E, Bottero L, Faillace G, Turra G, Fantini A, Longoni M (2007) Laparoscopic TAPP hernia repair: surgical phases and complications. Surg Endosc 21:646-652. (2B)

7. Schmedt CG, Leibl BJ, Däubler $P$, Bittner $R$ (2001)Access-related complications - an analysis of 6023 consecutive laparoscopic hernia repairs. Min Invas Ther Allied Technol 10:23-30. (2C)

8. Schmedt CG, Sauerland S, Bittner R (2005) Comparison of endoscopic procedures vs. Lichtenstein and other open mesh techniques for inguinal hernia repair. A metaanalysis of RCTs. Surg Endosc 19:188-199. (1A)

9. Bittner R, Sauerland S, Schmedt CG (2005) Comparison of endoscopic techniques vs. Shouldice and other open nonmesh techniques for inguinal hernia repair: a meta-analysis of randomized controlled trials. Surg Endosc 19:605-615. (1A)

10. Eklund A, Rudberg C, Leijonmarck C-E, Rasmussen I, Spangen L, Wickbom G, Wingren U, Montgomery A (2007) Recurrent inguinal hernia: randomized multicenter trial comparing laparoscopic and Lichtenstein repair. Surg Endosc 21:634-640. (1B)
11. Ulrich M (2006) Postoperatives management. In: Bittner R, Leibl BJ, Ulrich M (eds). Chirurgie der Leistenhernie. Karger, Freiburg; pp 140-142. (2C)

12. Simons MP, Aufenacker T, Bay-Nielsen M, Bouillot JL, Campanelli G, Conze J, de Lange D, Fortelny R, Heikkinen T, Kingsnorth A, Kukleta J, MoralesConde S, Nordin P, Schumpelick V, Smedberg S, Smietanski M, Weber G, Miserez M (2009) European Hernia Society guidelines on the treatment of inguinal hernia in adult patients. Hernia 13:343-403. (2C)

13. Phillips EH, Arregui M, Carroll BJ, Corbitt J, Crafton WB, Fallas MJ, Filipi C, Fitzgibbons RJ, Franklin MJ, McKernan B, Olsen D, Ortega A, Payne JH Jr, Peters J, Rodriguez R, Rosette P, Schultz L, Seid A, Sewell R, Smoot R, Toy F, Waddell R, Watson S (1995) Incidence of complications following laparoscopic hernioplasty. Surg Endosc 9:16-21. (3)

14. Wauschkuhn CA, Schwarz J, Bittner R (2009) Laparoscopic transperitoneal inguinal hernia repair (TAPP) after radical prostatectomy: is it safe? Results of prospectively collected data of more than 200 cases. Surg Endosc 23:973-977. (2B)

15. Jensen P, Mikkelsen T, Kehlet H (2002) Postherniorrhaphy urinary retention-effect of local, regional, and general anesthesia: a review. Reg Anesth Pain Med 27:612-617. (2A)

16. Koch CA, Grinberg GG, Farley DR (2006) Incidence and risk factors for urinary retention after endoscopic hernia repair. Am J Surg 191:381-385. (3)

17. Lau H, Patil NG, Yuen WK, Lee F (2002) Urinary retention following endoscopic totally extraperitoneal inguinal hernioplasty. Surg Endosc 16:1547-1550. (3)

18. Kjønniksen I, Andersen BM, Søndenaa VG, Segadal L (2002) Preoperative hair removal-a systematic literature review. AORN J 75:928-938, 940. (2B)

19. Orsi GB, Ferraro F, Franchi C (2005) Preoperative hair removal review [in Italian]. Ann Ig 17:401412. (2C)

20. Tanner J, Moncaster K, Woodings D (2007) Preoperative hair removal: a systematic review. J Perioper Pract 17:118-121, 124-132. (1A)

21. Tanner J, Woodings D, Moncaster K (2006) Preoperative hair removal to reduce surgical site infection. Cochrane Database Syst Rev (2):CD004122. (1A)

22. Dickinson KJ, Thomas M, Fawole AS, Lyndon PJ, White CM (2008) Predicting chronic postoperative pain following laparoscopic inguinal hernia repair. Hernia 12:597-601. (2B)

23. Crawford DL, Hiatt JR, Phillips EH (1998) Laparoscopy identifies unexpected groin hernias. Am Surg 64:976-978. (2B)

24. Kraft BM, Kolb H, Kuckuk B, Haaga S, Leibl BJ, Kraft K, Bittner R (2003) Diagnosis and classification 
of inguinal hernia. Accuracy of clinical, ultrasonographic and laparoscopic findings. Surg Endosc 17:2021-2024. (2C)

25. Novitsky YW, Czerniach DR, Kercher KW, Kaban GK, Gallagher KA, Kelly JJ, Heniford BT, Litwin DE (2007) Advantages of TAPP in the evaluation and management of inguinal hernias. Am J Surg 193:466470. (2C)

26. Thumbe VK, Evans DS (2001) To repair or not to repair incidental defects found on laparoscopic repair of groin hernia. Early results of a randomized controlled trial. Surg Endosc 15: 47-49. (1B)

27. Vilos GA, Vilos AG, Abu-Rafea B, Hollett-Caines J, Nikkhah-Abyaneh Z, Edris F (2009) Three simple steps during closed laparoscopic entry may minimize major injuries. Surg Endosc 23:758-764. (4)

28. Shamiyeh A, Glaser K, Kratochwill H, Hörmandinger K, Fellner F, Wayand W, ZehetnerJ (2009) Lifting of the umbilicus for the installation of pneumoperitoneum with the Veress needle increases the distance to the retroperitoneal and intraperitoneal structures. Surg Endosc 23:313-317. (3)

29. Vilos GA, Ternamian A, Dempster J, Laberge PY (2007) The Society of Obstetricians and Gynaecologists of Canada. Laparoscopic entry: a review of techniques, technologies, and complications. J Obstet Gynaecol Can 29:433-465. (1A)

30. Teoh B, Sen R, Abbot J (2005) An evaluation of four tests used to ascertain Veress needle placement at closed laparoscopy. 12:153-158. (4)

31. Catarci M, Carlini M, Gentileschi P, Santoro E (2001) Major and minor injuries during the creation of pneumoperitoneum: a multicenter study on 12,919 cases. Surg Endosc 15:566-569. (2C)

32. Hasson HM (1971) A modified instrument and method for laparoscopy. Am J Obstet Gynecol 110: 886-887. (5)

33. Peitgen K, Nimtz K, Hellinger A, Walz MK (1997) Open approach or Veress needle in laparoscopic interventions? Results of a prospective randomized controlled study [in German]. Chirurg 68:910-913. (2B)

34. Agresta F, De Simone P, Ciardo LF, Bedin N (2004) Direct trocar insertion vs Veress needle in nonobese patients undergoing laparoscopic procedures: a randomized prospective single-center study. Surg Endosc 18:1778-1781. (1B)

35. Altun H, Banli O, Kavlakoglu B, Kücükkayikci B, Kelesoglu C, Erez N (2007) Comparison between direct trocar and Veress needle insertion in laparoscopic cholecystectomy. J Laparoendosc Adv Surg Tech A 17:709-712. (1B)
36. Neudecker J, Sauerland S, Neugebauer E, Bergamaschi R, Bonjer HJ, Cuschieri A, Fuchs KH, Jacobi Ch, Janson FW, Koivusalo AM, Lacy A, McMahon MJ, Millat B, Schwenk W (2002) The EAES clinical practice guideline on the pneumoperitoneum for laparoscopic surgery. Surg Endosc 16:1121-1143. (2C)

37. Merlin TL, Hiller JE, Maddern GJ, Jamieson GG, Brown AR, Kolbe A (2003) Systematic review of the safety and effectiveness of methods used to establish pneumoperitoneum in laparoscopic surgery. Br J Surg 90:668-679. (1A)

38. Bhoyrul S, Payne J, Steffes B, Swanstrom L, Way LW (2000) A randomized prospective study of radially expanding trocars in laparoscopic surgery. J Gastrointest Surg 4:392-397. (1B)

39. Lam TY, Lee SW, So HS, Kwok SP (2000) Radially expanding trocar: a less painful alternative for laparoscopic surgery. J Laparoendosc Adv Surg Tech A 105:269-273. (2B)

40. Yim SF, Yuen PM (2001) Randomized doublemasked comparison of radially expanding access device and conventional cutting tip trocar in laparoscopy. Obstet Gynecol 97:435-438. (1B)

41. Bisgaard T, Jakobsen HL, Jacobsen B, Olsen SD, Rosenberg J (2007) Randomized clinical trial comparing radially expanding trocars with conventional cutting trocars for the effects on pain after laparoscopic cholecystectomy. Surg Endosc 21:2012-2016. (1B)

42. Dastur JK, Entikabi F, Parker MC (2006) Repair of incidental contralateral defects found during laparoscopic transabdominal preperitoneal (TAPP) repair of unilateral groin hernias. Surg Endosc 20:1924. (4)

43. Foelscher DJ, Leroy J, Jamali FR, Marescaux J (2000) Totally extrafascial endoscopic preperitoneal hernia repair: a merger of anatomy and surgery. The exact description to endoscopically dissect the spermatic fascia. Hernia 4:223-227. (5)

44. Leibl BJ, Schmedt CG, Kraft K, Ulrich M, Bittner R (2000) Scrotal hernias: a contraindication for an endoscopic procedure? Results of a single-institution experience in transabdominal preperitoneal repair. Surg Endosc 14:289-292. (2B)

45. Carilli S, Alper A, Emre A (2004) Inguinal cord lipomas. Hernia 8:252-254. (4)

46. Cavazzola LT, Lieberknecht M, Machado AS, Farias FR (2009) Giant lipoma of the spermatic cord. Am J Surg 198:54-55. (4)

47. Lau H (2007) Recurrence following endoscopic extraperitoneal inguinal hernioplasty. Hernia 11:415418. (4)

48. Lilly MC, Arregui ME (2002) Lipomas of the cord and round ligament. Ann Surg 235:586-590. (4) 
49. Lau H, Loong F, Yuen WK, Patil NG (2007) Management of herniated retroperitoneal adipose tissue during endoscopic extraperitoneal inguinal hernioplasty. Surg Endosc 21:1612-1616. (3)

50. Nasr AO, Tormey S, Walsh TN (2005) Lipoma of the cord and round ligament: an overlooked diagnosis? Hernia 9:245-247. (4)

51. Felix E, Scott S, Crafton B, Geis P, Duncan T, Sewell R, McKernan B (1998) Causes of recurrence after laparoscopic hernioplasty. A multicenter study. Surg Endosc 12:226-231. (3)

52. Gersin KS, Heniford BT, Garcia-Ruiz A, Ponsky JL (1999) Missed lipoma of the spermatic cord. A pitfall of transabdominal preperitoneal laparoscopic hernia repair. Surg Endosc 13:585-587. (3)

53. Reddy VM, Sutton CD, Bloxham L, Garcea G, Ubhi SS, Robertson GS (2007) Laparoscopic repair of direct inguinal hernia: a new technique that reduces the development of postoperative seroma. Hernia 11:393-396. (2B)

54. Bringman S, Blomqvist P (2005) Intestinal obstruction after inguinal and femoral hernia repair: a study of 33,275 operations during 1992-2000 in Sweden. Hernia 9:178-183. (2C)

55. Duran JJ, May JM, Msika S, Gaschard D, Domergue J, Gainant A, Fingerhut A (2000) Prevalence and mechanisms of small intestinal obstruction following laparoscopic abdominal surgery. Arch Surg 135: 208-212. (2C)

56. Eugene JR, Gashti M, Curras EB, Schwartz K, Edwards J (1998) Small bowel obstruction as a complication of laparoscopic extraperitoneal inguinal hernia repair. J Am Osteopath Assoc 98:510511. (2C)

57. Lodha K, Deans A, Bhattacharya P, Underwood JW (1990) Obstructing internal hernia complicating totally extraperitoneal inguinal hernia repair. J Laparoendosc Adv Surg Tech 8:167-168. (4)

58. McKay R (2008) Preperitoneal herniation and bowel obstruction post laparoscopic inguinal hernia repair: case report and review of the literature. Hernia 12:535-537. (4)

59. Boughey JC, Nottingham JM, Walls AC (2003) Richter's hernia in the laparoscopic era: four case reports and review of the literature. Surg Laparosc Endosc Percutan Tech 13:55-58. (4)

60. Jones DB, Callery MP, Soper NJ (1996) Strangulated incisional hernia at trocar site. Surg Laparosc Endosc 6:152-154. (4)

61. 65. Di Lorenzo N, Coscarella G, Lirosi F, Gaspari A (2002) Port-site closure: a new problem, an old device. JSLS 6:181-183. (4)
62. Kouba EJ, Hubbard JS, Wallen E, Pruthi RS (2007) Incisional hernia in a $12-\mathrm{mm}$ non-bladed trocar site following laparoscopic nephrectomy. Urol Int 79:276-279. (4)

63. Liu CD, McFadden DW (2000) Laparoscopic port sites do not require fascial closure when nonbladed trocars are used. Am Surg 66:853-854. (4)

64. Reardon PR, Preciado A, Scarborough T, Matthews B, Marti JL (1990) Hernia at 5-mm laparoscopic port site presenting as early postoperative small bowel obstruction. J Laparoendosc Adv Surg Tech A 9:523-525. (4)

65. Yee DS, Duel BP (2006) Omental herniation through a 3-mm umbilical trocar site. J Endourol 20: 133-134. (4)

66. Di Lorenzo N, Coscarella G, Lirosi F, Gaspari A (2002) Port-site closure: a new problem, an old device. JSLS 6:181-183. (4)

67. Tonouchi H, Ohmori Y, Kobayashi M, Kusunoki M (2004) Trocar site hernia. Arch Surg 139:1248-1256. (2A)

68. Hon SF, Poon CM, Leong HT, Tang YC (2009) Preemptive infiltration of Bupivacaine in laparoscopic total extraperitoneal hernioplasty: a randomized controlled trial. Hernia 13:53-56. (1B)

69. Grant AM (2002) EU Hernia Trialists Collaboration. Laparoscopic versus open groin hernia repair: metaanalysis of randomised trials based on individual patient data. Hernia 6:2-10. (1A)

70. McCormack K, Wake BL, Fraser C, Vale L, Perez J, Grant A (2005) Transabdominal pre-peritoneal (TAPP) versus totally extraperitoneal (TEP) laparoscopic techniques for inguinal hernia repair: a systematic review. Hernia 9: 109-114. (1A)

\section{Chapter 3: Technical key points: total extraperitoneal patch plasty (TEP) repair}

P. Chowbey, F. Köckerling, D. Lomanto

Search terms: inguinal hernia, femoral hernia, total extraperitoneal repair (TEP), preperitoneal access, space creation, needlescopic, ports, peritoneal tears, complications, mesh, fixation.

\section{Preoperative preparations}

Is it necessary to empty the urinary bladder before TEP?

Which is the best way of emptying the urinary bladder: catheterization or voiding?

Statements and recommendations are not different to TAPP. See Chap. 2 (Kukleta) and Chap. 11 (Fitzgibbons), and References 1-7. 


\section{Positioning of patient and surgeons Recommendation}

\begin{tabular}{ll}
\hline Level 5 & The patient is kept in the supine position. \\
Level 5 & $\begin{array}{c}\text { The operating surgeon and the camera assistant stay } \\
\text { on opposite sides of the hernias. }\end{array}$
\end{tabular}

No studies have compared different positions of the patient and the operating table or the positioning of the surgeons. However, there is a general agreement that the patient is kept in the supine position [8,9] on the operating table, which is in head-down position during the operation and slightly (approximately $15^{\circ}$ ) turned toward the surgeon. The operating surgeon and the camera assistant stay on opposite sides of the hernias [9].

\section{Preperitoneal access}

What is the most popular mode of accessing the preperitoneal space?

Level 4 Direct open access is a simple and reproducible technique for accessing the preperitoneal space.

Access by transperitoneal visualization is an alternative but is associated with the risks of entering the peritoneal cavity.

Suprapubic Veress needle technique also is used by few surgeons.

\section{Statements}

Grade D Direct access with the Hasson trocar via a 1-2-cm subumbilical incision on the side of hernia and opening of the rectus sheath, enlargement of the space between the rectus muscle and the posterior sheath.

\section{Recommendations}

Direct access with Hassan trocar has been popularized by many and is used by Ferzli et al. [10], McKernan and Laws [11], Chowbey [12], Garg et al. [9], and Köckerling [13]. The suprapubic Veress needle technique [8] requires the placement of Veress needle in the space of Retzius followed by carbon dioxide insufflation and direct trocar placement. In this method, it is difficult to place the Veress needle correctly and the working space is initially narrow.

The transperitoneal visualization technique of Philip $[14,15]$ requires creation of pneumoperitoneum and subsequently a preperitoneal blister is raised using $0.5 \%$ Bupivacaine followed by direct trocar placement in the preperitoneal space. This also has been used by Arregui and Young [16]. The disadvantage of this technique is the addition of complications inherent to a transperitoneal approach, such as bowel injury and port site hernia. The presence of pneumoperitoneum may compromise the extraperitoneal space.

\section{Space creation}

Which technique of space creation best achieves the required extraperitoneal space?

\section{Statements}

Level 1B Balloon dissection is associated with significantly reduced postoperative pain at $6 \mathrm{~h}$, scrotal edema, and seroma formation compared with telescopic dissection.

At 3 months follow-up, balloon dissection did not offer significant advantage over direct telescopic dissection.

The use of a dissection balloon in TEP reduces the conversion rate and may be especially beneficial early in the learning curve.

The technique of balloon dissection provides adequate extraperitoneal space creation and is evolving as a method of choice; indigenous balloons contribute to cost-effectiveness.

Dissection with the telescope is another frequently used method.

Anatomical delineation of inguinal area and dissection in the extraperitoneal space in TEP repair was equally satisfactory in both the balloon dissection and the telescope dissection group.

\section{Recommendations}

Grade A Balloon dissection should be considered for extraperitoneal space creation, especially during the learning period, when it is difficult to find the correct plane in the preperitoneal space.

Balloon dissection is the most commonly used method to create extraperitoneal space [17]. There are commercially available balloons [18, 19] as well as low-cost indigenous balloons, such as the ones used by Chowbey [12] in which two cut fingers stalls of an 8-size glove are applied over a suction-irrigation cannula and tied with silk. Similar techniques and minor variations thereof have been used by different authors [21-24].

A randomized, prospective, multicenter study showed that a dissection balloon made the dissection of preperitoneal space easier and safer, thus reducing operative time, conversion rate, and number of complications [19].

Blunt probe dissection under vision with a $10-\mathrm{mm}$ zerodegree operative scope with a 5-mm working channel was described by Ferzli et al. in 1992 [10]. Direct telescopic dissection has been described by McKernan and used in many centers across the globe [6].

Modifications to the technique of balloon dissection are needed for patients with previous lower abdominal surgery. The balloon is distended much less than in those without previous surgery and away from the scar site to prevent tearing of scar tissues and thereby decreasing the potential for tearing of bowel, bladder, or peritoneum [7]. Furthermore, balloon dissection has a major disadvantage in patients who have a linea alba that extends to the pubic symphysis. In these patients, the balloon will dissect one 
side of the preperitoneal space posterior to the epigastric vessels and may cause bleeding (Ferzli, personal comment). The role of needlescopic TEP

\section{Statements}

Level 2 B Needlescopic TEP is a safe technique for the repair
of inguinal hernia.
Postoperative recovery after needlescopic and
conventional TEP was similar.
Needlescopic TEP conferred a significantly lower pain
score upon coughing on the first day after operation.

\section{Recommendations}
Grade C In patients with a low pain threshold, a needlescopic TEP can be performed.

In the past, needlescopic TEP was difficult because the instruments were not strong enough to allow sufficient dissection of the hernia sac, especially of the indirect sac; however, new technical developments have eliminated this problem [25].

\section{Ports}

How does port positioning contribute to the technique of TEP repair?

\section{Statements}

Level 5 The midline ports have the advantage of accessing both
sides with equal ease and minimal risk of injuries
to the inferior epigastric vessels.
All three ports made in the midline at the
commencement of the procedure enable bimanual
dissection right from the start.
Another technique of a 10-mm port at the umbilicus,
a 5-mm port a few centimeters lower, and another
5-mm trocar laterally near the anterior-superior iliac
spine is the next alternative. Overlapping mesh in the
midline is thought to be easier with this technique.
Lateral ports, two in number, just lateral to the rectus
muscle, used along with a midline camera port are
an option.

\section{Recommendations}

\begin{tabular}{c}
\hline Grade D Two alternatives for the trocar placement: two 5-mm \\
working ports in the midline, and in the midway \\
between the camera port and the pubic symphysis. \\
Alternatively, the second working trocar (5 or $10 \mathrm{~mm})$ \\
can be placed after lateral dissection approximately \\
$3-4 \mathrm{~cm}$ superior and $1-2 \mathrm{~cm}$ anterior to the \\
anterosuperior iliac spine. \\
Lateral working trocars are favored when mesh \\
overlap over the midline is perceived to be difficult.
\end{tabular}

Three ports are required, of which the camera port is constant and is a $10-\mathrm{mm}$ subumbilical port. The two working ports are variable. Both of them may be in the midline as far cephalad as possible from the pubic symphysis.

Another option is one midline port below the camera and one lateral port near the anterior superior iliac spine $[13,26]$. This port placement gives a better trocar triangulation and makes complete dissection of large lateral hernia sacs easier.

Along with the three midline ports, additional ports if required can be placed lateral to the rectus muscle below the linea semicircularis [10]. Caution should be exercised to avoid injury to inferior epigastric vessels during introduction of the lateral trocar [27].

Dissection of preperitoneal space

What are the limits of dissection and the landmarks to be visualized?

\section{Statements}

Level 3 The dissection should extend superiorly up to the subumbilical area, inferiorly to the space of Retzius, inferolaterally to the psoas muscle and Bogros space until spina iliaca anterior superior is reached, and medially beyond the midline.

The landmarks to be visualized are the pubic bone, Cooper's ligament, inferior epigastric vessels, cord structures, the myopectineal orifice boundaries, and the fascia over psoas muscle.

Posteriorly, the peritoneum is reflected to the point of which the vas turns medially.

Level 4 Extensive preperitoneal dissection with complete exposure of the myopectineal orifice of Fruchaud is critical to the success of the laparoscopic inguinal hernia repair.

\section{Recommendations}

Grade B Complete parietalization of the vas deferens and the testicular vessels needs to be performed.

Complete dissection of the whole pelvic floor (anatomical) should be done for flat placement of the mesh to cover the entire myopectineal orifice and prevent its folding.

Before any dissection is performed, the pubic tubercle, the iliopubic tract, and Cooper's ligaments must be clearly identified. The complete space medial to the inferior epigastric vessels (Retzius) must be visible, and then the transversus abdominis muscle lateral to the epigastric vessels to the level of anterior superior iliac spine has to be exposed [28]. Wide exposure of preperitoneal space is the key to a good TEP repair [16].

What are the techniques of management of a peritoneal tear during TEP?

How can peritoneal tears be prevented and treated? Statements

Level 3 The incidence of peritoneal tear is $47 \%$.

Techniques for the closure of a peritoneal opening include pretied suture, loop ligation, endoscopic stapling, and endoscopic suturing.

To decrease the potential for peritoneal tear, the balloon dissection is modified. Less volume of saline is used for inflation; the balloon is sited away from the scar.

Careful dissection in close proximity to the vas deferens and adhesions, in addition to cautious use of traction and counter traction, associated with prudent application of sharp dissection with endo-scissors to divide adhesions can help to prevent peritoneal laceration. 


\section{Recommendations}

Grade D It is recommended that peritoneal tears be closed whenever feasible to prevent adhesions.

Peritoneal tear is the most common reason for conversion and predisposes patients to small-bowel adhesions and internal herniation. The mesh is no longer securely buttressed between the abdominal wall and retroperitoneum by intra-abdominal pressure and becomes susceptible to migration when not stapled. Hence, closure of the defect is preferred [29].

Difficulty in reaching the pubis by the balloon dissector is associated with an increased risk of peritoneal tear [30]. In a randomized multicentric trial, a $24 \%$ incidence of peritoneal tears was found, but loss of pneumopreperitoneum occurred only in $7 \%$, which required switching to another technique [27].

In a study of 107 consecutive TEP repairs [23], it was found that no peritoneal tear was noticed in two patients with previous laparotomy scars and 17 patients with previous hernia repair scars after balloon dissection of preperitoneal space. However, minor peritoneal tears resulted in a few cases during dissection and retraction of the hernial sac. None of the peritoneal defects in these few cases were closed. Shpitz et al. (2004) found no perioperative or postoperative complications related to these tears [31].

In a prospective study of 400 patients [32] with a total of 588 inguinal hernias, tiny peritoneal defects occurred in $13 \%$ of the hernias, which were closed in most cases with a running endoclip suture. Various methods of closure include loop ligation, pretied suture, endoscopic stapling, and endoscopic suturing [29].

How best can injury to the urinary bladder and epigastric vessels be avoided?

Urinary bladder injury (see Chap. 11, Fitzgibbons) Statements

Level 3 In patients who have previously undergone lower
abdominal surgery or suprapubic catheterization,
injury to the bladder is the most common major
complication of TEP $(0.06-0.3 \%)$.
Recognized intraoperatively bladder injuries may be
managed endoscopically.

\section{Recommendations}

Grade C Utmost caution to prevent a bladder injury is necessary in a patient with previous lower abdominal surgery and a high index of suspicion to recognize one intraoperatively and manage if it were to occur.

Injury to the bladder was seen in 8 of 3,868 patients who underwent surgery during a 7.5-year period, the majority of whom had previously undergone suprapubic catheterization $[13,32]$.
Inferior epigastric artery injury Statements

Level 3 Plane should be developed with inferior epigastric vessels anteriorly and the cord structures posteriorly.

In $2.75 \%$, bleeding from epigastric branches, vessels on the pubic bone or testicular vessels can occur.

Level 4 Inferior epigastric vessels were ligated in 3\%, because they blocked the view of the surgeon.

Inferior epigastric vessel injury occurred in $0.4 \%$ of patients during trocar insertion.

\section{Recommendations}

Grade C Dissection should be performed in the plane posterior to the inferior epigastric vessels, because they are prone to injury when they drop down and also obstruct the view of the surgeon.

Correct plane of dissection is important to prevent inferior epigastric vessel injury [7, 27, 32]. Bleeding is usually controlled endoscopically [33].

\section{Dissection of hernia sacs}

\section{Direct sac}

\section{How should a large direct sac be handled?}

\section{Statements}

Level 2B In large direct hernias, inversion and fixation of the extended fascia transversalis to Cooper's ligament may reduce the frequency of occurrence of serohematoma.

Level 3 Direct Hernias are already largely reduced by inflation of the balloon, through the wall of which the whitish enlarged fascia transversalis can be seen overlapping the Cooper's ligament.

Seroma formation seems to be more common after repair of direct hernia with significantly enlarged transversalis fascia.

In an incarcerated hernia, the opening of the defect may be enlarged to allow safe dissection of its contents. A releasing incision is made of the anteromedial aspect of the defect to avoid injury to epigastric or iliac vessels.

\section{Recommendations}

Grade B The direct sac should be inverted and anchored to Cooper's ligament to decrease the risk of seroma and external hematoma formation.

Grade D In incarcerated direct hernias, the opening of the defect may be enlarged or an anteromedial releasing incision may be used.

The direct hernial sac is the first structure to be reduced starting from midline laterally, medial to the inferior epigastric vessels. The fundus was separated from the redundant fascia transversalis, which gives the appearance of a reverse sac and then pulled down [24]. The defect may be enlarged or a releasing incision given when the hernia is incarcerated [34]. A prospective, nonrandomized study demonstrates significantly lower incidence of postoperative seromas in the 
group of patients with direct hernias and transversalis fascia inversion, without increase of postoperative pain despite the use of invasive fixation with tacks to the Cooper's ligament [35]. In some expert reports, fixation with sutures is recommended as a less expensive alternative.

\section{Indirect sac \\ How should a large indirect sac be handled? Statements}

Level 4 Dissection of the indirect hernial sac, for the most part blunt, is performed under exposure of the spermatic cord/ round ligament and all inguino-femoral hernial orifices.

Complete dissection of large indirect sacs may carry the risk of an injury of the cord structures or may disturb blood circulation to the testis.

\section{Recommendations}

\begin{tabular}{ll}
\hline Grade C & $\begin{array}{c}\text { A large indirect sac may be ligated proximally } \\
\text { and divided distally. }\end{array}$
\end{tabular}

In a case of indirect hernia, lateral to the inferior epigastric vessels, the peritoneal sac is dissected away from the cord structures, both medially and laterally until it is separated completely and then dealt with appropriately [24].

At times, a long indirect sac cannot be completely reduced from the deep inguinal ring and is divided, the peritoneal side being ligated with a laparoscopic suture [19, 34] (see Chap. 11 Fitzgibbons).

\section{Femoral hernia}

\section{Should occult femoral hernia be looked for and treated?} Statements

\begin{tabular}{ll}
\hline Level 2C & $\begin{array}{l}\text { Women have a higher risk of recurrence after an open } \\
\text { inguinal hernia repair operation due to a higher } \\
\text { occurrence of overlooked femoral hernia at primary } \\
\text { operation. }\end{array}$ \\
\hline
\end{tabular}

\section{Recommendations}

\begin{tabular}{cc}
\hline Grade D & $\begin{array}{c}\text { A preperitoneal endoscopic approach should } \\
\text { be considered in female hernia repair. }\end{array}$ \\
\hline
\end{tabular}

The high frequency of femoral recurrence after inguinal herniorrhaphy in women argues for the use of endoscopic repair covering both inguinal and femoral orifices simultaneously [1].

\section{Contralateral dissection: how far?}

Should occult contralateral hernias always be looked for?

\section{Statements}

Level 3 The incidence of incipient unsuspected contralateral hernia is $11.2-20 \%$.

Laparoscopic hernia repair (TAPP) has a major advantage of allowing the surgeon to explore the site contralateral to the clinically diagnosed hernia without any additional dissection steps.

In TEP, the contralateral medial space can be explored easily, but the exploration of the deep inguinal ring may be difficult.

\section{Recommendations}

Grade D The systematic exploration of the contralateral side using the TEP technique is controversial.

Further studies are needed.

Hertz and Holcomb performed a laparoscopic transabdominal exploration before performing a TEP inguinal hernia repair and reported an incidence of incipient contralateral hernias as high as $20 \%$.

Laparoscopic TAPP repair allows easy identification of the hernia sacs without any need to dissect the spermatic cord. However, it is accompanied by the risk of visceral adhesions to the mesh and the peritoneal dissection site. TEP eliminates the need to penetrate the abdominal cavity.

Skeletonization of the cord to detect an asymptomatic hernia is not necessary and avoiding excessive dissection limits the potential for injuries to vas deferens and spermatic vessel [28]. Tenting of the peritoneum toward the internal ring and inability to visualize the vas warrants further dissection of the cord.

The advantage of contralateral exploration is that an unsuspected contralateral inguinal hernia can be diagnosed at the time of initial surgery, and if treated, the patient can avoid reoperation, exposure to a second anesthesia, another period of work loss, and containment of costs to the healthcare system. The disadvantages would be the violation of a virgin space, difficulty in the event of a requirement for surgery at a later date, and the additional time and morbidity associated with the procedure. In the light of this observation, another question arises "once dissected, is there a need or advantage in placing a contralateral mesh?"

Should a drain be used after a TEP repair?

Should seromas be aspirated?

\section{Statements}

Level 1A Patients who receive anticoagulant are prone to afterbleed.

The most frequent early complications are hematomas and seromas $(8-22 \%)$

The incidence of hematomas is lower for endoscopic $(4.2-13.1 \%)$ techniques than for open repair $(5.6-16 \%)$.

The risk of seroma formation is higher for endoscopic techniques than for open repairs.

Level 1B The use of Fibrin sealant for mesh fixation during bilateral TEP leads to a significant reduction of analgesic consumption but is associated with an increased incidence of postoperative seroma.

Level 3 Most seromas disappear spontaneously within 6-8 weeks. Infection after aspiration of seromas is described.

Level 5 Perioperative drainage to prevent seromas is contradictory.

\section{Recommendations}

Grade B It is recommended that wound drains be used only when specifically indicated (large blood loss, coagulopathies). Anticoagulants should be stopped before surgery.

Seromas are best not aspirated.

Grade D If indicated, a closed suction drain is kept as per the assessed requirements. 
Incidence of seromas and hematomas are described in various studies $[32,36]$. In a study, the author recommends routine use of drain, because release of carbon dioxide pressure is followed by bleeding from tiny capillaries, resulting in unpredictable amount of blood collecting in the preperitoneal space. Avoidance of postoperative hematomas is important to the achievement of a low mesh infection rate and prevention of potential mesh displacement by the collection fluid. Furthermore, drainage also ensures complete deflation and readaptation of the tissue layer [13].

In a multi-institutional retrospective analysis, it was found that local complications, such as hematoma, seroma, and emphysema, were seen most commonly after TEP repair. Fifty-six local complications were found in 457 TEP repairs compared with a total 95 local complications in 1,514 repairs by various endoscopic techniques; the important local complications are hematoma and seroma [3]. In a study of 400 patients who had undergone TEP repair, one patient who received anticoagulant treatment had to undergo endoscopic revision of an afterbleed [32].

\section{Preparation and introduction of mesh}

\section{Recommendations}

Grade C The mesh should be taken out of its packaging just before introduction under absolutely sterile conditions.

No data allow any relevant recommendations. Under absolutely sterile conditions just before introduction, the mesh is prepared to facilitate its introduction into the preperitoneal space and its placement over the myopectineal orifice. The techniques of Felix [37], Philip [15], and Chowbey et al. [20] are subtle variations in the preparations of the flat polypropylene mesh. Chowbey recommended cutting the mesh to a size of $15 \times 13 \mathrm{~cm}$, rolled superiorinferiorly for approximately two-thirds of its length and fixed with two sutures. This ensures ease of introduction and placement, following which the stitches are cut and the mesh unrolled. Golash [22] rolls the mesh from both the medial and lateral edges. Lal et al. [24] also rolls up the mesh and secures it with two Vicryl ties to introduce it into the preperitoneal space via the $10-\mathrm{mm}$ telescope.

Should one or two meshes be used for bilateral hernias?

\section{Statements}

Level 1B To treat bilateral hernias, implantation of two meshes overlapping by $1-2 \mathrm{~cm}$ in the midline above the pubic symphysis or one large mesh are options.

Level 2B The issue stills remain unresolved as to whether two different meshes of adequate size with overlap in the midline or a single large mesh be used to treat bilateral inguinal hernias.

After implantation of two meshes, the recurrences detected (direct and bilateral) suggest the presence of a weak zone in the midline despite the twomeshes overlapping in the midline.

Level 3 Implantation of one large mesh seems to be technically more difficult than that of two meshes.

\section{Recommendations}

\begin{tabular}{ll}
\hline Grade C & In bilateral hernias, a sufficiently large mesh should be \\
used or two different meshes (e.g., $15 \times 13 \mathrm{~cm}$ on \\
both sides).
\end{tabular}

In a prospective, randomized, controlled trial of 100 patients comparing totally preperitoneal laparoscopic approach and Stoppa procedure (open), the author suggests the use of a large prosthesis rather than two small ones for bilateral hernias to minimize recurrence [38]. Another RCT concurs due to the presence of a weak zone in the midline [39]. A retrospective study [40] could not find a significant difference between the use one large or two small meshes in the totally extraperitoneal repair for bilateral inguinal hernias.

Mesh placement-how much overlap? Is there any scientific basis?

Are there cases for fixation?

\section{Statements}

Level 4/5 Mesh overlapping of less than 2-3 cm may lead to a protrusion of the mesh into the hernia opening.

The larger the hernia opening the more overlapping there should be.

In large direct defect, danger for protrusion of mesh into the opening is increased.

\section{Recommendations}

Grade C The minimum distance between the margin of the prosthesis and that of the hernial opening should be equal to the diameter of the opening in hernias of size $2 \mathrm{~cm}$ or larger.

For smaller lesions $(<1-2 \mathrm{~cm})$, a minimum mesh overlap of $2 \mathrm{~cm}$ is required. For hernias $\geq 4 \mathrm{~cm}$, the prosthesis should be fixed to prevent recurrence.

In direct hernia, medial overlapping should be $>4 \mathrm{~cm}$.

Grade D The mesh should cover without wrinkles all the facial defects in the groin, including Hesselbach's triangle, the indirect ring, the femoral ring, and the obturator ring.

The scientific basis of mesh overlap has been explained by Hollinsky [41]. The required mesh overlap over the hernial opening is calculated based on the distribution of adhesive force and load on the mesh. In a randomized, controlled trial, a medial overlap of mesh by some $4 \mathrm{~cm}$ is advised in direct unilateral hernias to prevent recurrence [38].

How to avoid uprolling of the mesh during desufflation of pneumopreperitoneum?

\section{Statements}

\begin{tabular}{c}
\hline Level 3 Uprolling of mesh is one main cause for recurrence. \\
Insufficient preperitoneal dissection (parietalization) \\
is the main cause for uprolling of mesh.
\end{tabular}




\section{Recommendations}

Grade B Extensive preperitoneal dissection is critical to prevent uprolling of mesh.

Desufflation of retropneumoperitoneum should be done under vision.

Grade D When fibrin sealant is used, it is applied to the Cooper's ligament, the inferior edge, and medial corner of the mesh, which is steadied in position in graspers for a few minutes to ensure firm adhesion before desufflation.

With adequate preperitoneal dissection, the mesh is spread out completely and steadied before desufflation [42].

References (in parentheses graduation of evidence)

1. Simons MP, Aufenacker T, Bay Nielsen M, Bouillot JL, Campanelli G, Conze J, de Lange D, Fortelny R, Heikkinen T, Kingsnorth A, Kukleta J, MoralesConde S, Nordin P, Schumpelick V, Smedberg S, Smietanski M, Weber G, Miserez M(2009) European Hernia Society guidelines on the treatment of inguinal hernia in adult patients. Hernia 13:343-403. (1A)

2. Lau H, Patil NG, Yuen WK, Lee F (2002) Urinary retention following endoscopic totally extraperitoneal inguinal hernioplasty. Surg Endosc 16:15471550. (3)

3. Tetik C, Arregui ME, Dulucq JL, Fitzgibbons RJ, Franklin ME, McKernan JB, Rosin RD, Schultz LS, Toy FK (1994) Complications and recurrences associated with laparoscopic repair of groin hernias. A multi-institutional retrospective analysis. Surg Endosc 8:1316-1323. (3)

4. McCormack K, Scott N, Go PM, Ross S, Grant A (2008) Collaboration the EU Hernia Trialists. Laparoscopic techniques versus open techniques for inguinal hernia repair (review). The Cochrane Collaboration. (1A)

5. Garg P, Menon GR, Rajagopal M, Ismail M (2010) Laparoscopic total extra peritoneal repair of recurrent inguinal hernias. Surg Endosc 24:450-454. (3)

6. Misra MC, Bhowate PD, Bansal VK, Kumar S (2009) Massive scrotal hernias: problems and solutions. J Laparoendosc Adv Surg Tech 19:19-22. (4)

7. Ramshaw B, Shuler FW, Jones HB, Duncan TD, White J, Wilson R, Lucas GW, Mason EM (2001) Laparoscopic inguinal hernia repair. Lessons learned after 1224 consecutive cases. Surg Endosc 15:50-54. (3)

8. Dulucq JL, Wintringer P, Mahajna A (2009) Laparosopic totally extraperitoneal inguinal hernia repair: lessons learned from 3,100 hernia repairs over 15 years. Surg Endosc 23:482-486. (4)

9. Garg P, Rajagopal M, Varghese V, Ismail M (2009) Laparoscopic total extraperitoneal inguinal hernia repair with nonfixation of the mesh for 1.692 hernias. Surg Edosc 23:1241-1245. (3)
10. Ferzli GS, Massad A, Albert P (1992) Extraperitoneal endoscopic inguinal hernia repair. J Laparoendosc Surg 2:281-286. (5)

11. McKernan JB, Laws HL (1993) Laparoscopic repair of inguinal hernias using a totally extraperitoneal prosthetic approach. Surg Endosc 7:26-28. (4)

12. Chowbey P (2004) Total Extraperitoneal repair of groin hernia. In: Chowbey $\mathrm{P}$ (ed) Endoscopic repair of abdominal wall hernias. New Delhi: Byword Viva Publishers Pvt. Ltd., pp 76-93. (4)

13. Tamme C, Scheidbach H, Hampe C, Schneider C, Köckerling F (2003) Totally extraperitoneal endoscopic inguinal hernia repair (TEP). Results of 5203 hernia repairs. Surg Endosc 17:192-195. (4)

14. Crawford DL, Phillips EH (2002) Laparoscopic totally extraperitoneal herniorrhaphy. In: Nyhus LM, Condon R (eds) Hernia, 5th edn. Philadelphia: Lippincott, pp 239-243. (4)

15. Shadduck PP, Schwartz LB, Eubanks S (2002) Laparoscopic inguinal herniorrhaphy. In: Nyhus LM, Condon R (eds) Hernia, 5th edn. Philadelphia: Lippincott. (4)

16. Arregui ME, Young SB (2005) Groin hernia repair by laparoscopic techniques: current status and controversies. World J Surg 29:1052-1057. (4)

17. Misra MC, Kumar S, Bansal VK (2008) Total extraperitoneal (TEP) mesh repair of inguinal hernia in the developing world: comparison of low-cost indigenous balloon dissection versus telescopic dissection: a prospective randomized controlled study. Surg Endosc 22:1947-1958. (1B)

18. Winslow ER, Quasebarth M, Brunt LM (2004) Perioperative outcomes and complications of open vs laparoscopic extraperitoneal inguinal hernia repair in a mature surgical practice. Surg Endosc 18:221-227. (2B)

19. Bringman S, Ek A, Haglind E, Heikkinen T, Kald A, Kylberg F, Ramel S, Wallon C, Anderberg B (2001) Is a dissection balloon beneficial in totally extraperitoneal endoscopic hernioplasty (TEP)? A randomized prospective multicentre study. Surg Endosc 15:266-270. (1B)

20. Chowbey PK et al. (2006) Totally extraperitoneal repair of inguinal hernia: Sir Ganga Ram Hospital technique. J Minim Access Surg 2:160-164. (5)

21. Pekmezci S, Sarideyoglu K (2001) Emergency replacement for damaged balloon dissector for laparoscopic extraperitoneal inguinal hernia repair. Surg Laparosc Endosc Percutan Tech 11:289-290. (5)

22. Golash V (2008) A handy balloon for total extraperitoneal repair of inguinal hernia. J Minim Access Surg 4:54-56. (4)

23. Ullah MZ et al. (2007) Totally extra-peritoneal repair of inguinal hernia by a glove- balloon: technical innovation. Surgeon 5:245-247. (4) 
24. Lal P, Phillips P, Saxena KN, Kajla RK, Chander J, Ramteke VK (2007) Laparoscopic total extraperitoneal (TEP) inguinal hernia repair under epidural anesthesia: a detailed evaluation. Surg Endosc 21:595-601. (4)

25. Lau H, Lee F (2002) A prospective comparative study of needlescopic and conventional endoscopic extraperitoneal inguinal hernioplasty. Surg Endosc 16:1737-1740. (2B)

26. Miserez M, Arregui M, Bisgaard T, Huyghe M, Bruwaene S, Peeters E, Penninckx F (2009) A standardized resident training program in endoscopic surgery in general and in laparoscopic totally extraperitoneal (TEP) inguinal hernia repair in particular. Surg Laparosc Endosc Percutan Tech 19:125-129. (5)

27. Liem MSL, van der Graaf Y et al. (1997) Comparison of conventional anterior surgery and laparoscopic surgery for inguinal hernia repair. $\mathrm{N}$ Engl $\mathrm{J}$ Med 336:141-1547. (1B)

28. Sayad P, Abdo Z, Cacchione R, Ferzli GR (2000) Incidence of incipient contralateral hernia during laparoscopic hernia repair. Surg Endosc 14:543-545. (4)

29. Lau H, Patil NG, Yuen WK. Lee F (2002) Management of peritoneal tear during endoscopic extraperitoneal inguinal hernioplasty. Surg Endosc 6:1474-1477. (2B)

30. Cohen RV, Morrel AC, Mendes JM, Alvarez G, Egarcia ME, Kawahara NT, Margarido NF, Rodrigues AJ (1998) Laparoscopic extraperitoneal repair of inguinal hernia. Surg Laparosc Endosc 8:14-16. (4)

31. Shpitz B (2004) Should peritoneal tears be routinely closed during laparoscopic total extraperitoneal repair of inguinal hernias? A reappraisal. Surg Endosc 18:1771-1773 (4)

32. Tamme C, Garde N, Klingler A, Hampe C, Munder R, Kockerling F (2005) Totally extraperitoneal inguinal hernioplasty with titanium coated light weight polypropylene mesh. Early results. Surg Endosc 19:1125-1129. (4)

33. Chowbey P (2007) TEP. In: Schumpelick V, Fitzgibbons RJ (eds) Recurrent hernia. Prevention and treatment. Berlin: Springer, pp 274-279. (4)

34. Ferzli G, Shapiro K, Chaudhry G, Patel S (2004) Laparoscopic extraperitoneal approach to acutely incarcerated inguinal hernia. Surg Endosc 18:228-231. (4)

35. Reddy VM, Sutton CD, Bloxham L, Garcea G, Ubhi SS, Robertson GS (2007) Laparoscopic repair of direct inguinal hernia: a new technique that reduces that reduces the development of postoperative seroma. Hernia 11:393-396. (2B)

36. Lau H (2005) Fibrin sealant versus mechanical stapling for mesh fixation during endoscopic extraperitoneal inguinal hernioplasty. A randomized prospective trial. Ann Surg 242:670-675. (1B)
37. Felix EL (2002) Mastery of endoscopic and laparoscopic surgery. In: Nyhus LM, Condon R (eds) Hernia, 5th edn. Philadelphia: Lippincott. (4)

38. Champault GG, Risk N, Catheline JM, Turner R, Boutelier $P$ (1997) Inguinal hernia repair: totally preperitoneal laparoscopic approach versus Stoppa operation: randomized trial of 100 cases. Surg Laparosc Endosc 7:445-450. (1B)

39. Moreno-Egea A et al. (2004) Randomized clinical trial of fixation vs nonfixation mesh in total extraperitoneal inguinal hernioplasty. Arch Surg 139:1376-1379. (1B)

40. Halm JA, Heisterkamp J, Boelhouwer RU, den Hoed PT, Weidema WF (2005) Totally extraperitoneal repair for bilateral inguinal hernia. Surg Endosc 19:1373-1376. (3)

41. Hollinsky C, Hollinsky KH (1999) Static calculations for mesh fixation by intra-abdominal pressure in laparoscopic extraperitoneal herniorrhaphy. Surg Laparosc Endosc Percutan Tech 9:106-109. (5)

42. Scheuerlein H, Schiller A, Schneider C, Scheidbach H, Tamme C, Köckerling F (2003) Totally extraperitoneal repair of recurrent inguinal hernia. Surg Endosc 17:1072-1076. (4)

\section{Chapter 4: TEP versus TAPP: which is better for the patient?}

Misra Mahesh Chandra, Kumar Subodh, Bansal Virinder Kumar, Krishna Asuri

Department of Surgical Disciplines, All India institute of Medical Sciences, New Delhi-29, India

Comparison of the two standardized techniques of laparoscopic inguinal hernia repair (LIHR): What is better for the patient-Transabdominal Preperitoneal (TAPP) or Totally Extraperitoneal (TEP) repair?

Search terms: "Inguinal hernia"; "laparoscopy"; "TAPP"; "TEP"

Uncomplicated inguinal hernia Statements

\begin{tabular}{|c|c|}
\hline Level $2 \mathrm{~A}$ & $\begin{array}{l}\text { Potentially serious adverse events are rare after both } \\
\text { TAPP and TEP. }\end{array}$ \\
\hline Level 3 & $\begin{array}{l}\text { Regarding overall complication rate, there is no } \\
\text { obvious difference between TAPP and TEP. } \\
\text { TAPP and TEP show a noticeable "learning curve." } \\
\text { TAPP has a shorter operation time in inexperienced } \\
\text { and experienced surgeons. }\end{array}$ \\
\hline Level 4 & TEP is more suitable for regional anesthesia. \\
\hline Level 5 & $\begin{array}{l}\text { Unsuspected hernias on the contralateral side are } \\
\text { easier to detect with TAPP. }\end{array}$ \\
\hline
\end{tabular}




\section{Recommendations}

\section{Grade B Both techniques are acceptable treatment options for inguinal hernia repair, but there is insufficient data to allow conclusions to be mde about relative effectiveness of TAPP compared with TEP. \\ Grade D In selected patients having a contraindication for general anesthesia, TEP in regional anesthesia can be done.}

\section{Introduction}

Two revolutions in the inguinal hernia surgery have occurred during the past two decades. The first was the introduction of tension-free open mesh repair (OMR) by Lichtenstein et al. [1] in 1989, which significantly reduced the recurrence rates. The second revolution was the application of laparoscopic surgery in the treatment of inguinal hernia during the early 1990s, which led to decrease in postoperative pain and faster recovery along with low recurrence rates [2]. Ger et al. [3] reported first laparoscopic inguinal hernia repair (LIHR). Schultz et al. [4] were the first to report the use of prosthetic material during laparoscopic inguinal hernia repair.

\section{Discussion}

There is only one RCT done by Schrenk et al. [5] who compared TAPP and TEP inguinal hernia repairs. The authors found less early postoperative pain after TAPP $(p<0.02)$ and a shorter hospital stay than after TEP $(p=0.03)$, but the number of patients randomized to the two techniques is very small (EBM IIb). The Cochrane database review 2005 [6] concluded that there are insufficient data to draw any significant conclusions regarding what is better TAPP or TEP.

\section{Anesthesia consideration}

LIHR requires general anesthesia and thus cannot be considered if the patient is unfit for this type of anesthesia. Few reports expressed their concern that general anesthesia is too much a procedure for uncomplicated unilateral inguinal hernia in a young patient and advocated OMR under local anesthesia [7, 8]. LIHR should be offered to patients with bilateral and recurrent hernias. We feel that to pass on the advantages of LIHR to patients with bilateral and recurrent hernias, one should be doing LIHR even in uncomplicated unilateral inguinal hernia routinely to overcome the steep learning curve. Sumpf et al. [8] reported another issue related to $\mathrm{CO}_{2}$ absorption during LIHR which can influence anesthetic management and perioperative morbidity. They observed that TEP group required more minute ventilation (range 9-22.6) than TAPP group (range 7.7-11.5) to maintain normocapnia and concluded that more $\mathrm{CO}_{2}$ absorption during TEP repair puts the patient with chronic lung disease at risk who might be unable to eliminate excess $\mathrm{CO}_{2}$ [8]. There are many reports published with variable experiences of TEP repairs performed under regional $(1,724$ repairs under spinal [9-12] and 82 under epidural $[13,14]$ ) anesthesia. All of the studies concluded that laparoscopic TEP repair under spinal/epidural anesthesia appears to be safe, technically feasible, and an acceptable alternative in patients who are at high risk or unfit for general anesthesia, but the same is not possible for TAPP (EBM IV and V).

Results of comparative studies and case series in primary, bilateral/recurrent/incarcerated inguinal hernia: laparoscopic repair (EBM III, IV, V)

Comparative studies and large case series (Table 1) show an overall very low rate of potentially serious adverse events independent of the technique used. Regarding vascular injuries, there is a slight advantage in favor of TAPP series [TAPP 0.25\% (35/13,475): TEP 0.42\% (47/11,160)]. Conversion rates are lower in TAPP studies. On the other hand, occurrence of visceral injuries, deep mesh infection, and port site hernias rates are in favor of TEP. Most vascular complications were injuries to inferior epigastric vessels and more often in TEP series. Most of the visceral complications were in the form of small bowel and urinary bladder injuries and were slightly more after TAPP repair (Table 2).

We compared overall complication and recurrence rates after TAPP and TEP repairs during the first decade [1990-1998; $N=8,761$ (TAPP), $N=4,849$ (TEP)] after the introduction of LIHR and during the subsequent second decade (1999-2008; $N=17,695$ (TAPP), $N=13,562$ (TEP); Tables $3,4,5,6)$. TAPP $(N=26,456)$ repair continued to be the favorite of most surgeons during both periods compared with TEP $(N=18,411)$. Overall complication rates significantly decreased during the second decade after both TAPP [first decade: mean 6.3 (range 1-22); second decade: mean 5.2 (range 2.6-11.7)] and TEP repairs [first decade: mean 7.6 (range 0-14); second decade: mean 5.4 (range 0.64-16.6)], indicating that surgeons gained more experience with the LIHR.

Overall recurrence rates also improved following both TAPP [first decade: mean 1.2 (range 0-5); second decade: mean 0.77 (range 0.4-2.84)] and TEP repairs [first decade: mean 0.66 (range 0-3.4); second decade: mean 0.54 (range 0.1-1.92)] and were comparable. Bittner et al. [25] have shown similar results in a large series of 8,050 patients after TAPP repair. Dulucq et al. [29] showed acceptable complication and recurrence rates after TEP repair in 3,100 patients. During TAPP repair, there is an advantage of diagnosing and repairing unexpected contralateral hernias in patients with unilateral hernias, which has been reported to occur in $25-50 \%$ of patients $[47,48]$.

The results of our systematic review are to be discussed with caution due to relevant inconsistencies of most of the studies published. 


\section{Learning curve (EBM IV)}

McCormack et al. [49] showed, in an analysis regarding learning of TAPP and TEP for inexperienced surgeons $(<20$ repairs), an operating time of $70 \mathrm{~min}$ for TAPP but $95 \mathrm{~min}$ for TEP, and for experienced surgeons (30-100 repairs), 40 min for TAPP and 55 min for TEP respectively, thus indicating that TAPP might be easier to perform, although there is no level 1 evidence to support this belief.

\section{Cost}

One of main issues in LIHR is to justify its cost-effectiveness. Greenberg et al. [50] concluded after a systemic review of laparoscopic and open repair of inguinal hernia that a shorter recovery time and shorter off work period after laparoscopic hernia repair could compensate for the increased hospital expenditures. Kapiris et al. [24] reported that the operation expenses can be reduced by eliminating the need for a fixation device. They advocated that fixation of mesh is not required in TAPP repair and advocated suturing of peritoneal flaps with absorbable sutures. They also concluded that hospital cost can be further reduced by doing laparoscopic hernia repair as day-care procedure. Beattie et al. [51] also reported that fixation of mesh is not required in TEP repair and not associated with increased risk of hernia recurrence. Farinas et al. [52] suggested that cost can be significantly reduced by performing TEP repair without balloon dissection using reusable cannulas and other instruments. Misra et al. [53] advocated the use of low-cost indigenous balloon to reduce the cost of TEP repair. In the recently completed RCT (unpublished; clinical trial identifier NCT 00687375), we did not fix the mesh

Table 1 Results of potentially serious adverse events from non-randomized studies of TAPP and TEP

\begin{tabular}{|c|c|c|c|c|c|c|c|c|c|c|}
\hline \multirow{2}{*}{$\begin{array}{l}\text { Study ID } \\
\text { Comparative } \\
\text { studies }\end{array}$} & \multicolumn{2}{|c|}{ Vascular injury } & \multicolumn{2}{|c|}{ Visceral injury } & \multicolumn{2}{|c|}{ Deep/mesh infection } & \multicolumn{2}{|c|}{ Port site hernia } & \multicolumn{2}{|l|}{ Conversion } \\
\hline & $\begin{array}{l}\text { TAPP \% } \\
(\mathrm{n} / \mathrm{N})\end{array}$ & $\begin{array}{l}\text { TEP \% } \\
(\mathrm{n} / \mathrm{N})\end{array}$ & $\begin{array}{l}\text { TAPP } \% \\
(\mathrm{n} / \mathrm{N})\end{array}$ & $\begin{array}{l}\text { TEP \% } \\
(\mathrm{n} / \mathrm{N})\end{array}$ & $\begin{array}{l}\text { TAPP \% } \\
(\mathrm{n} / \mathrm{N})\end{array}$ & $\begin{array}{l}\text { TEP \% } \\
(\mathrm{n} / \mathrm{N})\end{array}$ & $\begin{array}{l}\text { TAPP } \% \\
(\mathrm{n} / \mathrm{N})\end{array}$ & $\begin{array}{l}\text { TEP \% } \\
(\mathrm{n} / \mathrm{N})\end{array}$ & $\begin{array}{l}\text { TAPP \% } \\
(\mathrm{n} / \mathrm{N})\end{array}$ & $\begin{array}{l}\text { TEP \% } \\
(\mathrm{n} / \mathrm{N})\end{array}$ \\
\hline $\begin{array}{l}\text { Felix et al. (1995) } \\
\text { [15] }\end{array}$ & ${ }^{0}(0 / 733)$ & ${ }^{0}(0 / 382)$ & $\begin{array}{l}0.4 \\
(3 / 733)\end{array}$ & $\begin{array}{l}0_{(0 / 382)} \\
\end{array}$ & $0_{(0 / 733)}$ & ${ }^{0}(0 / 382)$ & $\begin{array}{l}0.8 \\
(6 / 733)\end{array}$ & ${ }^{0}(0 / 382)$ & $\begin{array}{l}0_{(0 / 733)} \\
\end{array}$ & $\begin{array}{l}1.8 \\
(7 / 382)\end{array}$ \\
\hline Khoury (1995) [16] & $\begin{array}{l}0 \\
(0 / 60)\end{array}$ & 3 & $\begin{array}{l}0 \\
(0 / 60)\end{array}$ & $\begin{array}{l}0 \\
(0 / 60)\end{array}$ & $\begin{array}{l}0 \\
(0 / 60)\end{array}$ & ${ }^{0}(0 / 60)$ & $\begin{array}{l}1.7 \\
(1 / 60)\end{array}$ & $\begin{array}{l}0 \\
(0 / 60)\end{array}$ & $\begin{array}{l}0 \\
\quad(0 / 60)\end{array}$ & $\begin{array}{l}0 \\
(0 / 60)\end{array}$ \\
\hline $\begin{array}{l}\text { Cohen et al. (1998) } \\
\text { [17] }\end{array}$ & NR & NR & $\begin{array}{l}0.9 \\
(1 / 108)\end{array}$ & $\begin{array}{l}0 \\
(0 / 100)\end{array}$ & NR & NR & $\begin{array}{l}3.7 \\
(4 / 108)\end{array}$ & $\begin{array}{l}0 \\
(0 / 100)\end{array}$ & ${ }^{0}(0 / 108)$ & $4_{(4 / 100)}$ \\
\hline $\begin{array}{l}\text { Van Hee et al. } \\
\text { (1998) [18] }\end{array}$ & ${ }^{0}(0 / 33)$ & $\begin{array}{l}0_{(0 / 58)} \\
\end{array}$ & ${ }^{0}(0 / 33)$ & ${ }^{0}(0 / 58)$ & ${ }^{0}(0 / 33)$ & ${ }^{0}(0 / 58)$ & ${ }^{0}(0 / 33)$ & ${ }^{0}(0 / 58)$ & ${ }^{5}(2 / 33)$ & ${ }^{7}(4 / 58)$ \\
\hline $\begin{array}{l}\text { Bobrzynski et al. } \\
\text { (2001) [19] }\end{array}$ & $\begin{array}{l}0.52 \% \\
(3 / 809)\end{array}$ & $\begin{array}{l}0.32 \% \\
\quad(1 / 368)\end{array}$ & NR & NR & NR & NR & NR & NR & NR & NR \\
\hline $\begin{array}{l}\text { Lepere et al. } \\
\text { (2000) [20] }\end{array}$ & $\begin{array}{l}0 \\
(0 / 1290)\end{array}$ & ${ }^{0}(0 / 682)$ & 0 & NR & & NR & & NR & NR & NR \\
\hline $\begin{array}{l}\text { Weiser and Klinge } \\
\text { (2000) [21] }\end{array}$ & NR & NR & $\begin{array}{l}0 \\
(0 / 1216)\end{array}$ & $\begin{array}{l}0.06 \\
\quad(1 / 1547)\end{array}$ & $\begin{array}{l}0.2 \\
\quad(2 / 1216)\end{array}$ & $\begin{array}{l}0 \\
\quad(0 / \\
1547)\end{array}$ & $\begin{array}{l}0.3 \\
(4 / 1216)\end{array}$ & $\begin{array}{l}0.1 \\
(2 / \\
1547)\end{array}$ & NR & NR \\
\hline $\begin{array}{l}\text { Ramshaw et al. }{ }^{\text {a }} \\
\text { (2001) [22] }\end{array}$ & NR & NR & $1_{(3 / 300)}$ & $1_{(3 / 300)}$ & NR & NR & NR & NR & NR & NR \\
\hline \multicolumn{11}{|l|}{ Case series } \\
\hline $\begin{array}{l}\text { Schultz et al. } \\
\text { (2001) [23] }\end{array}$ & $\begin{array}{l}0.28 \\
\quad(7 / 2500)\end{array}$ & NA & $\begin{array}{l}0.16 \\
\quad(4 / 2500)\end{array}$ & NA & $\begin{array}{l}0 \\
(0 / 2500)\end{array}$ & NA & $\begin{array}{l}0.24 \\
\quad(6 / 2500)\end{array}$ & NA & $\begin{array}{l}0.24 \\
\quad(6 / 2500)\end{array}$ & NA \\
\hline $\begin{array}{l}\text { Kapiris et al. } \\
\text { (2001) [24] }\end{array}$ & NR & NA & $\begin{array}{l}0.19 \\
\quad(7 / 3530)\end{array}$ & NA & $\begin{array}{l}0.11 \\
\quad(4 / 3530)\end{array}$ & NA & NR & NA & $\begin{array}{l}0.19 \\
\quad(7 / 3530)\end{array}$ & NA \\
\hline $\begin{array}{l}\text { Bittner et al. } \\
\text { (2002) [25] }\end{array}$ & $\begin{array}{l}0.3 \\
(25 / \\
8050)\end{array}$ & NA & $\begin{array}{l}0.2 \\
\quad(17 / \\
8050)\end{array}$ & NA & $\begin{array}{l}0.1 \\
\quad(8 / 8050)\end{array}$ & NA & $\begin{array}{l}0.7 \\
\quad(57 / \\
8050)\end{array}$ & NA & $\begin{array}{l}0.12 \\
(10 / \\
8050)\end{array}$ & NA \\
\hline $\begin{array}{l}\text { Chiofalo et al. } \\
\text { (2001) [26] }\end{array}$ & NA & NA & NA & NR & NA & NR & NA & NR & NA & $\begin{array}{l}0.5 \\
(2 / 431)\end{array}$ \\
\hline $\begin{array}{l}\text { Vanclooster et al. } \\
\text { (2001) [27] }\end{array}$ & NA & $\begin{array}{l}0.3 \% \\
\quad(4 / 1259)\end{array}$ & NA & $\begin{array}{l}0.08 \\
\quad(1 / 1259)\end{array}$ & NA & NR & NA & NR & NA & $\begin{array}{l}0.4 \\
\quad(5 / 1259)\end{array}$ \\
\hline $\begin{array}{l}\text { Tammeet al. } \\
\text { (2003) [28] }\end{array}$ & NA & $\begin{array}{l}0.56 \\
(29 / \\
5203)\end{array}$ & NA & $\begin{array}{l}0.15 \\
\quad(8 / 5203)\end{array}$ & NA & $\begin{array}{l}0.02 \\
(1 / \\
5203)\end{array}$ & NA & $\begin{array}{l}0 \\
(0 / \\
5203)\end{array}$ & NA & $\begin{array}{l}0.23 \\
(12 / \\
5203)\end{array}$ \\
\hline $\begin{array}{l}\text { Dulucq et al. } \\
\text { (2008) [29] }\end{array}$ & NA & $\begin{array}{l}0.47 \\
\quad(11 / \\
3100)\end{array}$ & NA & $\begin{array}{l}0.04 \\
\quad(1 / 3100)\end{array}$ & NA & $\begin{array}{l}0.04 \\
\quad(1 / \\
3100)\end{array}$ & NA & $\begin{array}{l}0.1 \\
\quad(3 / \\
3100)\end{array}$ & NA & $\begin{array}{l}1.2 \\
(36 / \\
3100)\end{array}$ \\
\hline Total & $\begin{array}{l}0.25 \\
\quad(35 / \\
13475)\end{array}$ & $\begin{array}{l}0.42 \\
\quad(47 / \\
11160)\end{array}$ & $\begin{array}{l}0.21 \\
(35 / \\
16604)\end{array}$ & $\begin{array}{l}0.11 \\
\quad(14 / \\
12009)\end{array}$ & $\begin{array}{l}0.08 \\
\quad(14 / \\
16122)\end{array}$ & $\begin{array}{l}0.02 \\
(2 / \\
10350)\end{array}$ & $\begin{array}{l}0.6 \\
(78 / \\
12700)\end{array}$ & $\begin{array}{l}0.05 \\
(5 / \\
10450)\end{array}$ & $\begin{array}{l}0.16 \\
(25 / \\
15014)\end{array}$ & $\begin{array}{l}0.66 \\
(70 / \\
10593)\end{array}$ \\
\hline
\end{tabular}

$N A$ not available, $N R$ not reported

a Only the first 300 repairs of each technique are included for comparison 
Table 2 Details of visceral and vascular injuries from non-randomized studies of TAPP and TEP

\begin{tabular}{|c|c|c|c|c|c|c|c|c|}
\hline \multirow[t]{3}{*}{ Study ID } & \multicolumn{4}{|c|}{ TAPP repair } & \multicolumn{4}{|l|}{ TEP repair } \\
\hline & \multicolumn{2}{|c|}{ Visceral injury $(n)$} & \multicolumn{2}{|l|}{ Vascular Injury $(n)$} & \multicolumn{2}{|c|}{ Visceral injury $(n)$} & \multicolumn{2}{|l|}{ Vascular Injury $(n)$} \\
\hline & $\begin{array}{l}\text { Bowel } \\
\text { injury }\end{array}$ & $\begin{array}{l}\text { Bladder } \\
\text { injury }\end{array}$ & $\begin{array}{l}\text { Inferior epigastric } \\
\text { vessels }\end{array}$ & $\begin{array}{l}\text { Iliac } \\
\text { vessels }\end{array}$ & $\begin{array}{l}\text { Bowel } \\
\text { injury }\end{array}$ & $\begin{array}{l}\text { Bladder } \\
\text { injury }\end{array}$ & $\begin{array}{l}\text { Inferior epigastric } \\
\text { vessels (IEV) }\end{array}$ & $\begin{array}{l}\text { Iliac } \\
\text { vessels }\end{array}$ \\
\hline Felix et al. [15] & $3 / 733$ & - & - & - & - & - & - & - \\
\hline Cohen et al. [17] & - & $1 / 108$ & - & - & - & - & - & - \\
\hline $\begin{array}{r}\text { Bobrzynski } \\
\text { et al. [19] }\end{array}$ & - & - & $3 / 809$ & - & - & - & - & 1 \\
\hline $\begin{array}{l}\text { Bittner et al. } \\
{[25]}\end{array}$ & $9 / 8050$ & $8 / 8050$ & $\begin{array}{l}14 \text { (trocar site) } \\
5 \text { (inguinal) } \\
6 \text { (others) }\end{array}$ & - & - & - & - & - \\
\hline $\begin{array}{l}\text { Schultz et al. } \\
\text { [23] }\end{array}$ & $1 / 2500$ & $3 / 2500$ & $\begin{array}{l}5 / 2500 \\
1 \text { (mesenteric) } \\
1 \text { (corona mort.) }\end{array}$ & - & - & - & - & - \\
\hline $\begin{array}{l}\text { Kapiris et al. } \\
{[24]}\end{array}$ & - & $7 / 3530$ & - & - & - & - & - & - \\
\hline $\begin{array}{l}\text { Ramshaw et al. } \\
\text { [22] }\end{array}$ & $2 / 300$ & $1 / 300$ & - & - & $2 / 300$ & $1 / 300$ & - & - \\
\hline Khourey [16] & - & - & - & - & - & - & $2 / 60$ & - \\
\hline $\begin{array}{r}\text { Vanclooster } \\
\text { et al. [27] }\end{array}$ & - & - & - & - & $\begin{array}{l}1 / 1259 \text { (large } \\
\text { bowel) }\end{array}$ & - & $4 / 1259$ & - \\
\hline $\begin{array}{l}\text { Tamme et al. } \\
{[28]}\end{array}$ & - & - & - & & - & $8 / 5203$ & 29/5203 (11 IEV) & - \\
\hline $\begin{array}{l}\text { Dulucq et al. } \\
\text { [29] }\end{array}$ & - & - & - & - & $1 / 3100$ & - & $11 / 3100$ & - \\
\hline
\end{tabular}

Table 3 Complications and recurrence rates after TAPP hernia repair in various series from 1990 to 1998

\begin{tabular}{llll}
\hline & No. of patients & Complications rate N (\%) & Recurrence rate N (\%) \\
\hline Bittner et al. [30] & 3400 & $241(7.1)$ & $31(0.9)$ \\
Phillips et al. [31] & 1944 & $120(6.2)$ & $19(1)$ \\
Tetik et al. [32] & 553 & NR & $4(0.7)$ \\
Fitzgibbon et al. [33] & 562 & NR & $28(5)$ \\
Felix et al. [15] & 733 & $9(1.2)$ & $2(0.2)$ \\
Ramshaw et al. [34] & 300 & $13(4.3)$ & $6(2)$ \\
Fielding [35] & 386 & $4(1)$ & $2(0.5)$ \\
Kald et al. [36] & 339 & $42(11)$ & $7(2)$ \\
Stoker et al. [37] & 75 & $6(8)$ & 0 \\
Payne et al. [38] & 48 & $6(12)$ & 0 \\
Maddern et al. [39] & 42 & $7(17)$ & 0 \\
Lawrence et al. [40] & 58 & $7(12)$ & $1(1.7)$ \\
Wright et al. [41] & 67 & $470(6.36)$ & NR \\
Total & 8507 & & $100(1.33)$ \\
\hline
\end{tabular}

in both the TAPP and the TEP repair. There was no difference in the cost of procedure. No recurrence was noted at mean follow-up of 17 months.

\section{Conclusions}

There are two standardized techniques for laparoscopic groin hernia repair (LIHR): (1) Trans-Abdominal Pre-
Peritoneal (TAPP) and (2) Totally Extra-Peritoneal (TEP) repair. There is a paucity of published data with level 1 evidence comparing TAPP versus TEP. There are advantages and disadvantages of both TAPP and TEP procedures. There is no statistically significant difference regarding postoperative complications, particularly recur- 
Table 4 Complications and recurrence rates after TEP hernia repair in various series from 1990 to 1998

\begin{tabular}{llcc}
\hline Study & No. of patients & Complications rate $N(\%)$ & Recurrent rate $N(\%)$ \\
\hline Smith et al. [42] & 100 & $14(14)$ & $2(2)$ \\
Vanclooster et al. [27] & 158 & $23(6.3)$ & 0 \\
Phillips et al. [31] & 253 & $36(14.2)$ & $2(0.3)$ \\
Felix et al. [15] & 382 & $40(10.5)$ & $1(0.2)$ \\
Heithold et al. [43] & 346 & $7(2)$ & $1(0.4)$ \\
McKernan and Laws [44] & 633 & $73(11.5)$ & $4(0.6)$ \\
Phillips et al. [45] & 578 & $55(9.5)$ & 0 \\
Tetik et al. [32] & 457 & - & $2(0.4)$ \\
Fitzgibbon et al. [33] & 87 & - & 0 \\
Ramshaw et al. [34] & 600 & $5(0.8)$ & $2(0.3)$ \\
Fielding [35] & 218 & 0 & $2(0.9)$ \\
Kald et al. [36] & 87 & $7(8)$ & 0 \\
Liem et al. [46] & 487 & $15(3)$ & $16(3.4)$ \\
Total & 4386 & $275(7.6)$ & $32(0.60)$ \\
\hline
\end{tabular}

Table 5 Complications and recurrence rates after TAPP hernia repair in various series from 1999 to 2008

\begin{tabular}{llcc}
\hline Study & No. of patients & Complications rate $N(\%)$ & Recurrence rate $N(\%)$ \\
\hline Lepere et al. [20] & 1290 & $129(10)$ & $13(<1)$ \\
Weiser and Klinge [21] & 1216 & $83(6.8)$ & $15(1.2)$ \\
Ramshaw et al. [22] & 300 & $9(3)$ & $6(2)$ \\
Bobrzynski et al. [19] & 809 & $95(11.7)$ & $23(2.84)$ \\
Schultz et al. [23] & 2500 & $89(3.56)$ & $26(1.04)$ \\
Kapiris et al. [24] & 3530 & $300(8.5)$ & $22(0.62)$ \\
Bittner et al. [25] & 8050 & $209(2.6)$ & $32(0.4)$ \\
Total & 17695 & $914(5.2)$ & $137(0.77)$ \\
\hline
\end{tabular}

Table 6 Complications and recurrence rates after TEP hernia repair in various series from 1999 to 2008

\begin{tabular}{llcc}
\hline Study & $N$ & Complications rate N (\%) & Recurrence rate $N(\%)$ \\
\hline Lepere et al. [20] & 682 & $68(10)$ & $7(<1)$ \\
Weiser and Klinge [21] & 1547 & $135(8.7)$ & $8(0.5)$ \\
Ramshaw et al. [22] & 924 & $6(0.64)$ & $2(0.21)$ \\
Bobrzynski et al. [19] & 416 & $69(16.6)$ & $8(1.92)$ \\
Tamme et al. [28] & 5203 & $164(3.15)$ & $31(0.6)$ \\
Chiofalo et al. [26] & 431 & $25(5.7)$ & $2(0.5)$ \\
Vanclooster et al. [27] & 1259 & $106(8.4)$ & $1(0.1)$ \\
Dulucq et al. [29] & 3100 & $167(5.4)$ & $14(0.46)$ \\
Total & 13562 & $740(5.4)$ & $73(0.54)$ \\
\hline
\end{tabular}

rence rates and chronic groin pain. It is generally believed that TAPP is easier to teach and learn, although there is no level 1 evidence in the literature to support this belief. We need to generate more data comparing TAPP and TEP by conducting randomized, controlled trials. A laparoscopic hernia surgeon must be familiar with open techniques, because there are instances where the procedure needs conversion. A TEP procedure can be easily converted to TAPP rather than to open procedure.

References (in parentheses graduation of evidence)

1. Lichtenstein IL, Shulman AG, Amid PK, Montllor MM (1989) The tension-free hernioplasty. Am J Surg 157:188-193. (4) 
2. Dulucq JL (1991) Traitement des hernies de l'aine par la mise en place d'un patch prothetique par laparoscopie. Voi totalement extraperitoneale. Cah Chir 79:15-16. (5)

3. Ger R, Monroe K, Duvivier R, Mishrick A (1990) Management of indirect inguinal hernias by laparoscopic closure of the neck of the sac. Am J Surg 159:370-373. (5)

4. Schultz LS, Graber JN, Pietrafitta J, Hickok DF (1990) Early results with laparoscopic inguinal herniorrhaphy are promising. Clin Laser Mon 8:103-105. (5)

5. Schrenk P, Woisetschlager R, Rieger R, Wayand W (1996) Prospective randomized trial comparing postoperative pain and return to physical activity after transabdominal preperitoneal, total preperitoneal or Shouldice technique for inguinal hernia repair. Br J Surg 83:1563-1566. (2B)

6. Wake BL, McCormack K, Fraser C, Vale L, Perez J, Grant AM (2005) Transabdominal pre-peritoneal (TAPP) vs totally extraperitoneal (TEP) laparoscopic techniques for inguinal hernia repair. Cochrane Database Syst Rev 1:CD004703. (1A and 4)

7. Scheyer M, Arnold S, Zimmerman G (2001) Minimally invasive operation techniques for inguinal hernia; spectrum of indications in Austria. Hernia 5:73-79. (5)

8. Sumpf E, Crozier TA, Ahrens D, Bräuer A, Neufang $\mathrm{T}$, Braun U (2000) Carbon dioxide absorption during extraperitoneal and transperitoneal endoscopic hernioplasty. Anesth Analg 91:589-595. (2B)

9. Ismail M, Garg P (2009) Laparoscopic inguinal total extraperitoneal hernia repair under spinal anesthesia without mesh fixation in 1,220 hernia repairs. Hernia 13:115-119. (4)

10. Sinha R, Gurwara AK, Gupta SC (2008) Laparoscopic total extraperitoneal inguinal hernia repair under spinal anesthesia: a study of 480 patients. J Laparoendosc Adv Surg Tech A 18:673-677. (4)

11. Molinelli BM, Tagliavia A, Bernstein D (2006) Total extraperitoneal preperitoneal laparoscopic hernia repair using spinal anesthesia. JSLS 10:341-344. (5)

12. Lau H, Wong C, Chu K, Patil NG (2005) Endoscopic totally extraperitoneal inguinal hernioplasty under spinal anesthesia. J Laparoendosc Adv Surg Tech A 15:121-124. (5)

13. Lal P, Philips P, Saxena KN, Kajla RK, Chander J, Ramteke VK (2007) Laparoscopic total extraperitoneal (TEP) inguinal hernia repair under epidural anesthesia: a detailed evaluation. Surg Endosc 2:595-601. (5)

14. Chowbey PK, Sood J, Vashistha A, Sharma A, Khullar R, Soni V, Baijal M (2003) Extraperitoneal endoscopic groin hernia repair under epidural anesthesia. Surg Laparosc Endosc Percutan Tech 13:185-190. (5)

15. Felix EL, Michas CA, Gonzalez MH Jr (1995) Laparoscopic hernioplasty. TAPP vs. TEP. Surg Endosc 9:984-989. (3)

16. Khoury N (1995) A comparative study of laparoscopic extraperitoneal and transabdominal preperitoneal herniorrhaphy. J Laparoendosc Surg 5:349-355. (3)

17. Cohen RV, Alvarez G, Roll S et al. (1998) Transabdominal or totally extraperitoneal laparoscopic hernia repair? Surg Laparosc Endosc 8:264-268. (3)

18. Van Hee R, Goverde P, Hendrick L et al. (1998) Laparoscopic transperitoneal versus extraperitoneal inguinal hernia repair: a prospective clinical trial. Acta Chir Belg 98:132-135. (3)

19. Bobrzynski A, Budzynski A, Biesiada Z, Kowalczyk M, Lubikowski J, Sienko J (2001) Experience-the key factor in successful laparoscopic total extraperitoneal and transabdominal preperitoneal hernia repair. Hernia 5:80-83. (3)

20. Lepere M, Benchetrit S, Debaert M et al. (2000) A multicentric comparison of transabdominal versus totally extraperitoneal laparoscopic hernia repair using PARIETEX meshes. J Soc Laparoendosc Surg 4:147-153. (3)

21. Weiser HF, Klinge B (2000) Endoscopic hernia repair- experiences and characteristic features. Viszeralchirurgie 35:316-320. (3)

22. Ramshaw B, Schular FW, Jones HB et al. (2001) Laparoscopic inguinal hernia repair: lessons learned after 1224 consecutive cases. Surg Endosc 15:50-54. (3)

23. Schultz C, Baca I, Götzen V (2001) Laparoscopic inguinal hernia repair. Surg Endosc. 15:582-584. (3)

24. Kapiris SA, Brough WA, Royston CM et al. (2001) Laparoscopic transabdominal preperitoneal (TAPP) hernia repair. A 7-year two-center experience in 3017patients. Surg Endosc 15:972-975. (3)

25. Bittner R, Schmedt CG, Schwarz J, Kraft K, Leibl BJ (2002) Laparoscopic transperitoneal procedure for routine repair of groin hernia. Br J Surg 89:10621066. (3)

26. Chiofalo R, Holzinger F, Klaiber C et al. (2001) Total endoscopic pre-peritoneal mesh implant in primary and recurrent inguinal hernia. Chirurg 72:1485-1491. (3)

27. Vanclooster P, Smet B, de Gheldere C et al. (2001) Laparoscopic inguinal hernia repair: review of 6 years experience. Acta Chir Belg 101:135-138. (3)

28. Tamme C, Scheidbach H, Hampe C et al. (2003) Totally extraperitoneal endoscopic inguinal hernia repair (TEP). Surg Endosc 17:190-195. (3)

29. Dulucq JL, Wintringer P, Mahajna A (2009) Laparoscopic totally extraperitoneal inguinal hernia repair: 
lessons learned from 3,100 hernia repairs over 15 years. Surg Endosc 23:482-486. (3)

30. Bittner R, Kraft K, Schmedt CG, Schwarz J, Leibl BJ (1998) Risks and benefits of laparoscopic hernioplasty (TAPP). 5 years experience with 3400 hernia repairs. Chirurg 69:854-858. (3)

31. Phillips EH, Carroll BJ, Fallas MJ (1993) Laparoscopic preperitoneal inguinal hernia repair without peritoneal incision. Surg Endosc 7:159-162. (3)

32. Tetik C, Arregui Mr, Dulucq JL et al. (1994) Complications and recurrences associated with laparoscopic repair of groin hernias: a multi-institutional retrospective analysis. Surg Endosc 8:1316-1323. (4)

33. Fitzgibbons RJ, Camps J, Cornet DA et al. (1995) Laproscopic inguinal herniorrhaphy: results of a multicenter trial. Ann Surg 221:3-13. (4)

34. Ramshaw BJ, Tucker JG, Conner T, Mason EM, Duncan TD, Lucas GW (1996) A comparison of the approaches to laparoscopic herniorrhaphy. Surg Endosc 10:29-32. (4).

35. Fielding GA (1995) Laparoscopic inguinal hernia repair. Aust N Z J Surg 65:304-307 (4)

36. Kald A, Anderberg B, Smedh K et al. (1997) Transperitoneal or totally extraperitoneal approach in laparoscopic hernia repair: results of 491 consecutive herniorrhaphies. Surg Laparosc Endosc 7: 86-89. (4)

37. Stoker DL, Spiegelhalter DJ, Singh R et al. (1994) Laparoscopic versus open inguinal hernia repair: randomised prospective trial. Lancet 343:1243-1245. (4)

38. Payne JH Jr, Grininger LM, Izawa MT et al. (1994) Laparoscopic or open inguinal herniorrhaphy? A randomized prospective trial. Arch Surg 129: 973-979. (4)

39. Maddern GJ, Rudkin G, Bessell JR et al. (1994) A comparison of laparoscopic and open hernia repair as a day surgical procedure. Surg Endosc 8:1404-1408. (4)

40. Lawrence K, McWhinnie D, Goodwin A et al. (1995) Randomized controlled trial of laparoscopic versus open repair of inguinal hernia: early results. Br Med J 311:981-985. (4)

41. Wright DM, Kennedy Am Baxter JN et al. (1996) Early outcome after open versus extraperitoneal endoscopic tension free hernioplasty: a randomized clnical trail. Surgery 119:552-557. (4)

42. Smith CD, Tiao G, Beebe T (1997) Intraoperative events common to videoscopic preperitoneal mesh inguinal herniorrhaphy. Am J Surg 174:403-405. (4)

43. Heithold DL, Ramshaw BJ, Mason EM et al. (1997) 500 total extraperitoneal approach laparoscopic herniorrhaphies: a single-institution review. Am Surg 63:299-301. (4)
44. McKernan JB, Laws HL (1993) Laparoscopic repair of inguinal hernias using a totally extraperitoneal prosthetic approach. Surg Endosc 7:26-28. (4)

45. Phillips EH, Arregui ME, Carroll BJ et al. (1995) Incidence of complications following laparoscopic hernioplasty. Surg Endosc 9:16-21. (4)

46. Liem MSL, Van Der Graff Y, Van Steensel CJ et al. (1997) Comparison of conventional anterior surgery and laparoscopic surgery for inguinal hernia repair. N Engl J Med 336:1541-1547. (4)

47. Crawford DL, Hiatt JR, Phillips EH (1998) Laparoscopy identifies unexpected groin hernias. Am Surg 64:976-978. (5)

48. Panton ON, Panton RJ (1994) Laparoscopic hernia repair. Am J Surg 167:535-537. (5)

49. McCormack K, Wake BL, Perez J, Fraser C, Cook J, McIntosh E et al. (2005) Laparoscopic surgery for inguinal hernia repair: systemic review of effectiveness and economic evaluation. Health Technol Assess 9:1-203. (1A and 4)

50. Greenberg D, Peiser JG (2001) Cost and benefits of laparoscopic inguinal hernia repair: is there an economic justification? Harefuah 140:580-585. (1A)

51. Beattie GC, Kumar S, Nixon SJ (2000) Laparoscopic total extraperitoneal hernia repair: mesh fixation is unnecessary. J Laparoendosc Adv Surg Tech A 10:71-73. (5)

52. Farinas LP, Griffen FD (2000) Cost containment and totally extraperitoneal laparoscopic herniorrhaphy. Surg Endosc 14:37-40. (5)

53. Misra MC, Kumar S, Bansal VK (2008) Total extraperitoneal (TEP) mesh repair of inguinal hernia in the developing world: comparison of low-cost indigenous balloon dissection versus direct telescopic dissection: a prospective randomized controlled study. Surg Endosc 22:1947-1958. (2B)

\section{Chapter 5: Laparoscopic surgery in complicated hernia: feasibility, risks, and benefits}

G. Ferzli, M. Timoney.

Search terms: "Scrotal hernia"; "Hernias with large defects"

\section{Statements}

Level 3 TAPP and TEP are possible therapeutic options in
scrotal hernia.
Operation time, complication rate, and frequency of
recurrences are higher than in normal hernia repair.
Sero-hematoma formation is the most frequent
complication.
Results will improve with gaining experience.
Complete reduction of hernia sack is possible.


Table continued

Level 5 The higher recurrence rate may result in some of these cases (large hernia openings), because the standard mesh size $(10 \times 15 \mathrm{~cm})$ was too small.

In large hernia openings a mesh with less flexural stiffness (lightweight) or insufficient overlapping may be pushed into the defect.

\section{Recommendations}

Grade C TAPP and TEP may be safely used when performed by surgeons with a higher level of experience in either technique.

Grade D In large hernia openings $(>3-4 \mathrm{~cm})$, a larger mesh may be used $(12 \times 17 \mathrm{~cm})$.

In large direct defects $(>3-4 \mathrm{~cm})$, a stapled fixation of the mesh to the symphysis, Cooper's ligament and rectus muscle may be done.

In large indirect defects $(>4-5 \mathrm{~cm})$, the overlapping of the mesh has to reach approximately $1-3 \mathrm{~cm}$ lateral to the spina iliaca anterior superior. In addition, fibrin fixation to the psoas muscle can be performed.

In large hernia defects, a mesh with greater flexural stiffness (heavyweight) or a well-fixed lightweight mesh with adequate overlapping may be used.

To reduce frequency of sero-hematomas, careful bleeding control by electrocoagulation should be done.

Laparoscopic repair of the scrotal hernia is a controversial subject in laparoscopy, because it implies a large abdominal wall defect and great difficulty in dissecting the extensive hernia sac. Literature on the subject is scant. Ferzli [1] first described laparoscopy for scrotal hernia in 17 patients in 1996. He utilized the TEP method and had no recurrences. In 1999, Leibl addressed the subject of TAPP for the scrotal hernia. He and his colleagues analyzed the results of 191 prospectively studied TAPP repairs for scrotal hernias. They only rarely transected the sac. Operative times were slightly increased compared with normal TAPP repair. Total minor complication rate was $12 \%$ for the scrotal repair versus $5 \%$ for the normal TAPP repair, with the most common complication being seroma. Major complications were $1.6 \%$ for scrotal versus $0.6 \%$ for the normal repair. The recurrence rate was $1 \%$ [2]. Bittner followed up this data with analysis of 440 scrotal hernias in their large, single-center series of 8,050 TAPP repairs. Overall recurrence for the series was $0.7 \%$ but $2.7 \%$ for scrotal hernias [3]. Detailed clinical analysis and experimental studies (Hollinsky) show that the higher recurrence rate in some cases of scrotal hernias having a large defect may be due to inadequate overlapping. Other causes for recurrence in these cases may be the use of meshes with less flexural stiffness and insufficient fixation (Hollinsky) [4, 5].

Bittner's overall morbidity was $3.2 \%$ and decreased with experience. The scrotal subgroup had a significantly increased rate of sero-hematoma (12.5\%), which mandated drainage [3]. Palanivelu also presented a small series of patients using TAPP to repair irreducible scrotal hernias with good results.
TAPP for incarcerated and strangulated inguinal hernia

\section{Statements}

Level 3 Operation time is longer than in uncomplicated hernia. Complication rate and recurrences are similar to uncomplicated cases.

Advantage of laparoscopy is that bowel viability can be observed during the whole time of procedure.

Frequency of bowel resection is less compared with open hernia surgery.

Level 5 Reduction of hernia content or cutting the hernia ring if necessary for reduction may be safer when overlooking both peritoneal and preperitoneal space.

\section{Recommendations}

Grade C TAPP may be used for the repair of incarcerated or strangulated inguinal hernias, but the technique should be reserved for surgeons with extensive experience in the TAPP technique.

Grade D Compromised bowel that is encountered during TAPP repair of strangulated hernia may be resected after the completion of the TAPP repair (after allowing time for the bowel to declare its viability). The resection should be performed extracorporeally for intestine or may be performed intracorporeally for omentum or appendix.

In 2001, Leibl et al. [7] published the results of 220 prospectively studied acutely (strangulated) and chronically incarcerated inguinal hernia repairs; 194 of these repairs were accomplished via TAPP. There was no difference in operative time comparing laparoscopic and conventional repair; however, the time of operation was significantly longer compared with elective TAPP repair. Recurrence rate for TAPP repairs of incarcerated hernias were low $(0.5 \%)$ and was similar to conventional open repair of incarcerated hernias. Other complications, including bleeding, mesh infection $(0.1 \%)$, organ injury, and death, were similarly low or lower. The authors noted that one advantage of the TAPP technique is that it allows assessment of the viability of the bowel. The time needed for hernia repair allows time for the congested bowel to return to normal or not. A comparison to the prelaparoscopic era shows less frequent bowel resections when performing TAPP.

Resection can be performed, if needed, after repair of the hernia. Leibl's group [7] has extensive experience with TAPP repair of routine hernia, and he cautions that surgeons must be comfortable with this technique in routine hernias before attempting it on a complex incarcerated hernia. Other smaller case series and case reports have shown the viability of the TAPP technique for incarcerated hernias [7-11].

The key step to the operation is the reduction of the sac and its contents. The hernia ring can be enlarged (while preventing injury to the femoral or epigastric vessels) through a ventromedial incision in the case of direct hernias and through a ventrolateral incision in the case of 
indirect hernias. If resection of nonviable tissue is required, it can be done intraperitoneally (for omentum or appendix) or extraperitoneally (for small bowel) after the repair has been accomplished [8, 10, 11].

\section{TEP for incarcerated and strangulated inguinal hernia} Statements

\author{
Level 3 The conversion rate in the acute setting is high. \\ Recurrence and complication rates are higher than \\ in the nonincarcerated hernia. \\ Level 5 A drawback to the TEP vs. TAPP approach for the \\ strangulated inguinal hernia is that TEP does not allow \\ inspection of the bowel without laparoscopy.
}

\section{Recommendations}

Grade C TEP may be used for repair of both incarcerated and strangulated inguinal hernias; however, the data on the subject are scant.

Grade D The umbilical port can be converted from a preperitoneal port to an intraperitoneal port to assess bowel viability when it is in question.

In 2004, Ferzli et al. described their experience with TEP to repair 11 acutely incarcerated inguinal hernias. Eight repairs were completed via TEP and three converted to open repairs. They describe the use of various releasing incisions to free the incarcerated sac depending on the nature of the hernia (direct, indirect, or femoral). Ferzli et al. [12] reported no recurrences, a single mesh infection that resolved with continuous irrigation, and a midline wound infection after bowel resection. In 2003, Tamme et al. [13] showed the results of a large series of TEP repairs of inguinal hernias. In this group, he includes, but does not detail, repairs performed on strangulated hernias. His overall results demonstrated low rates of recurrence and complications. Among his conclusions is that TEP is particularly advantageous for the treatment of bilateral, recurrent, and strangulated hernias versus open and TAPP repairs. He cites a reduction in postoperative neuralgia versus open repair and a reduction in bowel injury and port site hernia versus TAPP. Saggar and Sarang [14] retrospectively looked at 34 patients (of 286 elective TEP hernia repairs) who underwent repair of chronically incarcerated inguinal hernia using TEP. Recurrence rate was higher for incarcerated versus nonincarcerated hernias ( 5.8 vs. $0.35 \%)$. The recurrences in the incarcerated group $(n=2)$ occurred during the immediate postoperative period and 2 months postoperatively. Scrotal hematoma and cord induration also were significantly higher in the incarcerated group. He converted the umbilical port to an intraperitoneal port to inspect the bowel when its viability was in question.
TAPP and TEP for incarcerated femoral hernia Statements

Level 5

There are only few reports of successful treatment of incarcerated femoral hernia.

Reduction of hernia contents requires incision of the lacunar ligament.

\section{Recommendations}

Grade D Incarcerated femoral hernia may be safely repaired via the TAPP or TEP; however, in TEP additional laparoscopy for inspection of the incarcerated hernia content is necessary.

Although in some cases a plug repair was done, the general opinion is that a flat mesh having usual size should be inserted.

There are currently no major reports on the use of laparoscopy for the treatment of femoral hernia although case series exist $[15,16]$. Watson first reported the use of TAPP for an incarcerated femoral hernia in a 1993 case report. He used a plug and patch and resected the compromised bowel extracorporeally [17]. Yau et al. describe a cohort of eight patients with incarcerated femoral hernias that were repaired laparoscopically by the TAPP technique. The hernia was reduced with atraumatic forceps and, if needed, the lacunar ligament was incised. After opening the preperitoneal space, a Prolene mesh was inserted into the femoral canal and the peritoneum was reapproximated over the repair. The authors opted not to lay mesh over the entire pectineal orifice in the case of an isolated femoral hernia [18]. Rebuffat et al. [8] describes 7 TAPP repairs of strangulated femoral hernias in his series of 28 TAPP repairs for strangulated hernias. Comman et al. [19] wrote a case report of a single patient with an incarcerated femoral Littre's (herniation of a Meckel's diverticulum), which was treated successfully by TAPP repair.

The literature on the use of TEP for incarcerated femoral hernia is even sparser than for that of TAPP. Ferzli et al. [12] report one case in his series of TEP for incarcerated inguinal hernias.

Laparoscopic inguinal hernia repair in the setting of peritonitis and bowel necrosis

\section{Statements}

Level 5 A high risk for mesh infection is feared.

\section{Recommendations}

Grade D Laparoscopic repair of incarcerated inguinal hernia should be avoided in the setting of peritonitis and if an infected abdominal wall or intra-abdominal cavity is found on laparoscopic exploration.

Laparoscopic (TAPP or TEP) repair of an incarcerated hernia should be avoided in the setting of frank peritonitis or if an infected abdominal wall is encountered in association with necrotic bowel during laparoscopic evaluation. Standard surgical principles still dictate that the risks of mesh 
infection and its associated complications (recurrence, draining sinus, and enterocutaneous fistula) are too great and a myofascial repair should be performed [7, 9, 12].

\section{TAPP and TEP for recurrent inguinal hernia}

Recurrence of inguinal hernia is a common problem that vexes all general surgeons. Large database studies from Denmark and Sweden demonstrate that reoperation rates after first repair that range from 3.1 to $17 \%$ [20-23]. The re-recurrence rate of inguinal hernia after a repair for recurrence is even higher. Some reports state a re-recurrence rate as high as $33 \%$ [24]. The higher re-recurrence rate of inguinal hernia after a prior recurrence results from distortion of the normal anatomy and from the replacement of the fascial strength layer with weaker scar tissue.

The potential for reduction of re-recurrence after laparoscopic hernia repair stems from the use of mesh, which, as Lichtenstein demonstrated, reduces tension along the repair, thereby, reducing the rate of recurrence $[25,26]$. Just as importantly, the posterior approach of the laparoscopic inguinal hernia repair not only provides the mechanical advantage of an underlay repair but also provides the technical advantage of operating through virgin tissue when performed after prior anterior repair.

\section{TAPP for recurrent inguinal hernia}

\section{Statements}

Level IB TAPP is advantageous in terms of defining anatomy and providing improved mechanical strength.

Re-recurrence rate is equal or improved when compared with open techniques.

Complication rate at 1 week after surgery is less and sick leave is shorter compared with the Lichtenstein repair.

Acute and chronic pain are less compared with open mesh repair.

Level III Effectiveness of TAPP-repair in recurrent hernia is equal compared with TAPP repair in primary hernia.

\section{Recommendations}

Grade A TAPP for repair of recurrent inguinal hernia is the preferred alternative to tissue repair and to the Lichtenstein repair for recurrence after prior anterior repair.

Grade B TAPP for recurrent hernia should only be performed by surgeons with extensive experience in the TAPP technique.

Review of the literature from 1996 to present on the use of TAPP for repair of recurrent hernia demonstrates overall that TAPP is equal to or has a significantly better profile compared with the Lichtenstein and other open repairs in terms of re-recurrence. This is especially true for the use of TAPP after prior anterior (open) repair. These data include smaller prospective randomized trials, small and large nonrandomized prospective cohorts, and reviews of large, prospective national hernia databases. Several smaller, single-institution studies (Sandbilcher, Felix, Memon) demonstrate good re-recurrence rates for TAPP for recurrence $(0.5,0.6$, and $3 \%$, respectively). Ramshaw's large single institution review demonstrated a $2 \%$ rerecurrence rate after TAPP for recurrence. Bittner's rerecurrence rate $(1.1 \%)$ in his large series was no different than his rate of recurrence for primary unilateral or bilateral hernia. The same was true for operation time, complication rate, and time of sick leave. Bisgaard's large prospective study from the Danish national hernia database shows a re-recurrence rate of $1.3 \%$ for TAPP repair of recurrent inguinal hernia versus $11.3 \%$ for Lichtenstein repair of recurrent inguinal hernia. Dedemadi and Eklund demonstrated improved and equivalent re-recurrence results, respectively, for TAPP versus Lichtenstein. Furthermore, Mahon, Dedemadi, and Eklund found significantly less pain during the early postoperative period. In addition, Mahon reported significantly less chronic pain compared with open mesh repair. These and multiple other studies (most notably, Neumayer) are consistent in the finding that a significant learning curve is associated with the TAPP repair and that TAPP for recurrent hernia should only be attempted by surgeons who are very familiar with the technique [3, 20-22, 27-40].

\section{TEP for recurrent inguinal hernia}

\section{Statements}

Level I B TEP is advantageous in terms of defining anatomy and providing improved mechanical strength.

Re-recurrence rate is equal or improved compared with open techniques.

Level II C Re-operation rate is less compared with open techniques.

\section{Recommendations}

Grade A

TEP for repair of recurrent inguinal hernia is the preferred alternative to tissue repair and to the

Lichtenstein repair for recurrence after prior anterior repair.

A number of studies have demonstrated that TEP repair of recurrent inguinal hernia is a viable technique that can be done with low re-recurrence and low morbidity. These studies range from case series to data prospectively collected from multicenter and large national hernia databases. They also include one prospective, randomized study with a subset analysis of laparoscopy for recurrent hernia and a prospective, controlled, nonrandomized study looking at TEP versus open repair for recurrence [31, 41]. Conversion rates to open were comparable to conversion rates of repairs for primary hernias. Re-recurrence rates after recurrent repair by TEP ranged from 0 to $20 \%$, but most studies show a comparable or improved recurrence rate compared with the open re-repair [42, 43]. Ramshaw's large single institution study had a re-recurrence rate of $0.3 \%$ after TEP [36]. The study by Bay-Nielson et al. [21] showed a reoperation of $1.3 \%$ after TEP for recurrence 
versus 3.2 and $6.7 \%$ respectively for the Lichtenstein and muscle repair for recurrence. These results were later reconfirmed when his group looked at all laparoscopy for recurrence [20]. One drawback to the technique, as Ferzli and Sayad point out, is that sutures or scarring from the prior repair may result in inadvertent pneumoperitoneum. This results in a technical obstacle to repair, but the challenge can be overcome with experience [43]. Again, most authors emphasize the importance of the steep learning curve with this technique and caution that only surgeons who are well trained in the TEP technique utilize it for recurrent hernia [20, 21, 29, 34, 36, 40-54].

Pain score and return to regular activity after TAPP and TEP for recurrent inguinal hernia

\section{Statements}

\begin{tabular}{|c|c|}
\hline Level IB & $\begin{array}{l}\text { Compared with open repair, TAPP and TEP have a } \\
\text { better profile in terms of level of pain and return } \\
\text { to regular activity. } \\
\text { Incidence of wound and mesh infection is lower } \\
\text { compared with open hernia surgery. }\end{array}$ \\
\hline Level IV & Effectiveness of TAPP versus TEP is similar. \\
\hline
\end{tabular}

\section{Recommendations}

\begin{tabular}{|c|c|}
\hline Grade A & $\begin{array}{l}\text { Both techniques TAPP and TEP are recommended after } \\
\text { an anterior approach, providing the surgeon is } \\
\text { sufficiently experienced in the specific procedure. }\end{array}$ \\
\hline
\end{tabular}

The long skin incision and myofascial dissection of an open inguinal hernia repair create significant postoperative pain, resulting in prolonged recuperation and in delayed return to normal activity and return to work. TAPP has been directly compared in a number of retrospective and small, randomized, prospective studies to open repair for recurrent hernia and has been shown to be associated with significantly decreased postoperative pain and earlier return to work and activity. The incidence of wound and mesh infections also has been demonstrated to be lower [27-31, 44, 55-58].

TAPP and TEP seem to be similarly effective, although there is a scarcity of data comparing both techniques directly [56].

TAPP inguinal hernia repair after failed TAPP/TEP Statements

Level III Re-TAPP is possible.

Operation time is longer and morbidity higher compared with repair of primary hernia, but time of sick leave and re-recurrence rate are similar.

There is a steep learning curve.

Level IV/V TAPP is superior to TEP.

\section{Recommendations}

$\overline{\text { Grade C TAPP repair of recurrent inguinal hernia after prior TAPP }}$ or TEP may be performed; however, it should only be attempted by experts in TAPP inguinal hernia repair.

According to EHS Guidelines, it is generally agreed that an anterior approach seems to be the best choice after failed posterior repair. Yet, a number of studies have looked at TAPP repair for recurrence after TAPP as the primary repair modality (TAPP after TAPP). Most show excellent results. Bisgaard's review from the Danish hernia registry is the exception. The recurrence rate of $7.1 \%$ for TAPP vs. $2.7 \%$ for Lichtenstein repair may stem from the fact that this is a national study and includes all comers (expert and novice laparoscopic surgeons alike). Bisgaard's [20] review highlights the need for a high level of experience and comfort in the basic TAPP technique before attempting its use for TAPP after TAPP. Indeed, the largest series of TAPP after TAPP, Bittner $(n=135)$, demonstrates a significant learning curve, but with a low overall re-recurrence rate of $0.74 \%$ [20, 31, 59-61].

TAPP and TEP repair in patient after previous transabdominal radical prostatectomy

\section{Statements}

Level 3 TAPP and TEP are possible treatment options.

Operation time is longer and morbidity higher compared with repair of primary hernia, but time of sick leave and re-recurrence rate are similar.

There is a steep learning curve.

In TEP, there is a significant conversion rate to TAPP.

Level 5 TAPP seems to be easier to perform.

\section{Recommendations}

Grade D TAPP or TEP repair may be performed, but it should only be attempted by experts in TAPP or TEP inguinal hernia repair.

It is generally accepted that an anterior approach seems to be the best choice after previous preperitoneal surgery. Only two studies report the results of TAPP (Wauschkuhn et al. [62]) and TEP (Dulucq et al. [63]) in hernia patients after previous transabdominal radical prostatectomy. During a 1-year period, Dulucq operated on a total of 10 patients after prostatectomy with TEP. Operation time was longer than in uncomplicated repairs and two patients were converted to TAPP, but overall complication rate and outcome were similar. Wauschkuhn et al. report approximately 264 patients who underwent surgery during a 10 -year period. They found a longer operation time and a higher morbidity (5.7 vs. 2.8), but time of slick leave and recurrence rates were similar. Analysis of subgroups with respect to the time period during which they were operated on showed a steep learning curve $[62,63]$.

Pitfalls of TAPP and TEP repair for recurrent inguinal hernia

Statements

Level 4 The presence of two or more meshes in the inguinal region does not seem to enhance the frequency of chronic pain. Removal of a previously implanted preperitoneal mesh may increase the risk for lesion of urinary bladder, bleeding complications, and substantial defects of the peritoneum. 


\section{Recommendations}

Grade D Old mesh from prior preperitoneal hernia repair should be left in place.

The re-repair should be defect-adapted.

When an old plug is encountered that does not allow placement of a flat mesh, the protruding part of the plug may be best cut away with the use of electrocautery.

The presence of old mesh in the prior hernia repair presents a technical challenge for TAPP or TEP repairs of recurrence. The mesh from a prior Lichtenstein repair should not affect the field of a posterior approach. However, the mesh plug technique poses a unique problem for laparoscopic repair of recurrence. The old plug creates an obstacle to placing the mesh and replacing the peritoneum over the mesh. Removal of the plug is not simple and cannot be easily accomplished with endo-shears. We find that electrocautery more effectively cuts the protruding aspect of the plug, thus allowing posterior mesh placement and replacement and repair of the peritoneum.

The best approach to a mesh placed from prior laparoscopic repairs may be to leave it in place and avoid risk of injury to the iliac vein or to the bladder. The new mesh can be laid on top of the old to correct any technical failure of a slipped or misplaced prior mesh.

TAPP and TEP repair and the occult synchronous hernias.

\section{Statements}

Level 4 TAPP and TEP repair of inguinal hernia allow easy identification of the occult ipsilateral femoral or obturator hernia.

TEP allows easy identification of concomitant contralateral direct hernias.

TAPP allows easy identification of concomitant contralateral direct and indirect hernias.

The laparoscopic approach obliterates these associated occult synchronous or potential hernias utilizing a single repair without any particular modification to the technique.

\section{Recommendations}

Grade B In inguinal hernia repair for diagnosis of occult ipsilateral hernia defects, a careful dissection of the whole pelvic floor should be done.

One problem associated with the repair of the recurrent inguinal hernia repair is the missed synchronous hernia [64]. Felix et al. [33] found an occult femoral hernia incidence of 9\% in his 1996 series of laparoscopic repair of recurrent inguinal hernia. Mikkelsen et al. found the risk of femoral hernia to be 15 times higher after inguinal hernia repair than in the general population, and Chan believes prior inguinal hernia repair may precipitate femoral hernia $[65,66]$. He found that $50.9 \%$ of his series of 225 femoral hernia repairs had concurrent inguinal hernia and $18.2 \%$ had prior groin hernia repair. Laparoscopic inguinal hernia repair provides the benefit of a panoramic view of the all the potential hernia spaces: direct and indirect, femoral, and obturator hernias. TAPP and TEP therefore address the missed femoral and concomitant ipsilateral hernias. Furthermore, TAPP enables rapid evaluation of contralateral hernias (see Chap. 2, Kukleta). The laparoscopic approach obliterates these associated occult synchronous or potential hernias utilizing a single repair without any particular modification to the technique. There has been a general agreement that in every case of hernia repair a careful complete dissection of the whole ipsilateral pelvic floor is mandatory.

References (in parentheses graduation of evidence)

1. Ferzli GS, Kiel T (1997) The role of the endoscopic extraperitoneal approach in large inguinal scrotal hernias. Surg Endosc 11:299-302. (4)

2. Leibl BJ, Schmedt CG, Kraft K, Ulrich M, Bittner R (2000) Scrotal hernias: a contraindication for an endoscopic procedure? Results of a single-institution experience in transabdominal preperitoneal repair. Surg Endosc 14:289-292. (4)

3. Bittner R, Schmedt CG, Schwarz J, Kraft K, Leibl BJ (2002) Laparoscopic transperitoneal procedure for routine repair of groin hernia. Br J Surg 89:10621066. (4)

4. Hollinsky C, Sandberg S, Koch T, Seidler S (2008) Biomechanical properties of lightweight versus heavyweight meshes for laparoscopic inguinal hernia repair and their impact on recurrence rates. Surg Endosc 22:2679-2685. (5)

5. Hollinsky C, Hollinsky K (1999) Static calculations for mesh fixation by intraabdominal pressure in laparoscopic extraperitoneal herniorrhaphy. Surg Laparosc Endosc Percutan Tech 9:106-109. (5)

6. Palanivelu C, Rangarajan M, John SJ (2007) Modified technique of laparoscopic intraperitoneal hernioplasty for irreducible scrotal hernias (omentoceles): how to remove the hernial contents. World J Surg 31:1889-1891. (4)

7. Leibl BJ, Schmedt CG, Kraft K, Kraft B, Bittner R (2001) Laparoscopic transperitoneal hernia repair of incarcerated hernias: Is it feasible? Results of a prospective study. Surg Endosc 15:1179-1183. (4)

8. Rebuffat C, Galli A, Scalambra MS, Balsamo F (2006) Laparoscopic repair of strangulated hernias. Surg Endosc 20:131-134. (4)

9. Ishihara T, Kubota K, Eda N, Ishibashi S, Haraguchiy (1996) Laparoscopic approach to incarcerated inguinal hernia. Surg Endosc 10:1111-1113. (4)

10. Legnani GL, Rasini M, Pastori S, Sarli D (2008) Laparoscopic trans-peritoneal hernioplasty (TAPP) for the acute management of strangulated inguino- 
crural hernias: a report of nine cases. Hernia 12:185-188. (4)

11. Scierski A (2004) Laparoscopic operations of incarcerated inguinal and femoral hernias. Wiad Lek 57:245-248. (4)

12. Ferzli G, Shapiro K, Chaudry G, Patel S (2004) Laparoscopic extraperitoneal approach to acutely incarcerated inguinal hernia. Surg Endosc 18:228-231. (4)

13. Tamme C, Scheidbach H, Hampe C, Schneider C, Köckerling F (2003) Totally extraperitoneal endoscopic inguinal hernia repair (TEP). Surg Endosc 17:190-195. (4)

14. Saggar VR, Sarang R (2005) Endoscopic totally extraperitoneal repair of incarcerated inguinal hernia. Hernia 9:120-124. (4)

15. Hernandez-Richter T, Schardey HM, Rau HG, Schildberg FW, Meyer G (2000) The femoral hernia: an ideal approach for the transabdominal preperitoneal technique (TAPP). Surg Endosc 14:736-740. (4)

16. Yalamarthi S, Kumar S, Stapleton E, Nixon SJ (2004) Laparoscopic totally extraperitoneal mesh repair for femoral hernia. J Laparoendosc Adv Srg Tech A 14:358-361. (4)

17. Watson SD, Save W, Hollier PA (1993) Combined laparoscopic incarcerated herniorrhaphy and small bowel resection. Surg Laparosc Endosc 3:106-108. (5)

18. Yau KK, Siu WT, Cheung YS, Wong CH, Chung CC, Li KW (2007) Laparoscopic management of acutely incarcerated femoral hernia. J Laparoscopic Adv Surg Tech A 17(6):759-762. (4)

19. Comman A, Brunner SM, Gaetzschmann P, Kipf B, Baierl W, Behrend M (2008) Incarcerated femoral Littre's hernia-Transperitoneal preperitoneal hernia repair (TAPP) and laparoscopic resection of the necrotic diverticulum. Surg Laparosc Endosc Percutan Tech 18:409-413. (5)

20. Bisgaard T et al. (2008) Re-recurrence after operation for recurrent inguinal hernia. A nationwide 8-year follow-up study on the role of type of repair. Ann Surg 247:707-711. (2c)

21. Bay-Nielson M, Kehlet H, Strand L, Malmstrom J, Andersen FH, Wara P, Juul P, Callesen T (2001) Quality assessment of 26,304 herniorrhaphies in Denmark: a prospective nationwide study. Lancet 358:1124-1128. (2c)

22. Haapaniemi S et al. (2001) Reoperation after recurrent groin hernia repair. Ann Surg 234(1):122-126. (2c)

23. Nilsson E et al. (1998) Methods of repair and risk for reoperation in Swedish hernia surgery from 1992 to 1996. Br J Surg 85:1686-1691. (2c)

24. Schaap HM et al. (1992) The preperitoneal approach in the repair of recurrent inguinal hernias. Surg Gynecol Obstet 174:460-464. (4)
25. Amid PK, Shulman AG, Lichtenstein IL (1996) Open "tension-free" repair of inguinal hernias: the Lichtenstein technique. Eur J Surg 162:447-453. (4)

26. Kark AE, Kurzer M, Belsham PA (1998) Three thousand one hundred and seventy-five primary inguinal hernia repairs; advantages of ambulatory open mesh repair using local anesthesia. J Am Coll Surg 86:447-456. (4)

27. Beets GL et al. (1999) Open or laparoscopic preperitoneal mesh repair for recurrent inguinal hernia? A randomized controlled trial. Surg Endosc 13: 323-327. (1b)

28. Mahon D et al. (2003) Prospective randomized trial of laparoscopic (transabdominal preperitoneal) vs open (mesh) repair for bilateral and recurrent inguinal hernia. Surg Endosc 17:1386-1390. (1b)

29. Dedemadi G et al. (2006) Comparison of laparoscopic and open tension-free repair of recurrent inguinal hernias: a prospective randomized study. Surg Endosc 20:1099-1104. (1b)

30. Eklund A et al. (2007) Recurrent inguinal hernia: randomized multicenter trial comparing laparoscopic and Lichtenstein repair. Surg Endosc 21:634-640. (1b)

31. Neumayer L et al. (2004) Open mesh versus laparoscopic mesh repair of inguinal hernia. N Engl J Med 350:1819-1827. (1b)

32. Sandbichler P et al. (1996) Laparoscopic repair of recurrent inguinal hernia. Am J Surg 171:366-368. (4)

33. Felix EL et al. (1996) Laparoscopic repair of recurrent hernia. Am J Surg 172:580-584. (4)

34. Jarhult J et al. (1999) Laparoscopic treatment of recurrent inguinal hernias: experience from 281 operations. Surg Laparosc Endosc Percutan Tech 9:115-118. (4)

35. Memon MA et al. (1999) Laparoscopic repair of recurrent hernias. Surg Endosc 13:807-810. (4)

36. Ramshaw B et al. (2001) Laparoscopic inguinal hernia repair: lessons learned after 1,224 consecutive cases. Surg Endosc 15:50-54. (4)

37. Hawasli A et al. (2002) Laparoscopic transabdominal preperitoneal inguinal hernia repair for recurrent inguinal hernia. Am Surg 68:303-308. (4)

38. Keider A et al. (2002) Laparoscopic repair of recurrent inguinal hernia: long-term follow up. Surg Endosc 16:1708-1712. (4)

39. Wara P et al. (2005) Prospective nationwide analysis of laparoscopic versus Lichtenstein repair of inguinal hernia. Br J Surg 92:1277-1281. (2c)

40. Tantia $\mathrm{O}$ et al. (2009) Laparoscopic repair of recurrent groin hernia: results of a prospective study. Surg Endosc 23:734-738. (4)

41. Feliu X, Torres G, Vinas X, Martinez-Rodenas F, Fernandez-Sallent E, Pie J (2004) Preperitoneal repair for recurrent inguinal hernia: laparoscopic and open approach. Hernia 8:113-116. (4) 
42. Knook MTT, Weidema WF, Stassen LPS, van Steensel CJ (1999) Endoscopic total extraperitoneal repair of primary and recurrent inguinal hernias. Surg Endosc 13:507-511. (4)

43. Sayad P, Ferzli G (1999) Laparoscopic preperitoneal repair of recurrent inguinal hernias. J Laparoendosc Adv Surg Tech A 9:127-130. (4)

44. Aeberhard P, Klaiber C, Meyenberg A, Osterwalder A, Tschudi J (1999) Prospective audit of laparoscopic totally extraperitoneal inguinal hernia repair: a multicenter study of the Swiss Association for Laparoscopic and Thoracoscopic Surgery (SALTC). Surg Endosc 13:1115-1120. (2c)

45. Staarink M, van Veen RN, Hop WC, Weidema WF (2008) A 10-year follow-up study on endoscopic total extraperitoneal repair of primary and recurrent inguinal hernia. Surg Endosc 22:1803-1806. (4)

46. van der Hem JA, Hamming JF, Meeuwis JD, Oostvogel HJ (2001) Totally extraperitoneal endoscopic repair of recurrent inguinal hernia. Br J Surg 88:884-886. (4)

47. Ramshaw BJ, Tucker JG, Duncan TD, Heithold D, Garcha I, Mason EM, Wilson JP, Lucas GW (1996) Technical considerations of the different approaches to laparoscopic herniorrhaphy: an analysis of 500 cases. Am Surg 62:69-72. (4)

48. Felix EL, Michas CA, McKnight RL (1995) Laparoscopic repair of recurrent hernias. Surg Endosc 9:135-138. (4)

49. Thill V, Simeons C, Smets D, Ngongang C, da Costa PM (2008) Long-term results of a non-ramdomized prospective mono-centre study of 1000 laparoscopic totally extraperitoneal hernia repairs. Acta Chir Belg 108:405-408. (4)

50. Alani A, Duffy F, O'Dwyer PJ (2006) Laparoscopic or open preperitoneal repair in the management of recurrent groin hernias. Hernia 10:156-158. (4)

51. Bingener J, Dorman JP, Valdes G (2003) Recurrence rate after laparoscopic repair of recurrent inguinal hernias: have we improved? Surg Endosc 17:1781-1783. (4)

52. Feliu X, Jaurrieta E, Vinas X, Macarulla E, Abad JM, Fernandez-Sallent E (2004) Recurrent inguinal hernia: a ten-year review. J Laparoendosc Adv Surg Tech A 14:362-367. (4)

53. Frankum CE, Ramshaw BJ, White J, Duncan TD, Wilson RA, Mason EM, Lucas G, Promes J (1999) Laparoscopic repair of bilateral and recurrent hernias. Am Surg. 65:839-842. (4)

54. Barrat C, Surlin V, Bordea A, Champault G (2003) Management of recurrent inguinal hernias: a prospective study of 163 cases. Hernia 7:125-129. (4)

55. Kapiris SA, Brough WA, Royston CM, O'Boyle C, Sedman PC (2001) Laparoscopic transabdominal preperitoneal (TAPP) hernia repair. A 7-year two-center experience in 3017 patients. Surg Endosc 15:972-975. (4)

56. McCormack K, Wake B, Perez J, Fraser C, Cook J, McIntosh E, Vale L, Grant A (2005) Laparoscopic surgery for inguinal hernia repair: systematic review of effectiveness and economic evaluation. Health Technol Assess 9:14. (1a)

57. Bringman S, Ramel S, Heikkinen TJ, Englund T, Westman B, Anderberg B (2003) Tension-free inguinal hernia repair: TEP versus mesh-plug versus Lichtenstein: a prospective randomized controlled trial. Ann Surg 237:142-147. (1b)

58. Kuhry E, van Veen RN, Langeveld HR, Steyerberg EW, Jeekel J, Bonjer HJ (2007) Open or endoscopic total extraperitoneal inguinal hernia repair? A systematic review. Surg Endosc 21:161-166. (1a)

59. Bittner R, Schwarz J (2007) How to treat recurrent inguinal hernia-TAPP. In: Schumpelick V, Fitzgibbons JR (eds) Recurrent hernia. Prevention and treatment. Heidelberg, Springer, pp 297-301. (4)

60. Knook MT et al. (1999) Laparoscopic repair of recurrent inguinal hernias after endoscopic herniorrhaphy. 13:1145-1147. (4)

61. Leibl B et al. (2000) Recurrence after endoscopic transperitoneal hernia repair (TAPP): causes, reparative techniques, and results of the reoperation. J Am Coll Surg 190:651-655. (4)

62. Wauschkuhn CA, Schwarz J, Bittner R (2009) Laparoscopic transperitoneal inguinal hernia repair (TAPP) after radical prostatectomy: is it safe? Results of prospectively collected date of more than 200 cases. Surg Endosc 23:973-977. (4)

63. Dulucq JL, Wintringer P, Mahajna A (2006) Totally extraperitoneal (TEP) hernia repair after radical prostatectomy or lower abdominal surgery: is it safe?A prospective study. Surg Endosc 20: 473-476. (4)

64. Crawford DL, et al. (1998) Laparoscopy identifies unexpected groin hernias. Am Surg 64:976-978. (4)

65. Mikkelsen T et al. (2002) Risk of femoral hernia after inguinal herniorrhaphy. Br J Surg 89:486-488. (2c)

66. Chan G, Chan CK (2008) Long-term results of a prospective study of 225 femoral hernia repairs: Indications for tissue and mesh repair. J Am Coll Surg 207:360-367. (4)

Chapter 6: Mesh size and recurrence: what is the optimal size?

Thue Bisgaard, Jacob Rosenberg

Copenhagen, Denmark

Search terms: "mesh size"; "recurrence"; "inguinal hernia" 
Does the use of a larger mesh prevent recurrence after laparoscopic inguinal hernia repair?

\section{Statements}

Level 2A A small mesh may be a risk factor for recurrence after laparoscopic inguinal hernia repair.

Level 5 Insufficient dissection of the preperitoneal space makes it difficult to place a large mesh properly and avoid folds and wrinkles.

Fixation does not compensate for inadequate mesh size.

\section{Recommendations}

Grade A A mesh size of at least $10 \times 15 \mathrm{~cm}$ is recommended. Grade D Use a bigger mesh (i.e., $12 \times 17 \mathrm{~cm}$ or greater) for large hernias (direct $>3-4 \mathrm{~cm}$, indirect $>4-5 \mathrm{~cm}$ ).

A systematic literature search was performed in PubMed covering the period from 1966 to January 2009. Papers in English, German, and French were reviewed. Only human studies were included. The following search terms were used: mesh size, recurrence, inguinal hernia.

Mesh size may have a greater impact on recurrence than surgical technique $[1,2]$. A small mesh has been shown to be an independent risk factor for recurrence compared with a large one, irrespective of the type of mesh, i.e., light or heavyweight [3].

We found no randomized trials that specifically compared mesh sizes, but several studies on surgical techniques used different sizes of mesh. Data extracted from a recent meta-analysis of open versus laparoscopic hernia repairs provide some information about this issue [4]. A significant trend toward reduced recurrence rates with increasing mesh size was noted (a "large" mesh was most often $10 \times$ $15 \mathrm{~cm}^{2}$ size). Indeed, use of a small mesh almost doubled the risk for recurrence [4]. A large, retrospective series that included 3,017 patients who underwent TAPP inguinal herniorrhaphies showed a $5 \%$ recurrence rate using an $11 \times 6 \mathrm{~cm}^{2}$ mesh in 325 repairs and a $0.16 \%$ recurrence rate using a $15 \times 10 \mathrm{~cm}^{2}$ mesh in 3,205 repairs [5].

There are two large randomized studies from Sweden; one compared TAPP with Shouldice with a 5-year followup of 920 patients and showed a recurrence rate of $6.6 \%$ when using a mesh size of $7 \times 12 \mathrm{~cm}^{2}$ [6], and the other compared TEP with Lichtenstein with 5-year clinical examination of 1,370 patients when using a mesh size of $12 \times 15 \mathrm{~cm}^{2}$ and showed a recurrence rate of 3-5\% [7]. Animal data have suggested that a minimum of 3-cm mesh overlap is essential to prevent mesh protrusion through the hernia defect resulting in recurrence [8].

To summarize, the use of a large mesh for laparoscopic inguinal hernia repair is supported by the literature, albeit with a low level of evidence, which makes it impossible to recommend an optimal size. However, it seems reasonable to suggest that the mesh should overlap the hernia defect by at least $3 \mathrm{~cm}$ in all directions. It should be emphasized that dissection of the preperitoneal space has to be adequate for the size of mesh to ensure that the mesh lies flat against the abdominal wall [9-11].

\section{Comprehensive comments}

As recurrence factor, mesh size is much more important than the prosthetic material used. In daily clinical practice, we use a mesh of $10 \times 15 \mathrm{~cm}^{2}$ size, even in "small" patients. If the patient is big or has a large hernia defect, it is advisable to use a larger mesh. However, for logistic reasons, we have decided to use only $10 \times 15 \mathrm{~cm}^{2}$ meshes in our departments, and if we encounter a patient who requires a larger mesh, we simply implant two meshes instead of one with sufficient overlap.

Some surgeons routinely cut the mesh making it curved, i.e., rounding the edges. This is not necessary. Instead, the dissection should be thorough with a complete parietalization and a wide exposure of the entire preperitoneal space to ensure a flat positioning of the mesh.

References (in parentheses graduation of evidence)

1. Neumayer L, Giobbie-Hurder A, Jonasson O, Fitzgibbons R Jr, Dunlop D, Gibbs J, Reda D, Henderson W; Veterans Affairs Cooperative Studies Program 456 Investigators (2004) Open mesh versus laparoscopic mesh repair of inguinal hernia. N Engl J Med 350:1819-1827. (1B)

2. Neumayer L, Giobbi-Hurder A, Jonasson O (2004) Open mesh versus laparoscopic mesh hernia repair (authors reply). N Engl J Med 351:1463-1465. (4)

3. Lowham AS, Filipi CJ, Fitzgibbons RJ Jr, Stoppa R, Wantz GE, Felix EL, Crafton WB (1997) Mechanisms of hernia recurrence after preperitoneal mesh repair. Ann Surg 225:422-431. (2B)

4. Stengel D, Bauwens K, Ekkernkamp A (2004) Recurrence risks in randomized trials of laparoscopic versus open inguinal hernia repair: to pool or not to pool (this is not the question). Langenbecks Arch Surg 389:492-498. (2A)

5. Kapiris SA, Brough WA, Royston CM, O’Boyle C, Sedman PC (2001) Laparoscopic transabdominal preperitoneal (TAPP) hernia repair. A 7-year twocenter experience in 3,017 patients. Surg Endosc 15:972-975. (2C)

6. Arvidsson D, Berndsen FH, Larsson LG, Leijonmarck C-E, Rimbäck G, Rudberg C, Smedberg S, Spangen L, Montgomery A (2005) Randomized clinical trial comparing 5-year recurrence rate after laparoscopic versus Shouldice repair of primary inguinal hernia. Br J Surg 92:1085-1091. (IB)

7. Eklund AS, Montgomery A, Rasmussen C, Sandbue RP, Bergkvist LA, Rudberg CR (2009) Low recurrence rate after laparoscopic (TEP) and open (Lichtenstein) 
inguinal hernia repair. A randomized, multicenter trial with 5-year follow-up. Ann Surg 249:33-38. (IB)

8. Knook MT, van Rosmalen AC, Yoder BE, Kleinrensink GJ, Snijders CJ, Looman CW, van Steensel CJ (2001) Optimal mesh size for endoscopic inguinal hernia repair, a study in a porcine model. Surg Endosc 15:1471-1477. (5)

9. Totte E, Van Hee R, Kox E, Hendrickx L, Van Zwieten KJ (2005) Surgical anatomy of the inguinal region: implications during inguinal laparoscopic herniorrhaphy. Eur Surg Res 37:185-190. (5)

10. Lowham AS, Filipi CJ, Fitzgibbons RJ Jr, Stoppa R, Wantz GE, Felix EL, Crafton WB (1997) Mechanisms of hernia recurrence after preperitoneal mesh repair. Traditional and laparoscopic. Ann Surg. 225:422-431 (4, videotapes from 13 recurrence operations analysed by experts). (4)

11. Phillips EH, Rosenthal R, Fallas M, Carroll B, Arregui M, Corbitt J, Fitzgibbons R, Seid A, Schultz L, Toy F et al. (1995) Reasons for early recurrence following laparoscopic hernioplasty. Surg Endosc 9:140-144. (2C)

\section{Chapter 7: Selection of mesh material}

D. Weyhe, C. Schug-Pass, U. Klinge

Search terms: "TAPP" AND "mesh"; TEP AND "mesh"; "Biocompatibility" AND "mesh"; "groin pain" AND "mesh"; "inguinal hernia" AND "mesh"; "Quality of life" AND "mesh"

Does functional outcome and quality of life improve with the use of light meshes in TAPP and TEP?

\section{Statements}

Level 1A In the long-term comparison, lighter meshes with larger pores do not lead to improvements of the quality of life or a reduction of discomfort that are of statistical significance. They offer advantages in terms of convalescence during the first few postoperative weeks.

\section{Recommendations}

Grade B The hernia repair in the TAPP/TEP technique with a so-called material-reduced mesh (less amount of material, bigger pores, some elasticity) decreases the rate of mesh-related complaints, at least within the first 3 months.

Grade D A monofilament implant with a pore size of at least $1.0-1.5 \mathrm{~mm}$ (usually meaning low-weight) consisting of a minimum tensile strength in all directions (including subsequent tearing force) of $>16 \mathrm{~N} / \mathrm{cm}$ appeared to be most advantageous; however, this assumption mainly summarizes personal and published clinical and experimental experiences.

\section{Introduction}

The common approach in hernia surgery is the tensionfree technique with alloplastic materials to strengthen the connective tissue or partial connective tissue replacement in large fascia defects. Modern implants have to fulfill increasingly stringent requirements concerning their mechanical and biological qualities. A large number of investigations deal with the improvement of the biocompatibility of implants. In this respect, the definition of biocompatibility moves away from the concept of a biochemical inert material to an application-oriented definition. In the past, a variety of experimental studies were performed to improve the implants to prevent undesirable effects, such as chronic groin pain or movement-dependent discomfort, and allow quicker return to work and daily activities. Against this background, the light mesh concept has established itself over the years. An analysis of prospective, randomized, double blind studies that compared the theoretical effect of weight reduction to clinical outcome should result in a recommendation of the choice of mesh in TAPP and TEP technique based on the strength of the evidence.

\section{Materials and methods}

The clinical studies analyzed were conducted between January 2000 and February 2009, because no comparable studies are available before this period. We conducted a search of Pubmed, Medline, and Cochrane Library using the terms: TAPP/TEP and mesh, biocompatibility and mesh, groin and mesh. We analyzed each article. The classification in degrees of evidence followed the Oxford hierarchy of evidence starting from Level 1A (systematic review of RCTs with consistent results from individual studies) up to level 5 (expert opinion, animal, or lab experiments).

\section{Results \\ TAPP}

In total, 374 hits were found from January 2000 to February 2009. Excluding 48 review articles, 326 publications were classified according to the evidence criteria. The result was three articles [1-3; Study design Figs. 1-3] $(0.92 \%)$ based on a prospective study design, of which only two $[2,3]$ performed randomization $(0.6 \%)$. Early results (3 months) are described in one article [2], medium-term results (12-month follow-up) likewise in one article [1], and 5-year long-term results in one study [3].

TEP

The TEP search resulted in 359 articles. Excluding 42 review articles, 317 articles were (peer) reviewed. Three of 317 (0.94\%) publications were prospective, controlled, randomized studies [4-6; Study design Figs. 4-6]. Two articles [4, 5] described early results (2 months) and one [6] medium-term results. Long-term results were not available. Apart from the article by Horstmann et al., only five articles seem to be comparable (Table 1) [2-6]. This prospective, longitudinal study [1] continues to be taken 
Table 1 Overview of the study methods and assessment of the level of evidence

\begin{tabular}{lllllll}
\hline & Randomized & d- blind & VAS & SF-36 & Multicenter \\
\hline TAPP [1] & No & No & No & No & No & 2b \\
TAPP [2] & Yes & Yes & Yes & Yes & No \\
TAPP [3] & Yes & Yes & Yes & Yes & No & 1b \\
TEP [4] & Yes & Single & Yes & Yes & Yes \\
TEP [5] & Yes & Single & Yes & Yes & Yes & No \\
TEP [6] & Yes & Yes & Yes & No & $1 \mathrm{~b}$ \\
Accordance & 5 & 3 & 5 & 4 & 2 & $1 \mathrm{~b}$ \\
\hline
\end{tabular}

Study [1] is not comparable to the other

Table 2 Overview of the significant advantages of LM in the early, medium-, and long-term results

\begin{tabular}{|c|c|c|c|c|c|}
\hline & No. patients & Follow-up (\%) & $<3$-month Adv. LM & 12-month Adv. LM & 60-month Adv. LM \\
\hline TAPP [1] & 672 & 81 & - & Yes $^{\mathrm{a}}$ & - \\
\hline TAPP [2] & 90 & 100 & $\mathrm{Yes}^{\mathrm{b}}$ & - & - \\
\hline TAPP [3] & 180 & 97 & - & - & No \\
\hline TEP [4] & 139 & 94 & $\mathrm{Yes}^{\mathrm{c}}$ & - & - \\
\hline TEP [5] & 137 & 88 & Yes $^{d}$ & - & - \\
\hline TEP [6] & 50 & 100 & $\mathrm{Yes}^{\mathrm{e}}$ & $\mathrm{No}^{\mathrm{e}}$ & - \\
\hline Average & 211 & 93 & $n=4$ & - & $n=1$ \\
\hline
\end{tabular}

${ }^{a}$ Significant advantage with regard to formation of seroma/hematoma, sensation of foreign body, undue sensitivity to weather changes

b Significant advantage with regard to physical fitness, family activities, sensation during sexual activities for lightweight mesh

c Significant advantage concerning return to daily activities, no difference in the SF-36 or VAS score

${ }^{d}$ Significant advantage in general health and bodily pain but no difference in VAS and SF-36 score

e Significant advantage with regard to postoperative pain; no difference after 1 year

Table 3 Textile requirements to synthetic meshes for TAPP/TEP technique

Min. standard keyword

1. Monofile structure-infection

2. Pore size $1-1.5-\mathrm{mm}$ collagen (large pores usually are related with low weight)

3. Tensile strength $>16 \mathrm{~N} / \mathrm{cm}$ stability

into consideration despite the insufficiently standardized methodology; however, it is critically discussed in the overall analysis and separately assessed (Level 2B). The five analysed RCT studies (Level 1B) agree that postsurgical advantages last for up to 3 months. These advantages are partly very subtle and not always corroborated by the VAS and SF score (Tables 1, 2). Only one study (TAPP) has a survey of 5 years and could not detect any difference of statistical significance. Noteworthy, this long-term study reported on $5 \%$ of patients complaining about discomfort, similarly for three different mesh materials tested (smooth heavyweight, rigid ultra heavyweight, lightweight). There was no significant difference in the hernia recurrence rate in the long-term comparison between HM and LM.

\section{Discussion}

It is hardly possible to make a best treatment recommendation because the clinical studies do not accurately assess the value of medical devices. To this effect, we have to consider a huge variety of modifications (advantages of some slight changes, e.g., thinner filaments may be demonstrable only in nonclinical settings), a long delay of some device-related complications (e.g., infection, migration), the variable individual response with increased risk in yet insufficiently defined subgroups (e.g., collagen formation, intra-abdominal adhesions), and not least many confounders that make it difficult to associate clearly an outcome with a device.

In view of to these limitations of clinical studies and RCTs, any recommendation has to consider experimental results as basic evidence (see author's comment). Therefore, when comparing medical devices, the absence of any statistically significant differences in RCTs (Levels A-B) does not mean that a proper selection of a device will not be beneficial, but a negative result in a study rather expresses the principally limited power of clinical studies.

\section{Authors' comment}

Even if experimental studies and experts' opinions are to be allocated an evidence Level 5, their results cannot be 
Fig. 1 Study design of the prospective comparison of the postoperative quality of life after light mesh, extra light mesh, and heavy mesh implants with TAPP [1]

Fig. 2 Prospective, double blind study to compare the quality of life concerning heavy mesh, extra heavy mesh, and light mesh implants in TAPP [2]

Fig. 3 Long-term study with a 5-year follow-up to compare the quality of life and recurrence rate for smooth heavy mesh (HM), rigid ultra heavy mesh (UHM), and light mesh implants (LM) bei TAPP [3]

Fig. 4 Design of the 2-arm studies to compare the early results 8 weeks postoperatively for heavy versus light mesh implants in TEP technique at bilateral hernia repair [4] and at unilateral recurrent hernias [5]
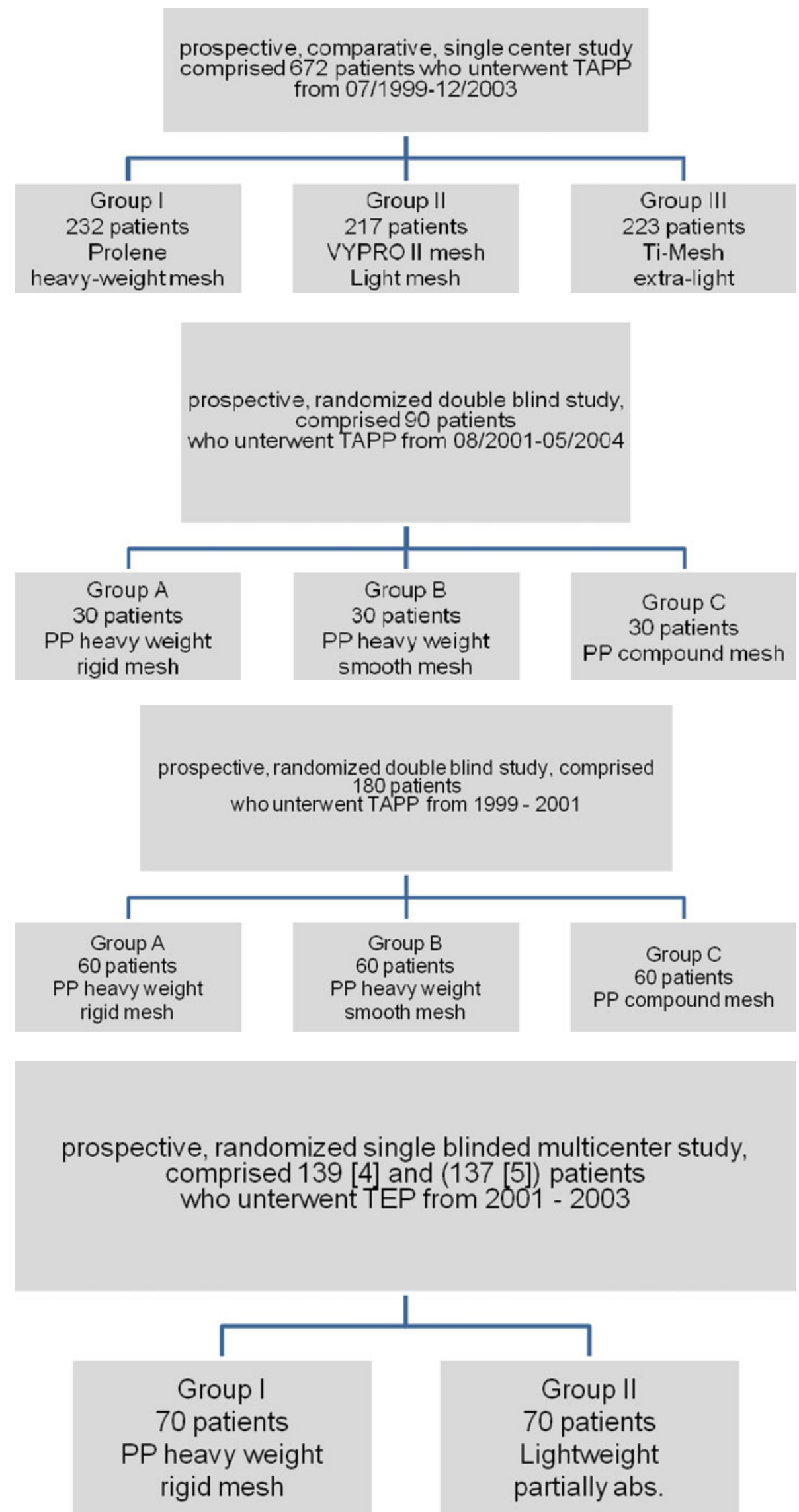
Fig. 5 Study design of the Agarwal study with 12 months of follow-up [6]

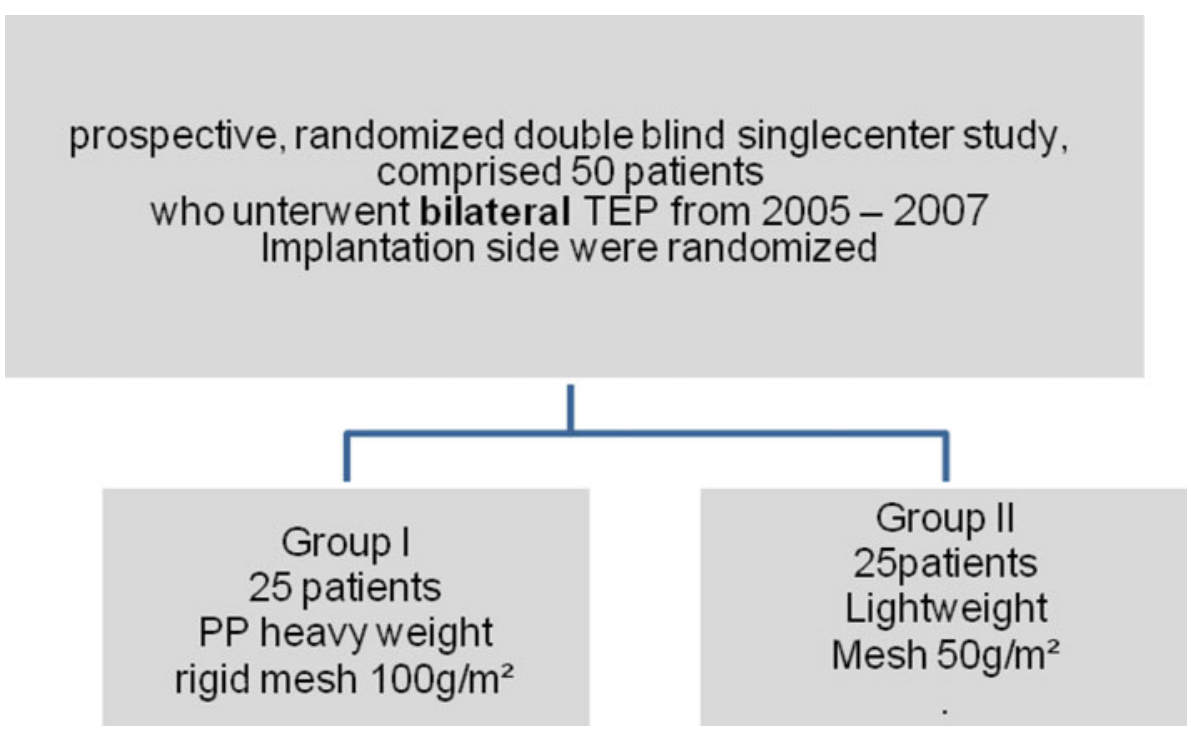

ignored. The summarized findings of these articles are listed consecutively and taken into account in the following recommendation:

1. The older generation of polypropylene mesh is oversized with regard to the mechanical properties.

2. Bigger pore size improves the integration into the tissue and also preserves a high degree of elasticity and stability in the implant matrix.

3. Monofilament meshes have a lower infection potential.

The authors' recommendations are based on three textile design construction parameters (Table 3 ). The implant weight parameter alone is unsuitable and, hence, is modified by the structural parameter: pore size. Usual meshes with small pores $<1 \mathrm{~mm}$ are "heavy" weight $\left(>60 \mathrm{~g} / \mathrm{m}^{2}\right)$, whereas those with large pores are "low" weight. However, there are no precisely defined limits, there are some meshes with low weight but small pores (e.g., Mersilene), and some heavyweight polymers despite large pores (e.g., made of PVDF). Because porosity is more difficult to measure than weight, the term most often used by manufacturers is "weight," and therefore, this is used in this text too.

The hernia repair in the TAPP/TEP technique using a monofilament implant with a pore size of at least $1.0-1.5 \mathrm{~mm}$ (usually meaning low weight) consisting of a minimum tensile strength in all directions (including subsequent tearing force) $>16 \mathrm{~N} / \mathrm{cm}$ appears to be most advantageous, summarizing personal and published clinical and experimental experiences (Figs. 1, 2, 3, 4, 5).

References (in parentheses graduation of evidence)

1. Horstmann R, Hellwig M, Classen C, Röttgermann S, Palmes D (2006) Impact of polypropylene amount on functional outcome and quality of life after inguinal hernia repair by the TAPP procedure using pure, mixed and titanium coated meshes. World J Surg 30:1742-1749. [2B]
2. Langenbach MR, Schmidt J, Zirngibl H (2006) Comparison of biomaterials:three meshes and TAPP for inguinal hernia. Surg Endosc 20:1511-1117. [1B]

3. Langenbach MR, Schmidt J, Ubrig B, Zirngibl H (2008) Sixty-month follow- up after endoscopic inguinal hernia repair with three types of mesh: a prospective randomized trial. Surg Endosc 22:1790-1797. [1B]

4. Bringmann S, Wollert S, Osterberg J, Heikkinen T (2005) Early results of a randomized multicenter trial comparing Prolene and Vypro II mesh in bilateral endoscopic extraperitoneal hernioplast (TEP). Surg Endosc 19:536-540. [1B]

5. Heikkinen T, Wollert S,.Österberg J, Smedberg S (2006) Early results of a randomized trial comparing Prolene and Vypro II mesh in endoscopic extraperitoneal inguinal hernia repair (TEP) of recurrent unilateral hernias. Hernia 10:34-40. [1B]

6. Agarwal BB, Agarwal KA, Mahajan KC (2009) Prospective double- blind randomized controlled study comparing heavy- and lightweight polypropylene mesh in totally extraperitoneal repair of inguinal hernia: early results. Surg Endosc 23:242-247. [1B]

Chapter 8: Cutting or not cutting of mesh: does it influence the recurrence rate?

Thue Bisgaard, Jacob Rosenberg

\section{Copenhagen, Denmark}

Search terms: "mesh"; "inguinal hernia"; "cutting"; "slit"

Should the mesh have a slit or not to surround the spermatic cord? 


\section{Statements}

Level 3 Cutting a slit in the mesh to allow the structures of the funicle to pass through the mesh may be a risk factor for recurrence after laparoscopic inguinal hernia repair.

Level 1B An intact mesh does not produce more postoperative complications or higher risk of recurrences compared with a cut mesh.

\section{Recommendations}

Grade B

We recommend not to cut a slit in the mesh.

A systematic literature search was performed in PubMed covering the period 1966 to January 2009. Papers in English, German, and French were accepted. Only human studies were included.

We identified one randomized trial [1]. In this threearmed study, including 360 patients, a TAPP procedure was performed. In group $\mathrm{A}$, the mesh was implanted through a central incision, creating a deep inguinal ring by overlapping the two incised sides. In groups $\mathrm{B}$ and $\mathrm{C}$, a non-incised mesh was used, which was fixed with staples in group B and with nonresorbable sutures in group C. The authors reported no significant differences between the groups regarding operation times, postoperative complaints, and need for pain killers. Furthermore, they found only one recurrence in group $\mathrm{C}$ (no recurrences in groups $\mathrm{A}$ and $\mathrm{B}$ ).

Moreover, we found one comparative study with historical controls [2], including 2,700 TAPP procedures from a single institution. After a median follow-up time of 26 months, there were 28 recurrences, $9(0.3 \%)$ of which were due to insufficient closure of the mesh slit. From the same institution, a later prospective study involving 8,050 procedures without slit in the mesh reported an overall recurrence rate of $0.4 \%$ [3].

Thus, there is no evidence to support use of a slit in the mesh for laparoscopic inguinal hernia repair. One study found some of the recurrences to be associated with insufficient closure of the mesh slit. This could argue against slitting the mesh at all.

\section{Comprehensive comments}

Routinely, we do not cut a slit in the mesh, because it does not bring any technical advantage for the surgeon or better clinical results for the patient.

References (in parentheses graduation of evidence)

1. Leibl BJ, Kraft B, Redecke JD, Schmedt CG, Ulrich M, Kraft K, Bittner R (2002) Are postoperative complaints and complications influenced by different techniques in fashioning and fixing the mesh in transperitoneal laparoscopic hernioplasty? Results of a prospective randomized trial. World J Surg 26:1481-1484. (2B)

2. Leibl BJ, Schmedt C-G, Schwarz J et al. (1998) A single institution's experience with transperitoneal laparoscopic hernia repair. Am J Surg 175:446-452. (2C)
3. Bittner R, Schmedt CG, Schwarz J, Kraft K, Leibl BJ (2002) Laparoscopic transperitoneal procedure for routine repair of groin hernia. $\mathrm{Br} \quad \mathrm{J}$ Surg 89:1062-1066. (2B)

\section{Chapter 9: Mesh fixation modalities: is there an association with acute or chronic pain?}

Esther Kuhry, Agneta Montgomery, Wolfgang

Reinpold, Rene Fortelny

Is it necessary to fixate the mesh in endoscopic inguinal hernia repair?

What kind of fixation is to be preferred?

Is type of fixation associated with acute and chronic pain?

Search terms: "Surgical Mesh (MeSH)" AND "Surgical fixation device" (MeSH) AND "Inguinal Hernia" (MeSH); "fixation AND mesh AND TEP"; "fixation AND mesh AND TAPP"; "TAPP AND pain"; "TEP AND pain"; "groin hernia AND pain"; "inguinal hernia AND pain"

\section{Statements}

Level 1B Fixation and nonfixation of the mesh are associated with equally low recurrence rates in both TAPP and TEP; however, in most studies the hernia opening was small $(<3 \mathrm{~cm})$ or not measured.

Staple fixation is associated with a higher risk of acute and chronic pain compared with nonfixation.

Fixation is more expensive than nonfixation.

Fibrin glue is associated with low recurrence rates.

Fibrin glue is associated with less acute and chronic pain than stapling.

Level 5 Fibrin glue is less expensive than most stapling devices.

\section{Recommendations}

Grade B If TAPP or TEP techniques are used, nonfixation could be considered in types LI, II, and MI, II hernias (EHS classification).

For fixation, fibrin glue should be considered to minimize the risk of postoperative acute and chronic pain.

Grade D For TAPP and TEP repair of big direct defects (LIII, MIII), the mesh should be fixated; however, fixation does not compensate for inadequate mesh size or overlap.

\section{Introduction}

Recurrence after surgery for primary inguinal hernia occurs after approximately $2 \%$ of both open and endoscopic procedures at specialized centres [1]. Several recurrence factors have been identified, such as mesh or no mesh, mesh size, hernia type, and surgeon's volume of procedures [2]. Most studies on this issue were performed in patients who underwent open surgery.

Acute and chronic pain, defined as pain lasting for 3 months or more [3], after inguinal hernia surgery has 
Table 1 Fixation versus nonfixation of the mesh in endoscopic inguinal hernia repair: recurrence

\begin{tabular}{|c|c|c|c|c|c|}
\hline \multirow[t]{2}{*}{ Study } & \multirow[t]{2}{*}{ Follow-up } & \multirow[t]{2}{*}{ Type of repair } & \multicolumn{2}{|c|}{ Recurrence } & \multirow[t]{2}{*}{ Level of evidence } \\
\hline & & & Fixation & No fixation & \\
\hline Taylor et al. (2008) [11] & $8(6-13)$ months $^{\mathrm{a}}$ & TEP & $1 / 247$ & $0 / 253$ & $1 b$ \\
\hline Smith et al. (1999) [18] & $16(1-32)$ months $^{\mathrm{a}}$ & TAPP & $3 / 273$ & $0 / 263$ & $1 b$ \\
\hline Moreno-Egea et al. (2004) [17] & $36 \pm 12$ months $^{\mathrm{b}}$ & TEP & $0 / 118$ & $3 / 111$ & $1 b$ \\
\hline Koch et al. (2006) [15] & $19(6-30) \mathrm{mo}^{\mathrm{b}}$ & TEP & $0 / 20$ & $0 / 20$ & $2 b$ \\
\hline Ferzli et al. (1999) [19] & 8 months $^{\mathrm{c}}$ & TEP & $0 / 50$ & $0 / 50$ & $2 b$ \\
\hline Garg et al. (2008) [21] & 17 (6-40) months ${ }^{\mathrm{d}}$ & TEP & $1 / 61$ & $2 / 1692$ & $3 b$ \\
\hline Lau et al. (2003) [26] & 1 year $^{\mathrm{c}}$ & TEP & $0 / 100$ & $0 / 100$ & $3 b$ \\
\hline Khajanchee et al. (2001) [27] & $15(1-23)$ months $^{\mathrm{d}}$ & TEP & $2 / 67$ & $4 / 105$ & $3 b$ \\
\hline Morrison et al. (2008) [30] & $89 \% 1$ year & TEP & - & $1 / 157$ & 4 \\
\hline Tamme et al. (2003) [40] & Not specified & TEP & - & $29 / 5203$ & 4 \\
\hline Kapiris et al. (2001) [28] & Not specified & TAPP & & $22 / 3868$ & 4 \\
\hline Beattie et al. (2000) [42] & Not specified & TEP & - & $0 / 89$ & 4 \\
\hline Spitz et al. (2000) [43] & Not specified & TEP & - & $0 / 203$ & 4 \\
\hline \multirow[t]{2}{*}{ Summary } & & & $7 / 936$ & $61 / 12114$ & \\
\hline & & & $0.7 \%$ & $0.5 \%$ & \\
\hline
\end{tabular}

${ }^{\mathrm{a}}$ Median (range); ${ }^{\mathrm{b}}$ mean $\pm \mathrm{SD} ;{ }^{\mathrm{c}}$ mean; ${ }^{\mathrm{d}}$ mean (range)

emerged as a key issue in the literature. Reported chronic pain rates after groin hernia repair vary from 0 to $75.5 \%$ $[1,3-8]$. Overall, moderate to severe pain was experienced by $10-12 \%$ of the patients. In this respect, operations performed endoscopically seem to be more favorable than both nonmesh and mesh open technique operations [9, 10]. Apparently, the use of mesh reduces the risk of chronic pain [11]. After the introduction of the endoscopic hernia surgery, mesh fixation was thought to be mandatory to avoid dislocation of the mesh and recurrences. Permanent fixation with tacks, staples, or sutures was used. The perplexing problem of chronic pain after endoscopic hernia surgery raised the question of whether fixation is really necessary. Nerve entrapment and pain caused by shrinkage of the mesh due to scar tissue formation have been suggested as possible causes. The technique of nonfixation or temporary fixation using glue is increasingly used to solve the pain problem.

It is unclear whether nonfixation increases recurrence rates, especially in large defects, or decreases chronic pain. When fixation may be indicated, it is not clear which method of fixation should be recommended. Indications for fixation may be different for totally extraperitoneal (TEP) repair and transabdominal preperitoneal (TAPP) repair or for direct and indirect hernias.

A total of 33 studies, described in 34 different articles [11-44], were included in this review. The number of patients included in each study varied widely. In most of the studies comparing fixation to nonfixation, a TEP repair was performed.

\section{Fixation or nonfixation of the mesh}

Permanent fixation using tacks, staplers, or anchors is compared with no fixation at all in terms of recurrence, acute pain, chronic pain, and costs. There are no studies comparing nonfixation with fibrin fixation for open or endoscopic hernia repair. A total of 16 studies were identified. Case series where fixation was used in all patients were not included.

\section{Recurrence}

Recurrences after fixation versus nonfixation are reported in Table 1. Five randomized, controlled trials (RCTs) [11, 15, 17-19], four case-controlled studies comparing fixation versus nonfixation [21, 26, 27, 29], and five case series on nonfixation $[28,30,40,42,43]$ were identified.

Only one study with a $1 \mathrm{~b}$ evidence level compared fixation versus nonfixation in TAPP repair [18] and found no significant differences in the incidence of recurrence between fixated and nonfixated repairs. However, the majority of hernia defects in this trial were smaller than $2 \mathrm{~cm}$.

In total, seven studies have compared fixation versus nonfixation in TEP, of which only two have $1 \mathrm{~b}$ evidence level. They did not discover any difference in the incidence of recurrence between fixated versus nonfixated mesh [11, 17]. Three of the case series used selective mesh fixation. Saggar and Sarangi [29] retrospectively analyzed 822 TEP reconstructions and demonstrated a $0.7 \%$ recurrence rate. The mesh was fixated in only 28 hernias with large defects. Kapiris et al. [28] demonstrated 1\% recurrences in 104 TAPP reconstructions. The mesh was fixated in only nine hernias with large defects in this study. 
Table 2 Fixation versus nonfixation of the mesh: chronic pain

\begin{tabular}{|c|c|c|c|c|c|c|}
\hline \multirow[t]{2}{*}{ Study } & \multirow[t]{2}{*}{ Pain score } & \multirow[t]{2}{*}{ Repair } & \multicolumn{2}{|l|}{ Pain } & \multirow[t]{2}{*}{$P$-value } & \multirow[t]{2}{*}{ Level of evidence } \\
\hline & & & Fixation & No fixation & & \\
\hline Taylor et al. (2008) [11] & Cunningham & TEP & $\uparrow$ & $\downarrow$ & 0.0003 & $1 b$ \\
\hline Smith et al. (1999) [18] & Not specified & TAPP & $=$ & $=$ & - & $1 b$ \\
\hline Moreno-Egea et al. (2004) [17] & VAS (24 mo) & TEP & $=$ & $=$ & 0.75 & $1 b$ \\
\hline Koch et al. (2006) [15] & Likert scale (9 mo) & TEP & $=$ & $=$ & 0.15 & $2 b$ \\
\hline
\end{tabular}

Table 3 Recurrences after fixation with staples versus fixation with fibrin glue

\begin{tabular}{|c|c|c|c|c|c|}
\hline \multirow[t]{2}{*}{ Study } & \multirow[t]{2}{*}{ Follow-up } & \multirow[t]{2}{*}{ Type of repair } & \multicolumn{2}{|l|}{ Recurrence } & \multirow[t]{2}{*}{ Level of evidence } \\
\hline & & & Stapling device & Fibrin glue & \\
\hline Olmi et al. (2007) [13] & 26 months $^{\mathrm{a}}$ & TAPP & $0 / 581$ & $0 / 222$ & $1 b$ \\
\hline Lau et al. (2005) [44] & 1.2 years $^{\mathrm{a}}$ & TEP & $0 / 94$ & $0 / 92$ & $1 b$ \\
\hline Lovisetto et al. (2007) [14] & 11.7 months & TAPP & $0 / 98$ & $1 / 99$ & $1 b$ \\
\hline Ceccarelli et al. (2008) [20] & $19(4-40)$ months $^{\mathrm{b}}$ & TAPP & $0 / 87$ & $0 / 83$ & $3 b$ \\
\hline Santoro et al. (2007) [22] & $13.2(5-24)$ months $^{\mathrm{b}}$ & TAPP & $0 / 245$ & $0 / 250$ & $3 b$ \\
\hline Schwab et al. (2006) [23] & $23.7(11-47)$ months $^{\mathrm{b}}$ & TEP & $5 / 87$ & $2 / 86$ & $3 b$ \\
\hline Novik al (2006) [24] & $1,16,40 \mathrm{mo}$ & TEP & $0 / 96$ & $0 / 9$ & $3 b$ \\
\hline Topart et al. (2005) [25] & $\begin{array}{l}28.3 \pm 10.9 \text { months }^{\mathrm{b}} \\
23.9 \pm 11.3 \text { months }^{\mathrm{b}}\end{array}$ & TEP & $3 / 117$ & $1 / 81$ & $3 b$ \\
\hline \multirow[t]{2}{*}{ Total } & & & $8 / 1405$ & $4 / 922$ & \\
\hline & & & $0.6 \%$ & $0.4 \%$ & \\
\hline
\end{tabular}

${ }^{\mathrm{a}}$ Median; ${ }^{\mathrm{b}}$ mean (range)

Table 4 Acute pain after fixation with staples versus fixation with fibrin glue

\begin{tabular}{llllll}
\hline Study & Repair & Acute pain & & $P$-value & Level of evidence \\
\cline { 3 - 6 } & & Staples & Fibrin glue & & n.s. \\
\hline Lau et al. (2005) [44] & TEP & $=$ & $=$ & $<0.05$ & $1 \mathrm{~b}$ \\
Olmi et al. (2007) [13] & TAPP & $\uparrow$ & $\downarrow$ & $<0.05$ & $1 \mathrm{~b}$ \\
Boldo et al. (2008) [12] & TAPP & $\uparrow$ & $\downarrow$ & $\mathrm{b}$ \\
\hline
\end{tabular}

In total, 12,114 hernia repairs were performed without fixation in all studies combined. The recurrence rate was 61 $(0.5 \%)$, which is comparable to the recurrence rate of 7 of $936(0.7 \%)$ after fixation.

\section{Acute and chronic pain}

There are only one small RCT $(N=20)$ and one cohort study $(N=509)$, both with a 2 b evidence level, that compare acute pain after stapler fixation versus nonfixation $[15,44]$. Significantly more acute pain is found after stapling compared with nonfixation in the cohort study, whereas the RCT shows no differences between fixation and nonfixation with respect to acute pain.

Chronic pain after fixation versus nonfixation is reported in Table 2. Four RCTs included data on chronic pain after fixation versus nonfixation $[11,15,17,18]$. A total of 1,072 patients were involved in these studies, which all used 8 different scales for pain scoring. A significant difference was demonstrated only in one large study, in which fixation was associated with a significant increase in chronic pain [11].

\section{Costs}

Costs are analyzed in three RCTs. In only one study, Moreno-Egea et al. [17] performed a cost-analysis, which included not only the costs for endoscopic equipment but also for hospitalization and surgery (including anaesthesia, time spent in the operating room, and materials). For fixation of the mesh, they found a mean increase in costs of $\$ 517$, mainly due to the costs of a stapling device. Ferzli et al. [19] reported a net saving of $\$ 120$ when the operation was performed without fixation and Taylor et al. [11] a net saving of $\$ 245$. 
Table 5 Chronic pain after fixation with staples versus fixation with fibrin glue

\begin{tabular}{lllllll}
\hline Study & Pain score & Repair & Chronic pain & & $P$-value & Level of evidence \\
\cline { 5 - 7 } & & & Stapling device & Fibrin glue & \\
\hline Lau et al. (2005) [44] & Linear scale & TEP & $=$ & $=$ & n.s. & $1 \mathrm{~b}$ \\
Lovisetto et al. (2007) [14] & VAS (6 mo) & TAPP & $\uparrow$ & $\downarrow$ & $<0.001$ & $1 \mathrm{~b}$ \\
Boldo et al. (2008) [12] & VAS (1 week) & TAPP & $=$ & $=$ & n.s. & $2 \mathrm{~b}$ \\
Topart et al. (2005) [25] & Chronic pain & TEP & $\uparrow$ & $\downarrow$ & 0.037 & $3 \mathrm{~b}$ \\
Schwab et al. (2006) [23] & Chronic pain & TEP & $\uparrow$ & $\downarrow$ & 0.002 & $3 \mathrm{~b}$ \\
Ceccarelli et al. (2008) [20] & Chronic pain & TAPP & $=$ & $=$ & n.s. & $3 \mathrm{~b}$ \\
\hline
\end{tabular}

\section{Type of fixation}

The following methods for fixation were used in the included studies: different types of permanent fixation devices (tacks, staples, and anchors), sutures, I-clips, fibrin glue, and autologous fibrin. Altogether, 17 studies were identified: 4 RCTs, 5 case-controlled studies, and 8 case series.

Two small studies have been published on the use of autologous fibrin: a small RCT in 22 patients that compared staples to autologous fibrin [12] and one case series that included 10 patients [37]. No reliable conclusions can be made based on these small studies.

One case series focused on the use of I-Clips (resorbable clips) to secure the mesh [31] and another on the use of sutures [39]. Additional studies are needed before any conclusions can be drawn regarding the use of these fixation techniques.

\section{Staples versus fibrin glue \\ Recurrence}

Recurrences after fixation with staples versus fixation with fibrin glue are reported in Table 3. Three RCTs and five case-control studies were found, including a total of 2,327 patients $[13,14,16,20,22-25]$. The recurrence rate was $0.6 \%$ in the stapled group and $0.4 \%$ in the fibrin glue group. One of the RCTs compared different types of stapling devices, e.g., spiral tacks, conventional staples, anchor-shaped devices, and fibrin glue [13].

Five case series were found [32-34, 36, 38], including a total of 460 hernia operations with fibrin glue fixation. Only one recurrence is reported with a minimum follow-up of 1 year. Three of the studies were performed on TAPP, one on TEP, and one on an intraperitoneal onlay mesh (IPOM).

\section{Acute and chronic pain}

Acute pain after fixation with staples versus fixation with fibrin glue is reported in Table 4. Three studies described acute postoperative pain. In the study by Boldo [12], autologous fibrin glue was used. Two of three studies reported significantly less acute pain after fibrin glue compared with stapled fixation.
Chronic pain after fixation with staples versus fixation with fibrin glue is reported in Table 5. Six of the studies comparing staples and fibrin glue for fixation reported chronic pain [12, 13, 20, 23, 25, 44]. Four of six studies found significantly less chronic pain in patients in whom the mesh was fixated with fibrin glue compared with patients in whom the mesh was fixated using staples [13, 23, 25, 44]. Costs

We did not find any publication that addressed this specific issue. Most studies agreed that stapling devices are more costly than fibrin glue, depending on the amount of fibrin glue used.

References (in parentheses graduation of evidence)

1. McCormack K, Scott NW, Go PM, Ross S, Grant AM (2000) Laparoscopic techniques versus open techniques for inguinal hernia repair. Cochrane Database Syst Rev 4:CD001785. doi:10.1002/1465 1858.CD001785 (1A)

2. Nordin P, van der Linden W (2008) Volume of procedures and risk of recurrence after repair of groin hernia: national register study. BMJ 336(7650): 934-937. (4)

3. Aasvang E, Kehlet H (1986) Classification of chronic pain. Descriptions of chronic pain syndromes and definitions of pain terms. Prepared by the International Association for the Study of Pain. Subcommittee on Taxonomy. Pain Suppl 3:S1-S226 (5)

4. Aasvang E, Kehlet H (2005) Chronic postoperative pain: the case of inguinal herniorrhaphy. BJA 95:69-76. (4)

5. Alfieri et al. (2006) Chronic pain after inguinal hernia mesh repair: possible role of surgical manipulation of the inguinal nerves. A prospective multicentre study. Chir Ital 58:23-31. (4)

6. Amid PK (2004) Causes, prevention, and surgical management of postherniorrhaphy neuropathic inguinodynia: triple neurectomy with proximal end implantation. Hernia 8:342-349. (5)

7. Cunningham J, Temple WJ, Mitchell P, Nixon J, Preshaw R, Hagen N (1996) Cooperative hernia 
study. Pain in the postrepair patient. Ann Surg 224:598-602. (4)

8. EU Hernia Trialists Collaboration (2002) Repair of groin hernia with synthetic mesh: meta-analysis of randomized controlled trials. Ann Surg 235:322-332. (1A)

9. Bittner R, Sauerland S, Schmedt CG (2005) Comparison of endoscopic techniques versus Shouldice and other open nonmesh techniques for inguinal hernia repair: a meta-analysis of randomized controlled trials. Surg Endosc 19:605-615. (1A)

10. Schmedt CG, Sauerland S, Bittner R (2005) Comparison of endoscopic procedures vs Lichtenstein and other open mesh techniques for inguinal hernia repair: a meta-analysis of randomized controlled trials. Surg Endosc 19:188-189. (1A)

11. Taylor C, Layani L, Liew V, Ghusn M, Crampton N, White S (2008) Laparoscopic inguinal hernia repair without mesh fixation: early results of a large randomised clinical trial. Surg Endosc 22:757-762 (1B)

12. Boldo E (2008) Pain after laparoscopic bilateral hernioplasty: early results of a prospective randomized double-blinded study comparing fibrin versus staples. Surg Endosc 22:1206-1209 (2B)

13. Olmi S, Scaini A, Erba L, Guaglio M, Groce E (2007) Quantification of pain in laparoscopic transabdominal preperitoneal (TAPP) inguinal hernioplasty identifies marked differences between prothesis fixation systems. Surgery 142:40-46 (1B)

14. Lovisetto F, Zonta S, Rota E, Mazzilli M, Bardone M, Bottero L, Faillace G, Longoni M (2007) Use of human fibrin glue (Tissucol) versus staples for mesh fixation in laparoscopic transabdominal preperitoneal hernioplasty: a prospective, randomized study. Ann Surg 245:222-231 (1B)

15. Koch CA, Greenlee SM, Larson DR, Harrington JR, Farley DR (2006) Randomized prospective study of totally extraperitoneal inguinal hernia repair: fixation versus no fixation of mesh. JSLS 10:457-460 (2B)

16. Lau H (2005) Fibrin sealant versus mechanical stapling for mesh fixation during endoscopic extraperitoneal inguinal hernioplasty: a randomized prospective trial. Ann Surg 242:670-675 (1B)

17. Moreno-Egea A, Torralba Martinez JA, Morales Cuenca G, Aguayo Albasini JL (2004) Randomized clinical trial of fixation vs nonfixation of mesh in total extraperitoneal inguinal hernioplasty. Arch Surg 139:1376-1379 (1B)

18. Smith AI, Royston CM, Sedman PC (1999) Stapled and nonstapled laparoscopic transabdominal preperitoneal (TAPP) inguinal hernia repair. A prospective randomized trial. Surg Endosc 13:804-806 (1B)
19. Ferzli GS, Frezza EE, Pecoraro AM Jr, Ahern KD (1999) Prospective randomized study of stapled versus unstapled mesh in a laparoscopic preperitoneal inguinal hernia repair. J Am Coll Surg 188:462-465 (2B)

20. Ceccarelli G, Casciola L, Pisanelli MC, Bartoli A, Di Zitti L, Spaziani A, Biancafarina A, Stefanoni M, Patriti A (2008) Comparing fibrin sealant with staples for mesh fxation in laparoscopic transabdominal hernia repair: a case-control study. Surg Endosc 22:668-673 (3B)

21. Garg P, Rajagopal M, Varghese V, Ismail M (2009) Laparoscopic total extraperitoneal inguinal hernia repair with nonfixation of the mesh for 1692 hernias. Surg Endosc 23:1241-1245 (3B)

22. Santoro E, Agesta F, Buscaglia F, Muglieri G, Mazzarolo G, Bedin N, Mulieri M (2007) Preliminary experience using fibrin glue for mesh fixation in 250 patients undergoing minilaparoscopic transabdominal preperitoneal hernia repair. J Laparoendosc Adv Surg Tech A 17:12-15 (3B)

23. Schwab R, Willms A, Kroger A, Becker HP (2006) Less chronic pain following mesh fixation using a fibrin sealant in TEP inguinal hernia repair. Hernia 10:272-277 (3B)

24. Novik B, Hagedorn S, Mork UB, Dahlin K, Skullman $S$ (2006) Fibrin glue for securing the mesh in laparoscopic totally extraperitoneal inguinal hernia repair: a study with a 40-month prospective follow-up period. Surh Endosc 20:462-467 (3b)

25. Topart P, Vanderbroucke F, Lozach P (2005) Tisseel versus tack staples as mesh fixation in totally extraperitoneal laparoscopic repair of groin hernias: a retrospective analysis. Surg Endosc 19:724-727 (3B)

26. Lau H, Patil NG (2003) Selective non-stapling of mesh during unilateral endoscopic total extraperitoneal inguinal hernioplasty: a case-control study. Arch Surg 138:1352-1355 (3B)

27. KhajancheeYS, Urbach DR, Swanstrom LL, Hansen PD (2001) Outcomes of laparoscopic herniorrhaphy without fixation of mesh to the abdominal wall. Surg Endosc 15:1102-1107 (3B)

28. Kapiris S, Mavromatis T, Andrikopoulos S, Georgiades C, Floros D, Diamantopoulos G (2009) Laparoscopic transabdominal preperitoneal hernia repair (TAPP): stapling the mesh is not mandatory. J Laparoendosc Adv Surg Tech A Apr 27 (Epub ahead of print) (4)

29. Saggar VR, Sarangi R (2008) Laparoscopic totally extraperitoneal repair of inguinal hernia: a policy of selective mesh fixation over a 10-year period. J Laparoendosc Adv Surg Tech A 18:209-212 (4) 
30. Morrison JE Jr, Jacobs VR (2008) Laparoscopic preperitoneal inguinal hernia repair using preformed polyester mesh without fixation: prospective study with 1-year follow-up in a rural setting. Surg Laparosc Endosc Percutan Tech 18:33-39 (4)

31. Lepere M, Benchetrit S, Bertrand JC, Chalbet JY, Combier JP, Detruit B, Herbault G, Jarsaillon P, Lagoutte J, Levard H, Rignier P (2008) Laparoscopic resorbable mesh fixation. Assessment of an innovative disposable instrument delivering resorbable fixation devices: I-Clip ${ }^{\mathrm{TM}}$. Final results of a prospective multicentre clinical trial. Hernia 12: 177-183 (4)

32. Fortelny RH, Schwab R, Glaser KS, Puchner KU, May C, Koning F, Redl H, Petter-Pucher AH (2008) The assessment of quality of life in a trial on light weight mesh fixation with fibrin sealant in transabdominal preperitoneal hernia repair. Hernia 12:499-505 (4)

33. Olmi S, Scaini A, Erba L, Bertolini A, Croce E (2007) Laparoscopic repair of inguinal hernias using an intraperitoneal online mesh technique and a Parietex composite mesh fixed with fibrin glue (Tissucol). Personal technique and preliminary results. Surg Endosc 21:1961-1964 (4)

34. Olmi S, Erba L, Bertolini A, Scaini A, Croce E (2006) Fibrin glue for mesh fixation in laparoscopic transabdominal preperitoneal (TAPP) hernia repair: indications, technique, and outcomes. Surg Endosc 20:1846-1850 (4)

35. Olmi S, Erba L, Bertolini A, Scaini A, Mastropasqua E, Conti M, Croci E (2005) Use of fibrin glue (Tissucol) for mesh fixation in laparoscopic transabdominal hernia repair. Chir Ital 57:753-759 (4)

36. Fine AP (2006) Laparoscopic repair of inguinal hernia using Surgisis mesh and fibrin sealant. JSLS 10:461-465 (4)

37. Schmidt SC, Langrehr JM (2006) Autologous fibrin sealant (Vivostat) for mesh fixation in laparoscopic transabdominal preperitontoneal hernia repair. Endoscopy 38:841-844 (4)

38. Langrehr JM, Schmidt SC, Neuhaus P (2005) Initial experience with the use of fibrin sealant for the fixation of the prosthetic mesh in laparoscopic transabdominal preperitoneal hernia repair. Rozhl Chir 84:399-402 (4)

39. Golash V (2004) Technique of suturing the mesh in laparoscopic total extraperitoneal (TEP) repair of inguinal hernia. Surgeon 2:264-272 (4)

40. Tamme C, Scheidbach H, Hampe C, Schneider C, Köckerling F (2003) Totally extraperitoneal endoscopic inguinal hernia repair (TEP). Surg Endosc 17:90-95 (4)
41. Kapiris SA, Brough WA, Roystone CM, O'Boyle C, Sedman PC (2001) Laparoscopic transabdominal preperitoneal (TAPP) hernia repair. A 7-year twocenter experience in 3017 patients. Surg Endosc 15:972-975 (4)

42. Beattie GC, Kumar S, Nixon SJ (2000) Laparoscopic total extraperitoneal hernia repair: mesh fixation is unnecessary. J Laparoendosc Adv Surg Tech A 10:71-73 (4)

43. Spitz JD, Attegui ME (2000) Sutureless laparoscopic extraperitoneal inguinal herniorrhaphy using reusable instruments: two hundred three repair without recurrence. Surg Laparosc Endosc Percutan Tech 10:24-29 (4)

44. Lau H, Patil NG (2005) Acute pain after endoscopic totally extraperitoneal (TEP) inguinal hernioplasty: multivariate analyis of predictive factors. Ann Surg 242:670-675 (2B)

\section{Chapter 10: Risk factors and prevention of acute and chronic pain}

\section{W. Reinpold}

\section{Introduction}

It is well established that surgical injury can lead to chronic pain, which is defined as pain lasting for 3 months or more by the International Association for the Study of Pain (IASP) [1]. In the literature, chronic pain rates after groin hernia repair vary between $0 \%$ and $75.5 \%$ [1-9]. Overall, moderate-to-severe pain was experienced by $10-12 \%$ of patients. The use of mesh seems to reduce the risk of chronic pain [10]. After a mesh-based inguinal hernia repair, 11\% of the patients suffer from chronic pain, more than a quarter of these report moderate-to-severe pain [11].

\section{Methods}

The conclusions and recommendations for risk factors and prevention of acute and chronic pain after endoscopic hernia repair are based on a systematic review of the literature and a consensus conference for the development of technical guidelines in endohernia surgery, which was held in February 2009 in New Delhi, India, during the fourth meeting of the International Endohernia Society (IEHS).

Search terms: Pubmed, Medline, Embase, British Journal of Surgery database, Science Citation Index, and the Cochrane database were searched for studies on acute and chronic pain after endoscopic hernia repair. Search terms were "TEP" and "pain"; "TAPP" and "pain"; "groin hernia" and "pain"; "inguinal hernia" and "pain." Additionally experts in the field of endoscopic hernia repair were contacted. The levels of evidence and grades of the recommendation are based on the Oxford evidence-based medicine criteria [12]. 
Surgery-related risk factors have to be differentiated from those not related to surgery. Risk factors for acute and chronic pain after endoscopic groin hernia repair and recommendations for its prevention:

\section{Statements}

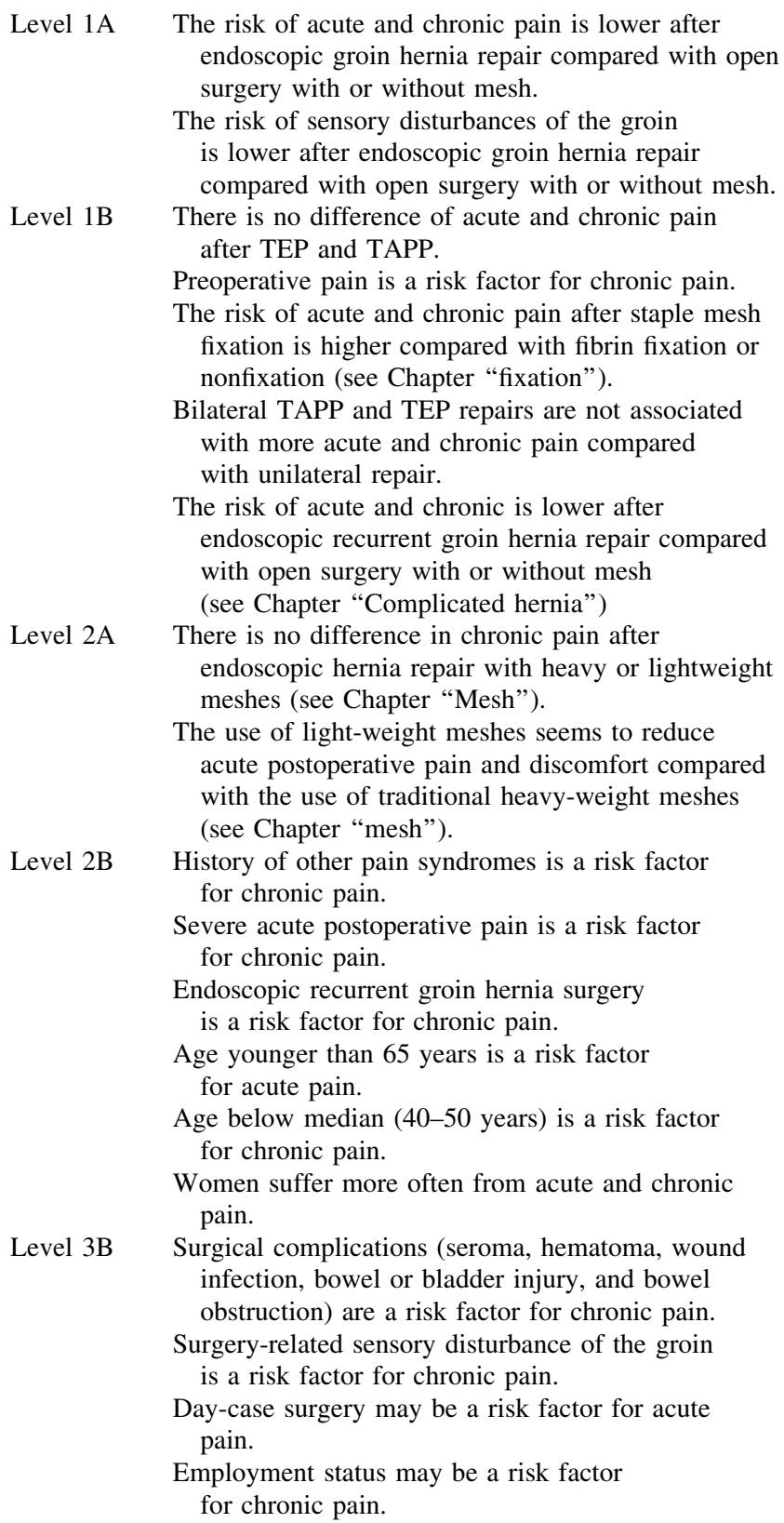

\section{Recommendations}

\footnotetext{
Grade A To reduce acute pain and the risk of chronic pain after inguinal hernia repair, the endoscopic techniques (TAPP and TEP) should be preferred to open mesh or nonmesh repair if expertise is present.

To reduce the risk of sensory disturbances of the groin after inguinal hernia repair, the endoscopic techniques (TAPP and TEP) should be preferred to open mesh or nonmesh repair if expertise is present.
}

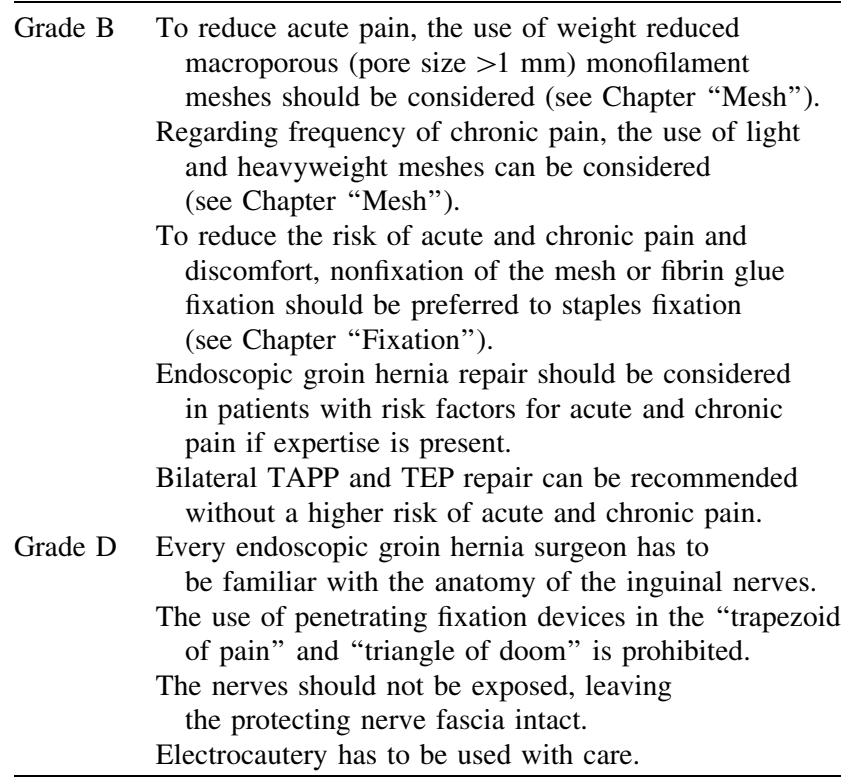

\section{Pain and sensory disturbances after endoscopic and open groin hernia repair}

According to Aasvang et al. [2], the overall incidence of chronic pain after open groin hernia repair is $18 \%$ (range, $0-75.5 \%$ ) and $6 \%$ after endoscopic repair (range, $1-16 \%$; $p<0.01)$

Eight systematic reviews published between 2001 and 2008 of which 7 included only prospective, randomized and quasirandomized trials concluded that endoscopic hernia repair is associated with less acute and chronic pain, less numbness, and a faster return to usual activities $[8,10$, $11,13-17]$. Four of these meta-analyses revealed statistically highly significant lower chronic pain rates $(p<0.001$ to $p<0.00001$ ), lower rates of numbness $(p<0.001$ to $p<0.00001$ ), and a highly significant faster return to normal activities $(p<0.001$ to $p<0.00001)$ after endoscopic hernia repair $[8,10,14,16]$. Only 2 of 58 controlled, randomized trials report more pain after endoscopic hernia repair. In a randomized, multicentric study of 390 patients comparing endoscopic and open groin hernia repair, Millat [18] found significantly more testicular pain 30 days after TEP and TAPP.

However, after a median follow-up of 2.5 years, there was no difference in chronic pain. In a prospective, randomized, controlled trial on 163 patients with a medium follow-up of 7.3 years, Hallen et al. [19] reported significantly more testicular pain $(p<0.003)$ after TEP versus open mesh repair. The analysis of quality adjusted life years favors endoscopic groin hernia repair [20]. A retrospective analysis by Hindmarsh et al. [21] showed that the attendance at a pain clinic with severe chronic pain was significantly more frequent after open inguinal hernia repairs. 


\section{Acute and chronic pain after TAPP and TEP repair}

Only two prospective, randomized trials with small patient numbers comparing both procedures have been published [22, 23]. Although Schrenk et al. [22] found less pain after TAPP on the operation day and day 1 after surgery $(p<0.02)$ without any difference later, Dedemadi et al. [23] reported no difference in pain at any time after surgery. A retrospective, multicentric comparison of 1,972 TAPP and TEP hernia repairs using polyester meshes found no difference in chronic pain with rates of 0.6 and $0.7 \%$ after TAPP and TEP respectively [24]. A systematic review of Wake et al. [25] comparing TAPP and TEP showed no difference in early and chronic pain. According to the present literature, there is no difference in acute and chronic pain after TAPP and TEP hernia repair.

\section{Preoperative pain and chronic pain}

Two review papers on chronic pain, which included publications on open and endoscopic repair [2, 15], reported that preoperative pain in the groin is a risk factor for chronic pain. In one controlled, randomized trial of 300 patients comparing laparoscopic and open groin hernia repair with a 5-year follow-up [26], preoperative pain was a significant risk factor for chronic pain $(p<0.001)$. A recent, prospective, nonrandomized trial on chronic pain after laparoscopic groin hernia repair [27], which included 881 patients with 1,029 hernias, found preoperative pain significantly associated with chronic pain $(p<0.001)$.

Two other large, prospective, nonrandomized trials on long-term pain $[28,29]$ with a follow-up of 81 and $72 \%$, respectively, which included 4,877 patients, the majority of whom had had an open hernia repair, showed that preoperative pain was significantly linked to long-term chronic groin pain $(p<0.001)$. In a retrospective, comparative study by Dennis and O'Riordan [30] on 24 patients with severe chronic pain after groin hernia repair, preoperative pain was a risk factor for chronic pain $(p<0.005)$.

Acute, chronic pain and discomfort and type of mesh: see Chapter "Selection of mesh material for TAPP and TEP"

Acute and chronic pain after nonfixation, glue, or stapler mesh fixation: see Chapter "Mesh fixation modalities in endoscopic inguinal hernia repair"

A history of nongroin hernia-related pain syndromes and chronic pain

Other preoperative chronic pain conditions not related to the groin are a risk factor for chronic postoperative groin pain. In one controlled, randomized trial comparing open and endoscopic hernia repair with a 5-year follow-up, other previous pain syndromes were a significant risk factor for chronic pain $(p<0.01)$ [26]. Two retrospective studies of patients with severe chronic postoperative groin pain mostly after open groin hernia repair are in accordance with these findings $[30,31]$.

\section{Severe early postoperative pain and chronic pain}

Whereas several publications have reported that severe early postoperative pain after groin hernia repair is significantly associated with chronic pain [15, 32], only a few publications are available on high acute pain rates and chronic pain after endoscopic hernia repair. In a randomized, controlled trial, Berndsen et al. [33] found that severe early postoperative pain was a risk factor for chronic pain after Shouldice repair but not after TAPP repair. However, two prospective, nonrandomized studies [34, 15] of 313 and 123 patients, respectively, reported that severe early postoperative pain was a significant risk factor for chronic pain after endoscopic hernia repair $(p<0.05$ and $p<0.03$, respectively).

\section{Recurrent groin hernia surgery and chronic pain}

Surgery for a recurrent hernia might be a risk factor for chronic pain. In a review, Poobalan et al. [15] found that surgery for a recurrent hernia was a risk factor for chronic pain. The exact number of endoscopic recurrent hernia repairs was not mentioned. A randomized, controlled trial by Liem et al. [36] did not confirm this finding. Four, large, prospective, nonrandomized trials are available on this issue [27, 32, 37, 38], but only two of these report exclusively on endoscopic recurrent hernia repair. Dickinson et al. [27] found significantly more chronic pain after a recurrence compared with primary endoscopic hernia repair $(p<0.02)$, Tantia et al. [38] reported no difference between primary and recurrent TAPP and TEP repair.

\section{Age and acute and chronic pain}

One prospective, nonrandomized study reported more acute pain after TEP repair in patients younger than age 65 years [39]. Nine studies identified age below median as a risk factor for chronic pain after groin hernia repair: one randomized controlled trial [26], five large prospective nonrandomized trials including the data of the Swedish and Danish hernia database [27-29, 40, 41], and three retrospective trials [31, 37, 42]. However, most of these trials include mainly patients after open hernia repair. Only one prospective, nonrandomized trial found that age younger than 50 years is a risk factor for chronic pain after endoscopic hernia repair $(p<0.001)$ [27].

\section{Acute and chronic pain after endoscopic hernia surgery} in women

The prospective, nonrandomized trial by Lau et al. [39] found significantly more acute pain in women after TEP repair. Two large prospective, nonrandomized trials by Bay-Nielsen et al. [40] and Kalliomäki et al. [29] of the Danish and Swedish hernia database identified female gender as a risk factor for chronic pain, but only a small fraction of the patient population had an endoscopic hernia repair. This finding was confirmed by a retrospective study by Sondenna et al. [43]. 
Surgical complications after groin hernia surgery and chronic pain

Two large, prospective, nonrandomized trials of the Danish and Swedish hernia database [28, 29], which included only a small number of endoscopic hernia repairs, identified surgical complications, such as seroma, wound infection, bowel or bladder injury, and bowel obstruction, as risk factors for chronic pain.

\section{Surgery-related sensory disturbances of the groin and} chronic pain

Chronic postoperative numbness and other sensory disorders of the groin were identified as risk factors for chronic pain in one retrospective trial $(p<0.001)$ [37].

\section{Employment status and chronic pain}

In one case control study [44] and one retrospective cohort study [42], patients who received workers' compensation and employed patients suffered significantly more often from chronic pain.

\section{Day-case surgery and acute pain}

In one prospective, nonrandomized trial, day-case surgery was identified as a risk factor for acute postoperative pain [39].

Bilateral endoscopic groin hernia surgery and acute and chronic pain

According to one systematic review by Pfeffer et al. [45], bilateral endoscopic groin hernia repair is not associated with more acute and chronic groin pain compared with a unilateral approach.

\section{History of lower abdominal surgery and direct defect closure and chronic pain}

A history of lower abdominal surgery was not identified as a risk factor for chronic pain after endoscopic groin hernia repair in a prospective nonrandomized trial by Elshof et al. [46]. In another prospective nonrandomized trial, Reddy et al. [47] reported that the inversion of the fascia transversalis for the closure of big direct defects is not associated with chronic pain.

Body weight, hernia defect size, hernia defect location, and mesh size are not related to acute and chronic pain. In the current literature on endoscopic groin hernia repair, insufficient or no data are available about the relationship between pain and the management of strangulated and incarcerated hernias, port defects, scrotal hernias, and cord lipomas. Although several publications have reported on pain and nerve management in open groin hernia surgery [48-53], no data are available on nerve manipulation and pain in endoscopic hernia repair.

References (in parentheses graduation of evidence)

1. Aasvang E, Kehlet H (1986) Classification of chronic pain. Descriptions of chronic pain syndromes and definitions of pain terms. Prepared by the the International Association for the Study of Pain. Subcommittee on Taxonomy. Pain Suppl 3:1-226 (5)
2. Aasvang E, Kehlet $\mathrm{H}$ (2005) Chronic postoperative pain: the case of inguinal herniorrhaphy. BJA 95:69-76. (4)

3. Aasvang E, Kehlet H (2005) Surgical management of chronic pain after inguinal hernia repair. Br J Surg 92:795-801 (4)

4. Aasvang E, Kehlet H (2006) Pain and functional impairment 6 years after inguinal herniorrhaphy. Hernia 10:316-321 (4)

5. Alfieri S, Rotondi F, Di Miceli D, Di Giorgio A (2006) Chronic pain after inguinal hernia mesh repair: possible role of surgical manipulation of the inguinal nerves. A prospective multicentre study. Chir Ital 58:23-31 (4)

6. Amid PK (2004) Causes, prevention, and surgical management of postherniorrhaphy neuropathic inguinodynia: triple neurectomy with proximal end implantation. Hernia 8:342-349 (5)

7. Cunningham J, Temple WJ, Mitchell P, Nixon J, Preshaw R, Hagen N (1996) Cooperative hernia study. Pain in the postrepair patient. Ann Surg 224:598-602 (4)

8. EU Hernia Trialists Collaboration (2002) Repair of groin hernia with synthetic mesh: meta-analysis of randomized controlled trials. Ann Surg 235:322-332 (1A)

9. McCormack K, Scott NW, Go PMNYH, Ross SJ, Grant AM on behalf of the EU Hernia Trialists Collaboration (2003) Laparoscopic techniques versus open techniques for inguinal hernia. (Cochrane review). In: The Cochrane Library, Issue 3, 2003. Oxford: Update Software (1A)

10. Bittner R, Sauerland S, Schmedt CG (2005) Comparison of endoscopic techniques versus Shouldice and other open nonmesh techniques for inguinal hernia repair: a meta-analysis of randomized controlled trials. Surg Endosc 19:605-615 (1B)

11. Nienhuijs S, Staal E, Bleichrodt R (2007) Chronic pain after mesh repair of inguinal hernia: a systematic review. Am J Surg 194:394-400 (1A)

12. Sackett DL, Strauss SE, Richardson WS, Rosenberg W, Haynes RB (2000) Evidence-based medicine: how to practice and teach EBM. 2nd edn. New York, Churchill Livingston

13. Eggert A, Reinpold W (1994) Repair of inguinal hernia - a determination of the current status. Zentralbl Chir 119:649-652 (5)

14. McCormack K, Grant A, Scott N; The EU Hernia Trialists Collaboration (2003) Laparoscopic versus open techniques for inguinal hernia repair. Cochrane Database Syst Rev (1):CD001785 (1A)

15. Poobalan AS, Bruce J, Smith WC, King PM, Krukowski ZH, Chambers WA (2003) A review of chronic pain after inguinal herniorrhaphy. Clin J Pain 19:48-54 (1A) 
16. Schmedt CG, Sauerland S, Bittner R (2005) Comparison of endoscopic procedures vs Lichtenstein and other open mesh techniques for inguinal hernia repair: a meta-analysis of randomized controlled trials. Surg Endosc 19: 188-199 (1A)

17. Wullstein C, Strey C, Woeste G, Bechstein WO (2008) Inguinal hernia: laparoscopic or open surgery? Zentralbl Chir 133:433-439 (2A)

18. Millat B, Fédération de Recherche en Cirurgie (2007) Inguinal hernia repair. A randomized multicentric study comparing laparoscopic and open surgical repair. J Chir (Paris) 144:119-124 (1B)

19. Hallén M, Bergenfelz A, Westerdahl J (2008) TEP hernia repair vs

20. open mesh repair: long term follow-up of a randomized controlled trial. Surgery 143:313-317 (1B)

21. McCormack K, Wake B, Perez J, Grant A (2005) Laparoscopic surgery for inguinal hernia repair: systematic review of effectiveness and economic evaluation. Health Technol Assess 9:1-203 (1A)

22. Hindmarsh $\mathrm{A}$, Cheong $\mathrm{E}$, Lewis MP, Rhodes $\mathrm{M}$ (2003) Attendance at a pain clinic with severe chronic pain after open and lap inguinal hernia repairs. Br J Surg 90:1152-1154 (3B)

23. Schrenk P, Woisetschlager R, Rieger R, Wayand W (1996) Prospective randomized trial comparing postoperative pain and return to physical activiy after TAPP, TEP and Shouldice technique for inguinal hernia repair. Br. J Surg 83: 1563-1566 (1B)

24. Dedemadi G, Sgourakis G, Karaliotas C et al. (2006) Comparison of lap and open tension free repair of recurrent inguinal hernias: a prospective randomized study. Surg Endosc 20:1099-1104 (1B)

25. Lepere M, Benchetrit S, Therin M et al. (2000) A multicentric comparison of TAPP vs TEP hernia repair using parietex meshes. JSLS 4: 147-153 (1B)

26. Wake BL, McCormack K, Fraser C, Vale L, Perez J, Grant AM (2005) Transabdominal preperitoneal (TAPP) vs totally extraperitoneal (TEP) laparoscopic techniques for inguinal hernia repair. Cochrane Database System Rev (1):CD004703 (1A)

27. Wright D, Paterson C, Scott N, O'Dwyer P et al. (2002) Five-year follow-up of patients undergoing laparoscopic or open groin hernia repair: a randomized controlled trial. Ann Surg 235:333-337 (1B)

28. Dickinson KJ, Thomas M, Fawole AS, Lyndon PJ, White CM (2008) Predicting chronic post-operative pain following laparoscopic inguinal hernia repair. Hernia 12:597-601 (2B)

29. Fränneby U, Sandblom G, Nordin P, Nyrén O, Gunnarsson U (2006) Risk factors for long term pain after hernia surgery. Ann Surg 244:212-219 (1B)
30. Kalliomäki ML, Meyerson J, Gunnarsson U et al. (2008) Long-term pain after inguinal hernia repair in a population-based cohort, risk factors and interference with daily activities. Eur J Pain 12:214-225 (2B)

31. Dennis R, O'Riordan D (2007) Risk factors for chronic pain after inguinal hernia repair. Ann R Coll Surg Engl 89:218-220 (3B)

32. Courtney CA, Duffy K, Serpell MG, O’Dwyer PJ (2002) Outcome of patients with severe chronic pain following repair of groin hernia. $\mathrm{Br} \mathrm{J}$ Surg 89:1310-1314 (3B)

33. Callesen T, Bech K, Kehlet H (1999) Prospective study of chronic pain after groin hernia repair. $\mathrm{Br} \mathbf{J}$ Surg 86:1528-1531 (1B)

34. Berndsen FH, Petersson U, Arvidsson D, Leijonmarck C-E, Rudberg C, Smedberg S, Montgomery A (2008) Discomfort five years after laparoscopic and Shouldice inguinal hernia repair: a randomised trial with 867 patients. A report from the SMIL study group. Hernia 11:307-313 (1B)

35. Patil NG, Yuen WK et al. (2003) Prevalence and severity of chronic pain after endoscopic totally extraperitoneal inguinal hernioplasty. Surg Endosc 17:1620-1623 (2B)

36. Heikkinen T, Bringman S, Ohtonen P et al. (2004) Five year outcome of laparoscopic and Lichtenstein hernioplasties. Surg Endosc 18:518-522 (2B)

37. Liem MS, van Duyn E, van der GY et al. (2003) Recurrences after conventional anterior and laparoscopic inguinal hernia repair: a randomized comparison. Ann Surg 237:136-141 (1B)

38. Loos MJ, Roumen RM, Scheltinga MR (2007) Chronic sequelae of common elective groin hernia repair. Hernia 11:169-173 (3B)

39. Tantia O, Jain M, Khanna S, Sen B (2009) Laparoscopic repair of recurrent groin hernia: results of a prospective study. Surg Endosc 23:734-738 (2B)

40. Lau H, Patil NG (2004) Acute pain after TEP: multivariate analysis of predictive factors. Surg Endosc 18:92-96 (2B)

41. Bay-Nielsen M, Perkins FM, Kehlet H (2001) Pain and functional impairment 1 year after inguinal herniorrhaphy: a nationwide questionnaire study. Ann Surg 233:1-7 (1B)

42. Bay-Nielsen M, Nilsson E, Nordin P, Kehlet H, Swedish and Danish Database (2004) Chronic pain after open mesh and sutured repair of inguinal hernia in young males. Br J Surg 91:1372-1376 (1B)

43. Poobalan A, Bruce J, King PM et al. (2001) Chronic pain and quality of life following open inguinal hernia repair. Br J Surg 88:1122-1126 (3B)

44. Sondenna K, Nesvik I, Breivik K et al. (2001) Long term follow-up of 1059 consecutive primary and 
recurrent inguinal hernias in a teaching hospital. Eur J Surg 167:125-129 (3B)

45. Salcedo-Wasicek MC, Thirlby RC (1995) Postoperative course after inguinal herniorrhaphy. A casecontrolled comparison of patients receiving workers' compensation vs patients with commercial insurance. Arch Surg 130:29-32 (2B)

46. Pfeffer F, Riediger H, Küfner Lein R, Hopt UT (2008) Repair of bilateral inguinal hernias-sequential or simultaneous? Zentralblatt Chir 133:446-451 (1A)

47. Elshof JW, Keus F, Burgmans JP, Clevers GJ, Davids PH, van Dalen T (2009) Feasibility of right sided TEP for inguinal hernia repair after appendectomy: a prospective cohort study. Surg Endosc 23:1754-1758 (2B)

48. Reddy VM, Sutton CD, Bloxham L, Garcea G, Ubhi SS, Robertson GS (2007) Laparoscopic repair of direct inguinal hernia: a new technique that reduces the development of postop seroma. Hernia 11:393-396 (2B)

49. Amid PK, Hiatt J (2007) New understanding of the causes and surgical treatment of postherniorrhaphy inguinodynia and orchalgia. J Am Coll Surg 205:381-385 (5)

50. Bartlett D, Porter C, Kingsnorth A (2007) A pragmatic approach to cutaneous nerve division during open hernia repair. Hernia 11:243-246 (4)

51. Dittrick G, Ridl K, Kuhn JA, McCarty TM (2004) Routine ilioinguinal nerve excision in inguinal hernia repairs. Am J Surg 188:736-740 (2B)

52. Mui WL Ng CS, Fung TM, Cheung FK, Wong CM, Ma TH, Bn MY, Ng EK (2006) Prophylactic ilioinguinal neurectomy in open hernia repair: a double blinded randomized controlled trial. Ann Surg 244:27-33 (1B)

53. Picchio M, Palimento D, Attanasio U, Matarazzo P, Bambini C (2004) Randomized controlled trial of preservation or elective division of inguinal nerve on open inguinal hernia repair with polypropylene mesh. Arch Surg 139:755-759 (1B)

54. Ravichandran D, Kalambe B, Pain J (2000) Pilot randomized controlled study of preservation or division of ilioinguinal nerve in open mesh repair of inguinal hernia. Br J Surg 87:1166-1167 (1B)

\section{Chapter 11: Urogenital complications associated with laparoscopic/endoscopic hernia repair}

Robert J. Fitzgibbons, Jr., MD, FACS

What are the urogenital complications associated with a laparoscopic inguinal herniorrhaphy (LIH) and how should they be treated?

Search terms: Laparoscopic inguinal herniorrhaphy, urinary complications, testicular complications, spermatic cord complications, infertility, sexual dysfunction
Disclaimer: For some of the complications described below, there is not enough literature devoted exclusively to LIH to make an accurate statement. Because many of them are common to both open and laparoscopic procedures, it seemed reasonable to extrapolate from the conventional open literature.

\section{Bladder perforation \\ Statements}
Level 4 Bladder injury can be the result of careless use of a Veress needle or a trocar.
The bladder is especially prone to injury during LIH if the preperitoneal space has previously been dissected.

\section{Recommendations}
Grade D The bladder should be decompressed either by having the patient void immediately preoperatively (preferred method) or by the use of an indwelling catheter
Grade A Consider referral of patients in need of a preperitoneal inguinal hernia repair who had a previous preperitoneal dissection, e.g., prostatectomy or failed previous hernia repair to a specialty center.

Laparoscopic peritoneal access or secondary suprapubic trocar placement can result in a bladder perforation, usually the result of failure to decompress a distended bladder. Less commonly, injury is associated with a congenital bladder abnormality. It should be suspected if urine is withdrawn into a syringe after Veress needle insertion or blood and gas are noticed in the urine drainage bag if the patient is catheterized. In questionable cases, methylene blue dye may be instilled into the bladder to look for leakage. Bladder injury recognized during laparoscopy should be repaired laparoscopically providing the experience of the surgeon is sufficient. This should be followed by bladder drainage for 7-10 days.

Bladder injury may present in a delayed fashion with hematuria and lower abdominal discomfort. Contrastenhanced computerized tomography, cystography, or cystoscopy are the primary imaging techniques used to evaluate patients for a suspected injury [1]. Small defects may be managed with postoperative decompression via an indwelling catheter for urinary drainage, whereas larger defects necessitate repair. The bladder is especially prone to injury during LIH when the preperitoneal space has previously been dissected, e.g., previous preperitoneal hernia repair or prostatectomy [2-4].

Mesh erosion into the bladder Statements

Level 4 Polypropylene and expanded polytetrafluoroethylene will erode into the bladder in a small number of patients in whom it is implanted. The reason is not known.

Mesh erosion into the bladder after LIH is rare; only eight cases have been reported since 1994 [5]. Therefore, 
the exact incidence is not known. Both polypropylene and expanded polytetrafluoroethylene have been incriminated $[6,7]$. Probable causes are unrecognized injury to the bladder wall at the time of the LIH and improper placement of mesh and fixation material. Repeated urinary tract infections, hematuria, or the development of bladder stones can all be presenting signs [8].

\section{Urinary retention \\ Statements}

Level 1a Urinary retention is higher after LIH than a conventional inguinal hernia performed under local anesthesia because of the need for general anesthesia for LIH

\section{Recommendations}

\begin{tabular}{ll}
\hline Grade C & $\begin{array}{l}\text { Intra- and postoperative intraveneous fluid } \\
\text { administration should be restricted to no more than } \\
500 \mathrm{cc} .\end{array}$ \\
\hline
\end{tabular}

Urinary retention is less common after inguinal herniorrhaphies performed under local anesthesia compared with general or regional $[9,10]$. Urinary retention is not unusual after a LIH, because the most common associated factor, the use of general anesthesia, is almost always used [11, 12]. The incidence varies widely from as low as $0.2 \%$ in a singleauthor study from France to as high as $22.2 \%$ of patients undergoing laparoscopic inguinal hernia repair in a study from the Mayo clinic in Rochester, Minnesota [13, 14]. More commonly, it is reported to occur in the $2-7 \%$ range [15-19]. Although reports in the literature conflict somewhat, in general older age, prostatic symptoms, postoperative use of narcotics, and the administration of postoperative intravenous fluid $>500 \mathrm{cc}$ have been found to be predictive [14]. Type of procedure (TEP vs. TAPP), surgical time, anesthesia time, intraoperative fluid restriction, or the development of other complications do not appear to be significant risk factors. Intermittent catheterization or temporary placement of an indwelling urinary catheter is usually adequate therapy.

\section{Urinary infection}

\section{Statements}

Level 2B Incidence is highest in patients older than aged 74 years or who have a urinary catheter placed.

\section{Recommendations}

Grade B Antibiotic prophylaxis should be considered in patients at risk for infection [20].Urinary catheterization should be avoided if at all possible.

\section{Miscellaneous cord and testicular problems Statements}

Level 1a Testicular complications occur after both open and endoscopic hernia surgery.

No significant difference in incidence between open and laparoscopic techniques was found in a large comparative trial and a Cochrane analysis did not show any difference between TEP and TAPP [20-22]

Scrotal hematomas can be prevented after LIH if complete hemostasis is assured before completing the procedure. Conservative treatment (ice, scrotal support, pain management, and observation) is sufficient for most, but large hematomas may require surgical drainage. Patients with bleeding disorders are especially prone to this complication [23]. Hydroceles can develop but the cause is not known. Whereas urological literature suggests that this is due to the practice of leaving the distal sac in situ, most experienced hernia surgeons do not accept this theory. The treatment is the same as for any other hydrocele. It is important to differentiate a hydrocele from a seroma because the later is almost always self-limiting and will resolve without treatment [24].

\section{Ischemic orchitis/testicular atrophy}

\section{Statements}

Level IA Unequivocal evidence that LIH will decrease the incidence of orchitis/testicular atrophy is not available.

Level III In most cases, complete dissection and reduction of the hernia sac is possible without serious risk of orchitis or testicular atrophy.

\section{Recommendations}

Grade B In herniorrhaphies where there is a question that damage to the cord structures could occur with complete excision (e.g., large inguinal-scrotal hernias, sacs extending all the way to the testicle, densely adherent sacs), the surgeon should consider dividing the sac at a convenient point distal to the internal inguinal ring, leaving the distal sac in situ. The proximal sac should then be ligated.

Orchitis is defined as postoperative inflammation of the testicle occurring within 1-5 days after surgery. It is felt to be due to acute thrombosis of the delicate venous pampiniform plexus rather than an arterial injury [25, 26]. It is most common after an inguinal scrotal herniorrhaphy when extensive dissection of the spermatic cord has been performed. The presenting symptoms are a lowgrade fever with a painful, enlarged, firm testicle. The differential diagnosis includes scrotal hematoma and testicular torsion. Management is supportive with scrotal support and anti-inflammatory agents. Duplex ultrasound scanning is useful when infarction is suspected. Ischemic orchitis may result in testicular necrosis within days or have a slower course resulting in testicular atrophy during a period of several months. Fortunately most patients recover from ischemic orchitis uneventfully without 
testicular atrophy. Interestingly, most patients who develop testicular atrophy do not give a history of orchitis. It is not yet known whether laparoscopy will have an advantage over conventional surgery because of the more proximal dissection in the preperitoneal space. However, in one large analysis of a prospectively maintained database containing of 8,050 TAPP laparoscopic hernia repairs, orchitis and testicular atrophy was reported to be extremely low at 0.1 and $0.05 \%$ respectively. Interestingly, this group removes all indirect sacs despite the size except in rare circumstances of excessive inflammation [3]. Nevertheless, based primarily of the extensive writings of the late George Wantz, undue dissection of the cord and testicle to remove an indirect inguinal hernia sac completely is not recommended [25, 27-30]. The hernia sac can be divided at a convenient point in the inguinal canal with the distal aspect left open. The proximal sac is then dissected from the cord structures and ligated.

\section{Sexual dysfunction}

Postherniorrhaphy impairment of sexual activity to a moderate or severe degree occurs in a small percentage of men after groin hernia repair, primarily inguinal scrotal or ejaculatory pain. In a Danish study, the incidence of substantial pain during sexual activity was higher with laparoscopic inguinal hernia repair compared with a Lichtenstein TFR (12.7 vs. 6.5\%), but this may have been related to the greater use of LIH for recurrent hernias [31]. The cause is not completely understood. There is no consistently effective therapy, but alpha receptor blockers to decrease contractility of the Vas and neurolytic agents, such as Pregabalin, have been tried [32].

\section{Recommendations}

\begin{tabular}{ll}
\hline Grade C & $\begin{array}{l}\text { Caution when dissecting the cord structures must be } \\
\text { exercised to avoid the possibility of injury to the vas } \\
\text { deferens or blood supply of the testicle. }\end{array}$ \\
\hline
\end{tabular}

\section{Infertility}

Injury to the vas deferens can occur during LIH, and if bilateral will lead to certain infertility. The vas deferens may be injured during dissection and mobilization or during fixation of the mesh. Unilateral injury to the vas can lead to the exposure of spermatozoa to the immune system and the formation of antisperm antibodies, causing secondary infertility [33]. Bilateral testicular atrophy (discussed earlier) is another cause. A recent study that detailed 14 patients whose infertility was apparently the result of damage to the spermatic cord caused by the normal fibroplastic response to polypropylene mesh resulting in obstruction of the of the vas deferens included 10 open procedures, 2 laparoscopic, and 2 where laparoscopy was used on one side and open on the other [34]. However, the explanation for their findings might be a more traditional injury mechanism at the time of surgery, such as ligation, division, or cauterization followed by scarring to the moist convenient adjacent structure, which in this case would be the mesh [35].

References (in parentheses graduation of evidence)

1. Ramchandani P, Buckler PM (2009) Imaging of genitourinary trauma. AJR Am J Roentgenol 192:1514-1523. (2C)

2. Leibl BJ, Schmedt CG, Kraft K, Ulrich M, Bittner R (2000) Recurrence after endoscopic transperitoneal hernia repair (TAPP): causes, reparative techniques, and results of the reoperation. J Am Coll Surg 190:651-655. (4)

3. Bittner R, Schmedt CG, Schwarz J, Kraft K, Leibl BJ (2002) Laparoscopic transperitoneal procedure for routine repair of groin hernia. Br J Surg 89:10621066. (2A)

4. Kapiris SA, Brough WA, Royston CM, O'Boyle C, Sedman PC (2001) Laparoscopic transabdominal preperitoneal (TAPP) hernia repair. A 7-year twocenter experience in 3017 patients. Surg Endosc 15:972-975. (4)

5. Hamouda A, Kennedy J, Grant N, Nigam A, Karanjia N (2009) Mesh erosion into the urinary bladder following laparoscopic inguinal hernia repair; is this the tip of the iceberg? Hernia 14:314-349. (4)

6. Baldassarre E, Valenti G, Porta IP, Vigano M (2006) Re: Mesh migration into the bladder after TEP repair: a rare case report. Surg Laparosc Endosc Percutan Tech 16:52-53. Surg Laparosc Endosc Percutan Tech 16:377-378. (4)

7. Kurukahvecioglu O, Ege B, Yazicioglu O, Tezel E, Ersoy E (2007) Polytetrafluoroethylene prosthesis migration into the bladder after laparoscopic hernia repair: a case report. Surg Laparosc Endosc Percutan Tech 17:474-476. (4)

8. Agrawal A, Avill R (2006) Mesh migration following repair of inguinal hernia: a case report and review of literature. Hernia 10:79-82. (4)

9. Jensen P, Mikkelsen T, Kehlet H (2002) Postherniorrhaphy urinary retention-effect of local, regional, and general anesthesia: a review. Reg Anesth Pain Med 27:612-617. (2A)

10. Finley RK Jr, Miller SF, Jones LM (1991) Elimination of urinary retention following inguinal herniorrhaphy. Am Surg 57:486-488; discussion 488-489. (3)

11. Winslow ER, Quasebarth M, Brunt LM (2004) Perioperative outcomes and complications of open vs laparoscopic extraperitoneal inguinal hernia repair in a mature surgical practice. Surg Endosc 18:221227. (3) 
12. van Veen RN, Mahabier C, Dawson I, Hop WC, Kok NF, Lange JF, Jeekel J (2008) Spinal or local anesthesia in Lichtenstein hernia repair: A randomized controlled trial. Ann Surg 247(3):428-433. (1B)

13. Dulucq JL, Wintringer P, Mahajna A (2009) Laparoscopic totally extraperitoneal inguinal hernia repair: lessons learned from 3,100 hernia repairs over 15 years. Surg Endosc 23:482-486. (4)

14. Koch CA, Grinberg GG, Farley DR (2006) Incidence and risk factors for urinary retention after endoscopic hernia repair. Am J Surg 191(3):381-385. (3)

15. Vidovic D, Kirac I, Glavan E, Filipovic-Cugura J, Ledinsky M, Bekavac-Beslin M (2007) Laparoscopic totally extraperitoneal hernia repair versus open Lichtenstein hernia repair: Results and complications. J Laparoendosc Adv Surg Tech A 17:585-590. (3)

16. Mazeh H, Beglaibter N, Grinbaum R, Samet Y, Badriyyah M, Zamir O, Freund HR (2008) Laparoscopic inguinal hernia repair on a general surgery ward: 5 years' experience. J Laparoendosc Adv Surg Tech A 18:373-376. (4)

17. Aeberhard P, Klaiber C, Meyenberg A, Osterwalder A, Tschudi J (1999) Prospective audit of laparoscopic totally extraperitoneal inguinal hernia repair: a multicenter study of the swiss association for laparoscopic and thoracoscopic surgery (SALTC). Surg Endosc 13:1115-1120. (2C)

18. Lau H, Patil NG, Yuen WK, Lee F (2002) Urinary retention following endoscopic totally extraperitoneal inguinal hernioplasty. Surg Endosc 16:1547-1550. (3)

19. Schmedt CG, Sauerland S, Bittner R (2005) Comparison of endoscopic procedures vs Lichtenstein and other open mesh techniques for inguinal hernia repair: a meta-analysis of randomized controlled trials. Surg Endosc 19:188-199. (1A)

20. Pessaux P, Lermite E, Blezel E, Msika S, Hay JM, Flamant Y, Deepak V, Arnaud JP (2006) Predictive risk score for infection after inguinal hernia repair. Am J Surg 192(2):165-171. (3)

21. Wake BL, McCormack K, Fraser C, Vale L, Perez J, Grant AM (2005) Transabdominal pre-peritoneal (TAPP) vs totally extraperitoneal (TEP) laparoscopic techniques for inguinal hernia repair. Cochrane Database Syst Rev (1):CD004703. (2A)

22. Neumayer L, Giobbie-Hurder A, Jonasson O, Fitzgibbons R Jr, Dunlop D, Gibbs J, Reda D, Henderson W (2004) Open mesh versus laparoscopic mesh repair of inguinal hernia. N Engl J Med 350:1819-1827. (1B)

23. Shah DK, Sagar J (2008) Massive penoscrotal haematoma following inguinal hernia repair: a case report. J Med Case Reports 2:357. (4)
24. Lau H, Lee F (2003) Seroma following endoscopic extraperitoneal inguinal hernioplasty. Surg Endosc 17:1773-1777. (4)

25. Wantz GE (1993) Testicular atrophy and chronic residual neuralgia as risks of inguinal hernioplasty. Surg Clin North Am 73:571-581. (4)

26. Moore JB, Hasenboehler EA (2007) Orchiectomy as a result of ischemic orchitis after laparoscopic inguinal hernia repair: case report of a rare complication. Patient Saf Surg 1:3. (5)

27. Wantz GE (1991) Testicular atrophy. A risk of inguinal hernioplasty. Chirurgie 117:645-651; discussion 651-652. (4)

28. Wantz GE (1986) Testicular atrophy as a sequela of inguinal hernioplasty. Int Surg 71:159-163. (4)

29. Wantz GE (1982) Testicular atrophy as a risk inguinal hernioplasty. Surg Gynecol Obstet 154:570-571. (4)

30. Wantz GE (1984) Complications of inguinal hernial repair. Surg Clin North Am 64:287-298. (4)

31. Aasvang EK, Mohl B, Bay-Nielsen M, Kehlet H (2006) Pain-related sexual dysfunction after inguinal herniorrhaphy. Pain 122:258-263. (4)

32. Finnerup NB, Otto M, McQuay HJ, Jensen TS, Sindrup SH (2005) Algorithm for neuropathic pain treatment: an evidence-based proposal. Pain 118: 289-305. (1A)

33. Chehval MJ, Doshi R, Kidd CF, Winkelmann T, Chehval V (2002) Antisperm autoantibody response after unilateral vas deferens ligation in rats: when does it develop? J Androl 23:669-673. (1B)

34. Shin D, Lipshultz LI, Goldstein M, Barmé GA, Fuchs EF, Nagler HM, McCallum SW, Niederberger CS, Schoor RA, Brugh VM 3rd, Honig SC (2005) Herniorrhaphy with polypropylene mesh causing inguinal vasal obstruction: a preventable cause of obstructive azoospermia. Ann Surg 241:553-558. (4)

35. Fitzgibbons RJ Jr (2005) Can we be sure polypropylene mesh causes infertility? Ann Surg 241:559561. (5)

\section{Chapter 12: Intraperitoneal onlay mesh (IPOM) for inguinal hernia repair-still a therapeutic option?}

Kirpal Singh, Maurice E. Arregui

\section{Is there any role for intraperitoneal onlay mesh in inguinal hernia repair?}

Search Items: "IPOM"; "Intraperitoneal onlay Mesh"; "Inguinal hernia" AND "Intraperitoneal" AND "Onlay" AND "mesh" 


\section{Statements}

Level 1B Higher recurrence rate with IPOM with longer follow-up. Lower operative times with IPOM technique.

Level 4 Fixation may play a significant role.

Level 5 Leaving the sac in situ may lead to higher recurrence.

\section{Recommendations}

Grade B IPOM can not be recommended for main stream inguinal hernia repair at this time.

Further long-term studies are needed to evaluate true recurrences.

Inguinal herniorrhaphy has been evolving since it was first described by Bassini. Lichtenstein popularized tension-free repair with mesh. Laparoscopy arrived on the scene in late 1980s and has further revolutionized the surgical techniques. It is well accepted that laparoscopic transabdominal preperitoneal (TAPP) and totally extraperitoneal (TEP) repairs have comparable recurrence rates and acceptable morbidity and mortality. Both techniques are challenging and have steep learning curves.

The IPOM technique was first introduced in 1991 as a way to reduce or eliminate the difficulty and potential complications of preperitoneal dissection and still maintain the tension free concept [21]. It also is perceived to be faster and easier to perform and teach. The simplicity and reduced operative times are the main attraction of this technique.

Unfortunately, there are not many prospective randomized studies with long-term results. There are three randomized trial (1B) [1-4] and one nonrandomized feasibility study [5] to evaluate IPOM technique. There also are 16 Level 4 case series [6-21].

A study by Vogt et al. [2] initially showed very good results at 8 months. The recurrence rate for IPOM was 3\% compared with $7 \%$ for open suture repair. Long-term data were then published by Kingsley et al. [1]. The recurrence rate at 41 months was $43 \%$ for IPOM and $15 \%$ for open suture repair! This really stresses the importance of longterm follow-up. The IPOM technique was performed with ePTFE mesh $\left(10 \times 15 \mathrm{~cm}^{2}\right)$ fenestrated to $1: 1.5$. Cooper's ligament was exposed through a small opening and mesh was secured to Cooper's, the iliopubic tract, and transversus abdominus with EMS Ethicon hernia stapler. The operative times were $62.5 \mathrm{~min}$ for IPOM and $80.9 \mathrm{~min}$ for the open group.

Another study [3] compared TAPP to IPOM in a prospective, randomized fashion (1B). A total of 76 patients underwent TAPP and 72 underwent IPOM; $10 \times 7 \mathrm{~cm}^{2}$ ePTFE was used for IPOM and $15 \times 12 \mathrm{~cm}^{2}$ polypropylene mesh was used for TAPP. There were no recurrences in
TAPP at 32 months compared with an $11.1 \%$ recurrence rate for IPOM. The mesh was tacked with a hernia stapler in both techniques. Neuralgia was noted with 3 TAPP and 11 IPOM patients $(p<0.05)$. The IPOM technique was faster (53 vs. $71 \mathrm{~min}, p<0.001$ ). The strength of this study was that only two surgeons performed all of the operations with reasonable follow-up. The size of the mesh, however, was not standardized!

The last Level 1B study [4] compared IPOM to open tension free repair. Catani randomized 26 patients to IPOM and 24 to open. The IPOM technique used "GoreTex DualMesh Plus biomaterial with holes Corduroy" and the open approach utilized Marlex plug and patch. Analgesic requirements were less for IPOM $(p<0.001)$ and resumption to normal activity was faster with IPOM ( 8 vs. 17 days, $p<0.001$ ). There were no recurrences with either approach at 12 months. The follow-up is not long enough to draw any strong conclusions from this study.

A multicenter feasibility trial was performed by Fitzgibbons et al. [5]. There were 562 patients in TAPP group, 217 patients in IPOM group, and 87 patients in the TEP group. The recurrence rate was 5\% for TAPP and IPOM compared with $0 \%$ for TEP at an average of 23 months. Polypropylene mesh was used with "appropriate size." This was tacked using a hernia stapler "like TAPP," and the sack was left in situ. IPOM had the highest rate of neuralgia. One patient had to have the mesh removed due to inflammatory mass next to the cecum. No fistula was noted, and there was no mention of bowel resection. The investigators concluded that "IPOM should be considered investigation."

Of the 16 Level 4 case series, 10 favored the IPOM technique due to less operative time and acceptable recurrence rate [6-15]. Four of them were against IPOM due to higher recurrence rates or complications [16-19], and two were neutral $[20,21]$. Most of the studies had a short and inadequate follow-up. Some of the studies only used a questionnaire rather than physical examinations. More recent studies by Cantani and Olmi have shown more promise with IPOM technique. Catani used Dual GoreTex with Titanium spiral tacs and Olmi used Parietex Composite mesh with fibrin glue. Recurrence rate was $3.3 \%$ at an average of 18 months for Catani and $0 \%$ at an average of 23.7 months for Olmi. Unfortunately, only $65 \%$ of the patients had follow-up at 1 year and only $20 \%$ had followup at 2 years. This really brings home the point that adequate follow-up is needed before true recurrence rate can be defined for IPOM.

Interestingly, Kurukahvecioglu reported a 50-year-old patient with bilateral IPOM with ePTFE repair. The mesh was secured to Cooper's ligament with small peritoneal incision and to peritoneal surface with tacks. This patient 
had blood in stool 1 year later and defecated one of the GoreTex mesh. Four years later, he had hematuria and actually urinated four tacks! He had to undergo surgery to remove the GorTex from his bladder.

We feel that the IPOM technique is inferior, because mesh is not secured to any substantial fascia. The tacks usually do not penetrate deep into the tissue and there is no posterior fascia. These tacks also can become a source of chronic pain. The hernia sac is left in place and others have noted migration of the mesh into the hernia sac over time (Grade 5). There is a deviation from standard technique of trying to reduce the hernia sac for faster operation. Faster is not always better (Grade 5). There have been case reports of mesh-related bowel and bladder fistulae, which further complicates patient management. We feel that such complications are under-reported.

\section{References (in parentheses graduation of evidence)}

1. Kingsley D, Vogt DM et al. (1998) Laparoscopic intraperitoneal onlay inguinal herniorrhaphy. Am J Surg 176:548-553. (1B)

2. Vogt DM, Curet MJ et al. (1995) Preliminary results of a prostective randomized trial of laparoscopic onlay versus coventional inguinal herniorrhaphy. Am J Surg 169:84-90. (1B)

3. Sarli L, Pietra N et al. (1997) Laparoscopic hernia repair. Surg Laparosc Endosc 7:472-476. (1B)

4. Catani M, De Milito R et al. (2003) Laparoscopic inguinal hernia repair "IPOM" vs "open tensionfree." Preliminary results of a prospective randomized study. Minerva Chir 58:783. (1B)

5. Fitzgibbons RJ Jr etal (1995) Laparoscopic inguinal herniorrhaphy - results of a multicenter trial. Ann of Surg 221:3-13. (2B)

6. Catani M, Milito R De et al. (2004) Is there a place for intraperitoneal onlay mesh repari (IPOM) of inguinal hernia among laparoscopic techniques? HepatoGastroenterology 51:1387-1392. (4)

7. Olmi S, Scaini A et al. (2007) Laparoscopic repair of inguinal hernias using an intraperitoneal only mesh technique and a Parietes composite mesh fixed with fibrin glue (Tissucol). Personal technique and preliminary results. Surg Endosc 21:1961-1964. (4)

8. Chan ACW, Lee TW et al. (1984) Early results of laparoscopic intraperitoneal onlay mesh repair for inguinal hernia. Br J Surg 81:1761-1762. (4)

9. Phillips EH, Rosenthal R et al. (1995) Reasons for early recurrence following laparoscopic hernioplasty. Surg Endosc 9:140-145. (4)

10. Schmidt J, Carbajo MA et al. (2001) Laparoscopic intraperitoneal onlay polytetrafluoroethylene mesh repair (IPOM) for inguinal hernia during spinal anesthesia in patients with severe medical conditions. Surg Laparosc Endosc Percutan Tech 11:34-37. (4)

11. Carbajo MA, Martin JC et al. (1999) Laparoscopic inguinal hernioplasty with PTFE mesh. Personal technique and results. Hernia 3:99. (4)

12. Toy FK, Moskowitz M et al. (1996) Results of a prospective multicenter trial evaluating the ePTFE peritoneal onlay laparoscopic inguinal hernioplasty. J Laparoendosc Surg 6:375-386. (4)

13. Czudec S, Mec V (2001) Comparison of TAPP and IPOM method in laparoscopic inguinal hernia repair. Hernia 5:S60. (4)

14. Almedia JA, Franklin ME et al. (2001) Laparoscopic intraperitoneal onlay mesh hernioplasty. Hernia 5:S54. (4)

15. Gillion JF, Balique JC et al. (1996) Celioscopic treatment of recurrence of inguinal hernia after insertion of a prosthesis. Value of the interperitoneal technique with ePTFE patch? Group CHIC (Cure des Heries Inguino-crurales sous Coelioscopie). Ann Surg 50:821-826. (4)

16. Memon MA, Fitzgibbons RJ Jr et al. (1990) Laparoscopic repair of recurrent hernias. Surg Endosc 13:807-810. (4)

17. Kurukahvecioglu O, Ege B et al. (2007) Polytetrafluoroethylene prosthesis migration into the bladder after laparoscopic hernia repair. Surg Laparosc Endosc Percutan Tech 17: 474-476. (4)

18. Filipi CJ, Fitzgibbons RJ Jr et al. (1992) Laparoscopic herniorrhapy. Surg Clin N Am 72: 1109-1124. (4)

19. Blanc P, Porcheron J et al. (1999) Results of laparoscopic hernioplasty. A study of 401 cases in 318 patients. Chirurgie 124:412-418. (4)

20. Hatzitheofilou C, Lakhoo M et al. (1997) Laparoscopic inguinal hernia repair by an intraperitoneal onlay mesh technique using expanded PTFE. Surg Laparosc Endosc 7:451-455. (4)

21. Toy FK, Smoot RT (1991) Toy-Smoot laparoscopic hernioplasty. Surg Laparosc Endosc 1:151-155. (4)

\section{Chapter 13: Role for open preperitoneal mesh placement in the era of laparoscopic inguinal hernia repair}

Kirpal Singh, Maurice E. Arregui

What is the role of open preperitoneal hernia repair in the era of laparasoscopic inguinal hernia repair?

Search terms: "open preperitoneal hernia repair"; "laparoscopic inguinal hernia repair"; "TAPP" AND "preperitoneal" AND "hernia repair"; "TEP" AND "preperitoneal" 
AND "hernia repair"; "preperitoneal" AND "hernia" AND "repair"

\section{Statements}

\begin{tabular}{|c|c|}
\hline \multirow[t]{3}{*}{ Level $1 \mathrm{~A}$} & $\begin{array}{l}\text { Laparoscopic approaches have fewer local } \\
\text { complications. }\end{array}$ \\
\hline & Laparoscopic approaches have less pain. \\
\hline & $\begin{array}{l}\text { Laparoscopic approaches have faster return to normal } \\
\text { activities. }\end{array}$ \\
\hline \multirow[t]{2}{*}{ Level 1B } & $\begin{array}{l}\text { Laparoscopic approaches have lower morbidities. } \\
\text { Laparoscopic approaches have longer operative times. }\end{array}$ \\
\hline & $\begin{array}{l}\text { Laparoscopic approaches have less pain and faster } \\
\text { return to normal activity and work. }\end{array}$ \\
\hline Level 5 & $\begin{array}{l}\text { Minimally invasive open approaches (i.e., Kugel) have } \\
\text { limited visualization and higher likely hood of injury } \\
\text { or incomplete dissection. }\end{array}$ \\
\hline & $\begin{array}{l}\text { Both anterior and posterior spaces are violated leading } \\
\text { to difficult reoperative surgery. }\end{array}$ \\
\hline
\end{tabular}

\section{Recommendations}

\begin{tabular}{ll}
\hline Grade B & $\begin{array}{c}\text { Laparoscopic approach is recommended over open } \\
\text { preperitoneal due to less morbidity, less pain, } \\
\text { and faster recovery. } \\
\text { Open approach may be considered in patients with } \\
\text { recurrent hernia and inability to undergo general } \\
\text { anesthesia. }\end{array}$ \\
\hline
\end{tabular}

The approach to inguinal hernia has been evolving since Bassini first described it. There are proponents of open anterior tissue repairs (Shouldice), open preperitoneal repairs, open anterior repairs with mesh, and laparoscopic repairs with mesh, including TAPP (laparoscopic transabdominal preperitoneal repair) and TEP (laparoscopic totally extraperitoneal repair). Many different open preperitoneal approaches have been described, making it difficult to summarize and compare them with laparoscopic approaches.

Two Level 1A studies concluded that endoscopic repairs do have advantages in terms of local complications, painassociated parameters, and faster return to normal activities; however, "Well structured trials with improved standardization of hernia type, operative technique, and surgeons' experience are necessary" [1,2]. Both of these studies were reviewed by the Database of Abstracts of Reviews of Effects in 2008. It was concluded that "overall methodological quality of the studies was poor and limited the conclusions that could be drawn." However, laparoscopic hernia repairs did have less postoperative pain and faster return to normal activities.

The five Level 1B studies have been outlined in Table 1 and overall are in favor of laparoscopic approaches due to less pain and faster return to normal activity [3-7]. Champault et al. [3] compared 51 patients with TEP to 49 patients with Stoppa. They noted a $6 \%$ recurrence rate with TEP and 2\% with Stoppa repair, although the mesh used for TEP was smaller $\left(11 \times 6\right.$ vs. $\left.12 \times 15 \mathrm{~cm}^{2}\right)$. Morbidity was only $4 \%$ with TEP compared with $30 \%$ with Stoppa $(p=0.01)$. TEP also had less pain and a faster recovery with statistical significance.

Beets et al. [4] compared TAPP with GPRVS (great prosthetic replacement of the visceral sac). There was a difference in size of the mesh but not far from what is utilized now $\left(10 \times 15\right.$ vs. $\left.18 \times 26 \mathrm{~cm}^{2}\right)$. The open operation was faster ( $56 \mathrm{vs}$. $79 \mathrm{~min} ; p=0.001$ ). There were no wound infections in TAPP compared with four with the open $(p=0.04)$. The recurrence rate was higher for TAPP (12.5 vs. $1.9 \%$ ), but there was "variable degree of experience with the TAPP approach, and all surgeons had performed less than 50 cases. The TAPP group was able to be discharged same day in $93 \%$ of the cases compared with $77 \%$ with open. Interestingly, the cost of surgery was comparable in both goups $(\$ 1,179$ for TAPP and $\$ 1,150$ for open).

Aitola et al. [5] compared TAPP with open preperitoneal approach (opening the transversalis fascia from internal ring to pubic tubercle and suturing $6 \times 12 \mathrm{~cm}^{2}$ Marlex mesh to Cooper's, rectus, and Transversalis fascia). There were 24 patients in TAPP and 25 in the open group. Interestingly, there were twice as many patients with recurrent hernia in TAPP group. The open group was faster (55 vs. $66 \mathrm{~min}, p<0.01$ ), but pain was less in TAPP group $(p<0.01)$. The recurrence rate was $13 \%$ with TAPP and $8 \%$ with open. They concluded that open is better due to less cost and lower recurrence rate. The size of the mesh was small in this series and the method chosen to secure the mesh was different (sutures vs. staples). The staples do not go as deep as the sutures are able.

Johansson et al. [6] compared TAPP to open preperitoneal (split incision) to conventional (suture only). Follow-up was 1 year and most of the TAPP recurred in 6 months, indicating technical failure. Also, the open approach used sutures compared with tacks for TAPP.

Simmermacher et al. [7] studied TEP compared with the Grid-Iron (Ugahary) approach. The open approach was faster. There were no differences in pain and return back to work. However, the major limitation of this study is that there was no follow-up period and no recurrence rate mentioned.

There were six Level 2B studies but only three of these directly compared the laparoscopic to open surgeries. Mok et al. [8] compared TAPP with the Nyhus repair for recurrent inguinal hernia repairs. The size of mesh was $8 \times 12$ for TAPP but not mentioned for the open approach. There was less pain with TAPP $(p<0.01)$ and faster return to work (14 vs. 28 days, $p<0.01)$. Despite the smaller mesh, the recurrence rate was only $1 \%$ at 54 months. TAPP cost $\$ 615$ more.

Goodwin and Traverso [9] compared TAPP with open periperitoneal (PPO). PPO took less time and had lower 


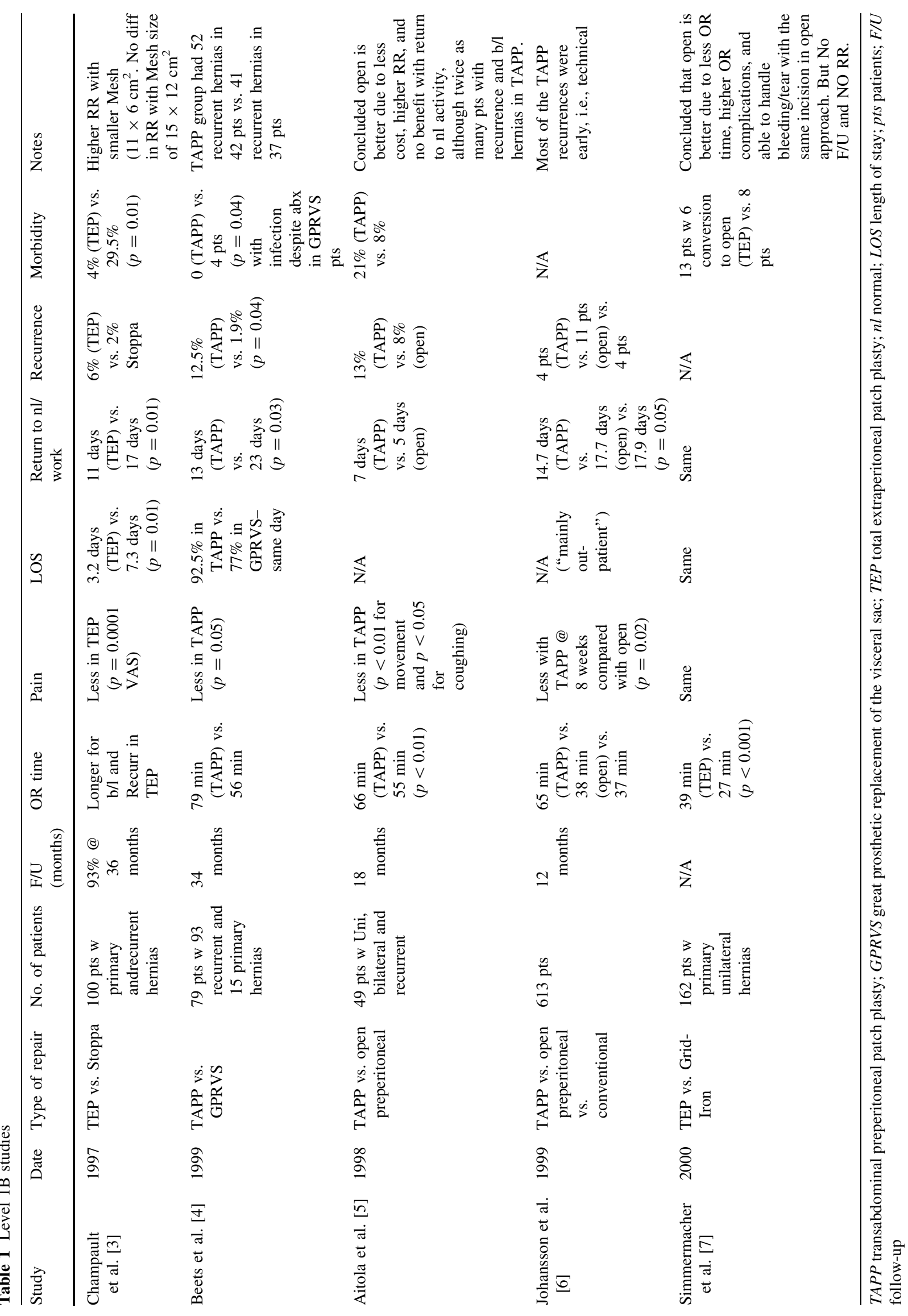


cost $(\$ 1,343$ vs. $\$ 2,176, p<0.001)$. Size of mesh was $6 \times 12 \mathrm{~cm}^{2}$ for TAPP and $6 \times 10 \mathrm{~cm}^{2}$ for PPO. There was one recurrence at 5 months, indicating technical failure. There was higher morbidity with TAPP compared with PPO. Follow-up was done by mail and averaged 7 months for PPO and 22 months for TAPP.

Velasco et al. [10] compared TAPP to the Stoppa repair. Both were stapled and TAPP was noted to be $\$ 500$ more. TAPP patients stayed in the hospital for $4 \mathrm{~h}$ compared with $48 \mathrm{~h}$. Recurrence rate was not different (approximately $6 \%$ ). TAPP patients resumed normal activity in 9 days compared with 22 days for Stoppa.

The other three studies did not compare the open preperitoneal approach to laparoscopy. All favored the open perperitoneal approach: Nieuwenhove et al. [11] studied only Kugel (five times more expensive than regular mesh) but with $3.5 \%$ persistent pain; Reddy et al. [12] were in favor of Kugel but with $2.8 \%$ dull ache at 1 year without treatment; Kurzer et al. [13] studied the Stoppa or Wantz repair for recurrent hernias with 5\% RR at 4 years.

The ten Level 4 studies showed nine for open approach and one against open preperitoneal approach [14-23]. The majority of these studies had short follow-up, and there was much heterogeneity.

References (in parentheses graduation of evidence)

1. Schmedt CG, Sauerland S, Bittner R (2005) Comparison of endoscopic procedures vs Lichtenstein and other open mesh techniques for inguinal hernia repair. Surg Endosc 19:188-199. (1A)

2. Cheek CM, Black NA et al. (1998) Groin hernia surgery: a systematic review. Ann R Coll Surg Engl 80(Suppl 1):S1-S80. (1A)

3. Champault GG, Rizk $N$ et al. (1997) Inguinal hernia repair. Totally preperitoneal laparoscopic approach versus Stoppa operation: randomized trial of 100 cases. Surg Laparose Endosc 7:445-450. (1B)

4. Beets GL, Dirksen CD et al. (1999) Open or laparoscopic preperitoneal mesh repair for recurrent inguinal hernia? A randomized controlled trial. Surg Endosc Ultrasound Intervent Tech 13:323-327. (1B)

5. Aitola P, Airo I, Matikainen M (1998) Laparoscopic versus open preperitoneal inguinal hernia repair: a prospective randomized trial. Ann Chirurgiae Gynaecol 87:22-25. (1B)

6. Johansson B, Hallerback B et al. (1999) Laparoscopic mesh versus open preperitoneal mesh versus conventional technique for inguinal hernia repair. Ann of Surg 230:225-231. (1B)

7. Simmermacher RKJ, Clevers GJ et al. (2000) Preperitoneal mesh in groin hernia surgery. A randomized clinical trial emphasizing the surgical aspects of preperitoneal placement via a laparoscopic (TEP) or Grid-iron (Ugahary) approach. Hernia. 4:296-298. (1B)

8. Mok KT, Wang BW et al. (1998) Laparoscopic versus open preperitoneal prosthetic herniorrhaphy for recurrent inguinal hernia. Int Surg 83:174-176. (2B)

9. Goodwin JS II, Traverso LW (1995) A prospective cost and outcome comparison of inguinal hernia repairs. Surg Endosc 9:981-983. (2B)

10. Velasco JM, Gelman C, Vallina VL (1996) Preperitoneal bilateral inguinal herniorrhaphy. Surg Endosc 10:122-127. (2B)

11. Nieuwenhove $\mathrm{YV}$, Vansteenkiste $\mathrm{F}$ et al. (2007) Open, preperitoneal hernia repair with the Kugel patch: a prospective multicenter study of 450 repairs. Hernia 11:9-13. (2B)

12. Reddy KM Humphreys W, Chew A, Toouli J (2005) Inguinal hernia repair with the Kugel Patch. ANZ J Surg 75:43-47. (2B)

13. Kurzer M, Belsham PA, Kark AE (2002) Prospective study of open preperitoneal mesh repair for recurrent inguinal hernia. Br J Surg 89:90-93. (2B)

14. Kugel RD (2003) The Kugel repair for groin hernias. Surg Clin N Am 83:1119-1139. (4)

15. Baroody M, Bansal V, Maish G (2004) The open preperitoneal approach to recurrent inguinal hernias in high-risk patients. Hernia 8:373-375. (4)

16. Hoste W, Nieuwenhove YV, Vierendeels T (2006) Early Belgian experience with the Kugel patch inguinal hernia repair. Acta Chir Belg 106:44-46. (4)

17. Fenoglio ME, Bermas HR et al. (2005) Inguinal hernia repair: results using an open prepritoneal approach. Hernia 9:160-161. (4)

18. Ceriani V, Faleschini E, Sarli D et al. (2005) Kugel hernia repair: open "mini-invasive" technique. Personal experience on 620 patients. Hernia 9:344347. (4)

19. Horton MD, Florence MG (1993) Simplified preperitoneal marlex hernia repair. Am J Surg 165:595599. (4)

20. Schroder DM, Lloyd LR et al. (2004) Inguinal hernia recurrence following preperitoneal Kugel patch repair. Am Surg 70:132-136. (4)

21. Farooq $O$ et al. (2005) Recurrent inguinal hernia repair by open preperitoneal approach. JCPSP 15:261-265. (4)

22. Kugel RD (1999) Minimally invasive, nonlaparoscopic, preperitoneal, and sutureless, inguinal herniorrhaphy. Am J Surg 178:298-302. (4)

23. Ugahary F, Simmermacher RKJ (1998) Groin hernia repair via a grid-iron incision: an alternative technique for preperitoneal mesh insertion. Hernia 2:123-125. (4) 


\section{Chapter 14: Sportsman hernia-diagnosis and treatment}

\author{
Moshe Dudai/Salvador Morales-Conde, Reinhard \\ Bittner
}

\section{Tel Aviv, Israel/Salvador Morales-Conde, Sevilla (Spain), Stuttgart, Germany}

\section{Search terms}

To write the guideline recommendations for the Sportsman Hernia (SH), a literature search was conducted in PubMed and Medline through the years 1990-2008 using the terms: Sportsmen Hernia, Sport Hernia, Athletes Hernia, Athletes Pubalgia, Groin Injury/Treatment, Surgery, Technique, Repair, Surgical finding, Pathology, Diagnosis, Etiology, Results, Complications

Of the 127 articles found, 66 are relevant, but only 13 with a level of evidence better than 4: 1 Level 1B, 2 Level 2B, 4 Level 3A, 6 Level 3B, 43 Level 4, 10 Level 5 (review articles). The four systematic reviews of the literature were assigned Level 3A, because all but three studies analyzed were only Level 4.

\section{Definition and differential diagnosis}

\section{Statements}

Level 3A Chronic pain (longstanding groin pain-LSGP) is a leading cause of athletes' retirement from competitive sports.

Chronic pain in athletes is an obscure condition of uncertain etiology commonly seen in soccer, football, rugby, and ice hockey players.

At a high level of play, teams have significantly higher risk of injury than teams at a lower level.

Physical examination reveals no detectable inguinal hernia.

The differential diagnosis is difficult to make from physical examination and is thus largely established only at the time of surgery.

Although there are several reports of chronic pain in women, it is almost exclusively found in men.

Level 4 Chronic pain is a challenging problem among not only athletes but also the general population.

In the majority of athletic maneuvers, a tremendous amount of torque or twisting occurs in the midportion of the body, and the front or anterior portion of the pelvis accounts for the majority of the force.

The main muscles inserting at or near the pubis are the rectus abdominis muscle, which combines with the transversus abdominis. Across from these muscles, and directly opposing their forces, is the abductor longus.

The opposing forces of the muscles at their insertion site on the pubis cause a disruption of the muscle/ tendon, causing chronic pain related to the fact that forces are excessive and imbalanced, leading to an increase of the weakness of the posterior wall of the groin or to a pubic bone stress injury (PBSI), which may lead to degenerative arthropathy of the pubic symphysis in advanced stages.
Chronic groin pain in athletes is mainly caused by two different pathologic entities: the sportsman hernia (SH) or the athletes pubalgia due to a pubic bone stress injury (PBSI).

PBSI include entities, such us tendon enthesitis, pubic osteitis, or avulsion fractures.

In $\mathrm{SH}$, the likely causative factor is a posterior wall deficiency (PWD).

Entrapment of inguinal nerves may create symptoms that resemble those of a sports hernia.

The sports hernia is one of the least understood, poorly defined, and under-researched maladies to affect the human body [9] and is a leading cause of athletes' retirement from competitive sports $[44,45]$. It is more common in highlevel athletes [29]. It is an obscure condition of uncertain etiology commonly seen in soccer, football, rugby, and ice hockey players $[9,17,58]$. It reflects a compilation of diagnoses grouped together with a wide range of other pathologies that need to be excluded before this should be considered as a diagnosis [9]. The etiology, onset, anatomy involved, and terminology used to define it vary widely in the literature $[9,58]$. The precise sequence of events that lead to its development is not well known, but the combination of abdominal and hip adductor muscle strength, endurance and coordination imbalances, lumbopelvic and hip rotation range of motion deficits, poor tissue extensibility, and intense or high-repetition hip adductor muscle shearing forces through their pelvic attachments may be the primary factors $[9,17,27,44,51,61]$.

Some authors emphasize inguinal nerve compression (entrapment) as a cause of chronic pain in athletes produced by direct trauma or overzealous training and hypertrophy of abdominal musculature $[2,23,43,53,63]$. The phrase "groin disruption" was popularized by Gilmore for sport injuries followed by chronic pain in the groin and abdominal muscles area with no findings of hernia, but inguinal wall and superficial inguinal ring disorders caused by injuries to the internal oblique aponeurosis, conjoined tendon-pubic tubercle attachment and dehiscence between the tendoninguinal ligament. He successfully advised a surgical technique for treatment based on modifications of the historic Bassini operation [20,21]. Gilmore, as well as others, found that the pain is caused by posterior wall deficiency (PWD) as a result of trauma to the tranversalis fascia or conjoint tendon, which is formed by the medial portion of internal oblique and transversus abdominis muscle [2, 12, 22, 47]. Nevertheless, many uncertainties remain, not the least due to the existence of other pathologies around the symphysis pubis, which were in some way easier to diagnose. Diagnostic imaging is useful to exclude other conditions [9] but does not generally reveal a sports hernia. With time, especially after the introduction of laparoscopy, the 
Table 1

CAUSE OF CHRONIC GROIN PAIN IN ATHLETES

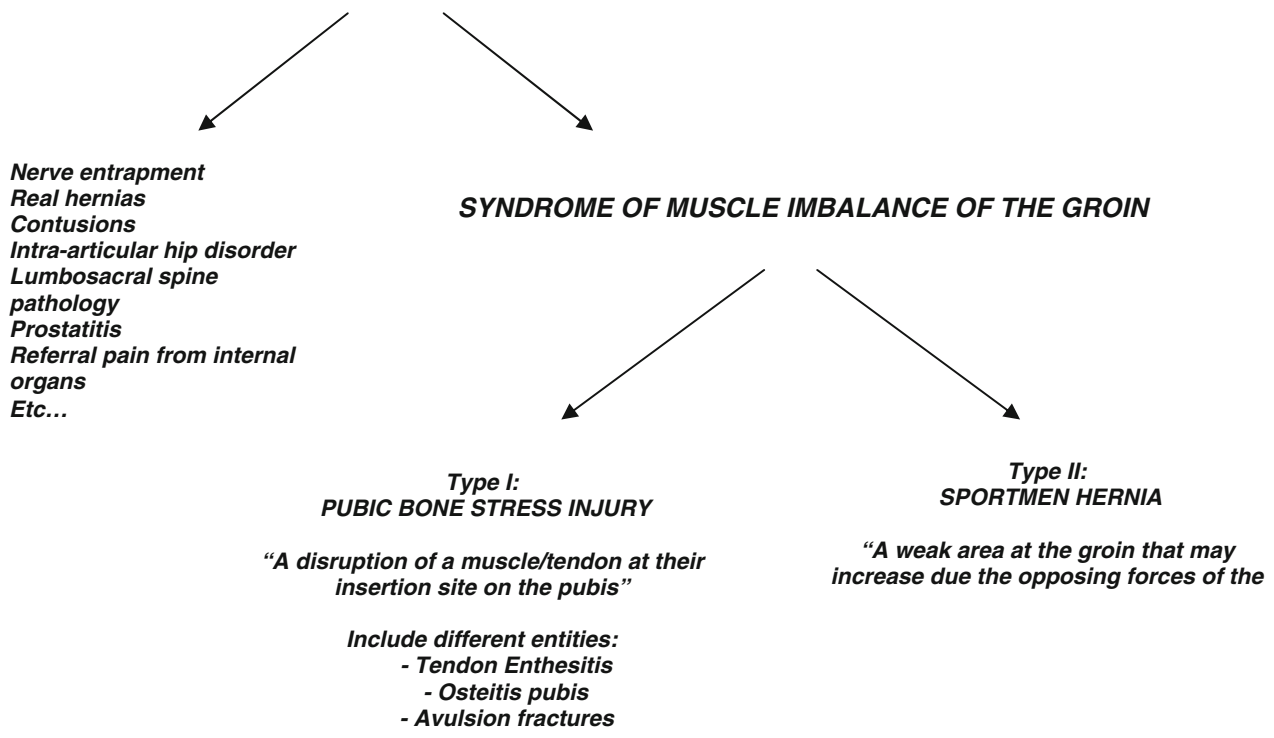

understanding of the different pathologies and pathogenetic mechanisms has improved. Today, posterior inguinal wall insufficiency that creates an occult hernia that is not apparent on physical examination is recognized as the most common surgical finding [9]. For this reason, the pathological definition of PWD was accepted as equivalent to the pathology of $\mathrm{SH}$, and confirmed by multiple studies $[17,47,52,58]$.

From an anatomical point of view, the definition and the name of this entity should be reviewed. Confusion related to "sportsmen hernia" often arises from the complex anatomy and biomechanics of the symphysis region, from the large number of potential sources of groin pain, and from the similarity of symptoms in athletes with different sites of injuries. There are different anatomic areas to be considered when we talk about this entity, including ligaments, tendons, nerves, muscles, and bones.

In the majority of athletic maneuvers, a tremendous amount of torque or twisting occurs in the midportion of the body, and the front or anterior portion of the pelvis accounts for the majority of the force. The main muscles inserting at or near the pubis are the rectus abdominis muscle, which combines with the transversus abdominis. Across from these muscles, and directly opposing their forces, is the abductor longus. These opposing forces cause a disruption of the muscle/tendon at their insertion site on the pubis, so the problem could be related to the fact that forces are excessive and imbalanced, and a weak area at the groin could be increased due to the forces produced by the muscles. The forces produced by these muscles may be imbalanced and could produce a disruption of the muscle/tendon at their insertion site on the pubis or/and a weak area may be increased due to the forces produced by the muscles; just this last possibility could be defined as sportsmen hernia.

On the other hand, this disruption of the muscle/tendon at their insertion site could be defined as a PBSI (pubic bone stress injury), which affects not only the pubic bone itself but also the muscles and their tendons on both sides of the symphysis pubis [44]. (In the past, it was mistakenly referred to as osteitis pubis.) For that reason, this term could include different entities, such as tendon enthesitis, pubic osteitis, or avulsion fractures.

In conclusion, this global entity could be considered an imbalance of the muscles (abductor and abdominal) at the pubis, which leads to an increase of the weakness of the posterior wall of the groin and produces a tendon enthesitis. Once a true origin is not detected, because, for example, a hernia is a hernia or a nerve entrapment is a nerve entrapment, etc., that may lead to a degenerative arthropathy of the pubic symphyses in the advanced stages. Based on this, this entity could be renamed, "syndrome of muscle imbalance of the groin," and the sportsmen hernia could be considered an entity included in this syndrome (Table 1).

\section{History}

\section{Statements}

Level 4 Groin pain starts during extreme sport activity, usually with no proper buildup of durability, acceleration, deceleration, and rotation.

Pain responds to conservative treatment, anti-inflammatory drugs, and rest.

Pain typically recurs at the resumption of sport activity. 


\section{Diagnostic procedures Statements}

Level 2B In patients with chronic groin pain and clinically uncertain herniations, magnetic resonance imaging (MRI) and ultrasound (US) are valid diagnostic tools.

Level 3B Ultrasound is a useful adjunct diagnostic tool, not only to evaluate the groin for hernias, with high overall accuracy, but also in SH to identify inguinal canal posterior wall deficiency in young men with no clinical signs of hernia with chronic groin pain.

Level 4 The management of groin injuries demands the recruitment of a team with experience with different aspects of groin pain.

Both the history and quality of symptoms and the physical examination may help to differentiate between SH and TE.

History of chronic groin pain that is nonresponsive to conservative treatment should raise suspicion of SH.

MRI appears to have excellent diagnostic potential for assessing various causes of long-standing groin pain (LSGP) in athletes.

MRI may not be a useful tool for deciding between operative or conservative treatment.

MRI is a valuable tool to monitor the alterations with reference to their response to conservative treatment, which alos may help the athletes to return to their activities.

Dynamic ultrasound shows promising results in accurately diagnosing $\mathrm{SH}$.

In selected cases, laparoscopic inguinal exploration may be helpful.

Essentially, it is a diagnosis that can only be confirmed at surgery.

\section{Recommendations}

Grade 3A Comprehensive physical examination that requires excluding numerous other musculoskeletal and nonmuscoloskeletal conditions is mandatory.

Plain radiography, ultrasonography, and scintigraphy should be the first-line investigations to supplement clinical investigation.

The cost of computed tomography and magnetic resonance imaging are such that their routine use for assessment of patients with groin pain cannot be justified. They may, however, be employed in difficult cases to help define the anatomical extent of a groin injury.

Dynamic ultrasound may be able to replace historical inguinal herniography.

Grade 4 In unclear cases with some suspicion of posterior wall deficiency, surgical exploration should be performed.

Gradual physical therapy combined with pharmacotherapy should be effective in most cases and should be part of the diagnosis process.

Diagnosis of chronic groin pain is difficult, but early diagnosis is very important because morbidity will be reduced. These groin injuries are some of the most challenging injuries in the field of sports medicine, and the literature provides no consensus on definitions of diagnostic criteria for groin pain in athletes [34]. The combination of complex anatomy [16], variability of presentation, and the nonspecific nature of the signs and symptoms make the diagnostic process problematical.

Therefore, management of groin injuries can be challenging, and diagnosis can be difficult because of the degree of overlap of symptoms between the different problems [41]. This clinical setting demands the recruitment of a team with experience of different aspects of groin pain. Ekberg et al. [13] have established a multidisciplinary investigation to reveal the underlying cause. These examinations included general surgeons for detection of inguinal hernia and neuralgia, orthopedic surgeons for detection of adductor tenoperiostitis and symphysitis, urologist for detection of prostatitis, radiologist for performing different imaging tests, and nuclear medicine for isotope studies. For these reasons, the so-called SH is largely a clinical diagnosis of exclusion [46].

$\mathrm{SH}$ must be distinguished from the more common osteitis pubis and musculotendinous injuries [18]. The first step is to determine the differential diagnosis of hip and groin pain with respect to the high frequency of referred pain from the lumbar spine, lower abdomen, and pelvis [25], which is very difficult in some cases. A systematic approach to the hip and groin area is important to identify the origin of pain. Both the history and quality of symptoms and the physical examination are the basics of the diagnostic algorithm. In some cases, the diagnostic workup with roentgenograms and possibly an injection with a local anesthetic to the suspected origin of pain are completed [25]. There are clinical signs for the diagnosis of nerve pathologies, such us obturator neuropathies. These patients usually have clinical symptoms and signs of postexercise groin, lower abdominal or medial tight pain, and adductor muscles weakness and paresthesia in cutaneous distribution of medial thigh. Except clinical signs in the diagnosis of obturator neuropathy diagnostic local anesthetic block and electromyography have been used [39].

History of chronic groin pain that is nonresponsive to treatment should raise suspicion of SH [1, 17, 39]; however, physical examination findings are subtle and most diagnostic tests do not definitively confirm the diagnosis [46]. Traditional physiotherapy of isometric active weight-bearing exercise will result in complete healing of almost all athletes $[24,47]$. It is important to highlight that adductor strain is a possible part of this pathological syndrome and therefore tenotomy should not be performed under any circumstances [31]. Finally, in selected cases, correct diagnosis is only possible with diagnostic laparoscopy $[17,57]$. 


\section{Physical examination}

Physical examination is the first step in the diagnosis of groin pain, although symptoms often are vague and diffuse [34]. When active, sportsmen start to feel a dull pain in the groin region.

A deep palpation above the inguinal canal will find the area to be sensitive and the external inguinal ring dilated [9]. In a digital examination of the canal, a soft bulge can be felt against the tip of the finger and extreme sensitivity to pressure applied with the tip of the finger against the floor of the canal where the genito-femoral nerve passes. With this syndrome, the nerve is entrapped under the IPT (ileo-pubic tract) in the internal inguinal ring area [2, 43]. In addition, all of the symptoms increase during coughing.

The clinical assessment of groin pain in athletes is difficult; the lack of specific clinical tests is in part responsible. The examinations could include evaluation of adductor muscle-related pain and strength, iliopsoas muscle-related pain, strength, and flexibility, abdominal muscle-related pain, and strength and pain at the symphysis joint, but the only test without acceptable interobserver reliability was the strength test for iliopsoas muscle [26].

Gradual physical therapy combined with pharmacotherapy should be effective in most cases and should be part of the diagnosis process. This process includes nonsteroid antiinflammatory drugs and muscle relaxants. A physical therapy program usually involves stretching and strengthening of adductor muscles, abdominal wall muscles, iliopsoas muscle, quadriceps, and hamstrings. If physical therapy and pharmacotherapy fail, different tests should be performed.

\section{Ultrasound}

Ultrasound is a useful adjunct to evaluate the groin for hernia. The overall accuracy in finding a hernia of any kind by ultrasound is $92 \%$. On the other hand, this imaging test identifies the pathology in a groin without a palpable bulge at an accuracy of $75 \%$ [38].

Ultrasound, which enables a dynamic assessment, is particularly useful in these patients [7, 9, 17, 49]. Dynamic ultrasound examination is able to detect inguinal canal posterior wall deficiency in young men with no clinical signs of hernia with chronic groin pain. As the patient actively strains during the investigation, a real-time convex anterior bulge and ballooning of the inguinal canal can be observed at the superficial inguinal ring. This examination has been proposed to be performed with the patient in the supine and erect positions, in a relaxed state, as well as during coughing and during Valsalva maneuver [40].

Orchard et al. [49] have shown a correlation between bilateral deficiency of the posterior wall and groin pain, although the temporal relationship between the clinical and ultrasound findings was not established by this study.
Depasquale et al. [11] also have shown that ultrasound is a useful tool for identifying hernias, and therefore, aids surgical management; $39 \% \quad(n=94)$ of the patients examined who had groin pain were positive for hernias. Only four false-positive were found of the 62 who underwent surgery, giving a positive predictive value of $94 \%$ in operated patients.

Not seldom, a preperitoneal lipoma herniating into the inner inguinal ring and canal or the obturator canal can be demonstrated by ultrasound. Evidence of genito-femoral nerve entrapment can be shown by edema behind the IPT on the level of internal inguinal ring. In some cases, tears and strain of the conjoint tendon in its insertion to the pubis can be seen.

Even though some authors still advocate herniography for identifying impalpable herniations causing pain in athletes [64], today dynamic ultrasound should be the diagnostic tool of first choice.

\section{CT scan and MRI}

CT scan and MRI have been proposed as diagnostic tests for chronic groin pain, but the costs are such that their routine use for assessment of patients with groin pain cannot be justified [18]. Furthermore, MRI is not a useful tool for deciding between operative and conservative treatment [10].

Bone scan, plain radiography, and ultrasound has been used for diagnosing these entities, but MRI appears to be superior [45, 58, 61, 62]. A clinical and imaging diagnosis is crucial, because in PBSI there is no need for surgical intervention.

The use of CT scans could help to identify posterior inguinal wall deficiencies and hernias in some cases [56] and may be employed in difficult cases to help define the anatomical extent of a groin injury [18]. On the other hand, MRI provided an accurate depiction of pubic bone alterations and of adjacent myotendinous structures $[6,52]$ and also was very useful to determine the presence of inguinal hernias [6], because allows the direct visualization of the hernial sac within the inguinal canal. Athletes with groin pain and tenderness of the pubic symphysis and/or superior pubic ramus have clinical features consistent with the diagnosis of osteitis pubis. The increased signal intensity seen on MRI is due to pubic bone marrow edema. A stress injury to the pubic bone is the most likely explanation for these MRI findings.

MRI can permit an accurate and early diagnosis of the different sport-related pubic conditions and also is a valuable tool for monitoring the alterations with reference to their response to treatment, which may help the athletes return to their activities. It should be considered that abnormal magnetic resonance imaging findings are common in asymptomatic athletes, which decreases the value of magnetic resonance imaging in surgical decision-making [50]. 


\section{Indication for surgery}

\section{Statements}

Level 1B An active physical therapy program designed to strengthen the muscles to stabilize the hip and pelvis has positive effects and leads to earlier return to sports at the same level, and it is superior to a physiotherapy treatment without active training.

Level 3A Until now, there has been no evidence-based consensus available to guide decision-making.

The methodological quality of the studies available or analysis is low.

A single entheseal pubic cleft injection can be expected to afford at least 1 year of relief from adductor-related groin pain in a competitive athlete with normal findings on a magnetic resonance imaging scan.

Surgery seems to be more effective than conservative treatment for $\mathrm{SH}$.

Good results can be obtained with surgery when posterior inguinal wall deficiency is the sole diagnosis.

Information on specific conservative interventions is poorly presented, and well-designed studies are lacking.

Level 4 In PBSI, conservative management results more likely in an excellent outcome.

In $\mathrm{SH}$, the results of surgical repair to the posterior inguinal wall are excellent.

\section{Recommendations}

Grade B A multidisciplinary approach to groin pain should be adopted.

Generally, conservative measures should be tried first, consisting of an initial period of rest or restricted activities, followed by physical therapy designed to stabilize the pelvis and hip.

When conservative management has failed, surgical intervention should be done.

Grade D Athletes with chronic groin pain and PWD who are unable to compete in active sports should be considered for routine inguinal hernia repair if no other pathology is evident after clinical examination and investigation.

\section{Type of surgical procedure}

\section{Statements}

Level 3A Both open and laparoscopic surgical approaches have been reported to eliminate symptoms effectively and enable patients to return to previous sporting activity levels.

The success rates are very good and comparable between open (92.8\%) and laparoscopic (96\%) repairs based solely on the criterion of return to sports activity.

A wide variety of open repair techniques are described with or without mesh, including repair of a presumed "thin" or damaged insertion of the tendon of the rectus abdominis onto the pubic crest, but there are no data allowing a comparison between these techniques.

There is no scientific evidence that an adductor tenotomy is of any additional value.

In open repair, ilioinguinal nerve resection seems to be beneficial.

Laparoscopic approach may provide better posterior inguinal wall exposure, enabling easier bilateral reinforcement.
During surgery, the inguinal canal should be thoroughly explored to find different entities responsible for inguinal pain (preperitoneal lipoma, etc.).

Laparoscopic techniques generally enable a quicker recovery time than open techniques.

Level 4 Two variations of laparoscopic surgery are applied: the transabdominal preperitoneal patch plasty (TAPP) and the total extraperitoneal patch plasty (TEP); however, no study shows the superiority of one compared with the other.

\section{Recommendations}

Grade C Regarding time of recovery and return to preinjury sports activity levels, laparoscopic surgery-either TAPP or TEP — should be the treatment of choice.

Well-designed prospective, randomized, controlled studies are greatly needed to establish the true efficacy of these different surgical approaches.

\section{Postsurgical rehabilitation \\ Statements}

Level 3A A detailed description of postsurgical rehabilitation programs is generally lacking.

Level 4 For patients who underwent open repair, overall postsurgical recovery time (based on return to sports activity) was found to be 17.7 weeks compared with 6.1 weeks for laparoscopic repairs.

\section{Recommendations}

Grade 3A Early, sharp, sudden movements after surgery should be avoided, and core and leg musculoskeletal inflexibility, weakness, poor endurance, or poor coordination should be identified and corrected.

Grade 4 A gradually progressive 6-week rehabilitation program should be undertaken after both open and laparoscopic repair.

Grade 5 Well-designed studies are greatly needed.

Chronic groin pain in athletes is a difficult problem that requires a multidisciplinary approach not only to diagnosis but also for treatment planning $[4,58]$. Based on previous definitions, if this imbalance of the groin causes a disruption of the muscle/tendon at their insertion site on the pubis, treatment should be based on rest, anti-inflammatory medication, and a proper training program followed by reevaluation. For that reason, conservative treatment is tried first [31], but there is no evidence-based consensus available to guide decision-making [58]. If a weak area has been found at the groin due to the forces produced by the muscles, patients should undergo surgical repair of the groin reinforcing the posterior wall with mesh, because if a conjoined tendon is adequately supported by mesh, abductor discomfort almost uniformly resolves with postoperative rehabilitation. Rarely will the abductor require an operative release, tenotomy, or perforation on the pubis. 


\section{Conservative treatment}

Much groin pain due to problems related to the musculoskeletal system are a self-limiting disease that can take several months to resolve, and corticosteroid injection can sometimes hasten this rehabilitation process [41]. Traditional conservative treatment has low success rates $[9,39$, 47]. Only one RCT could demonstrate that an active physical training program designed to strengthen the muscles to stabilize the hip and pelvis is of advantage for the patient compared with passive measures [27]. Most studies agree that surgical therapy seems to be superior to nonsurgical treatment $[9,14,17,23,28,36]$, but there is only one randomized comparison of poor quality [15].

On the other hand, Schilders et al. [54] has shown the efficiency of a single entheseal pubic cleft injection. This treatment can be expected to afford at least 1 year of relief of adductor-related groin pain in a competitive athlete with normal findings on a magnetic resonance imaging scan; however, it should be employed only as a diagnostic test or short-term treatment for a competitive athlete with evidence of enthesopathy on magnetic resonance imaging.

\section{Surgery}

Conservative treatment of this entity often does not result in resolution of symptoms [46]. In some series, the athletes have received different conservative treatments without success, and the surgical procedures performed in these cases have offered a definitive resolution to this problem [22]. Several surgical approaches are available for the repair of inguinal hernias, but without knowing the true natural history of this disorder, the problem is that it is difficult to know when it is appropriate to have a hernia repaired [40]. Operating is recommended only if conservative therapy, with prolonged rest, fails [33].

It is important to establish that precise diagnose is always preferable before performing a hernia repair in a patient with chronic groin pain. Steele et al. [56] showed no significant difference in outcome between subjects who had an abnormal ultrasound scan on the symptomatic side and those who had a normal scan. There was a significant difference in outcome between patients who had a bone scan with increased uptake at the symptomatic pubic tubercle and those who did not $(p<0.04)$. This study supports other research that shows that good results can be obtained with surgery when posterior inguinal wall deficiency is the sole diagnosis.

Surgical intervention of hernia repair for chronic groin pain results in pain-free return of full activities in a majority of cases [46]. No consensus view supports any particular surgical procedure for sportsman's hernia [18]. Various types of operations, based on the variable theories regarding the pathophysiological process, have been developed for the treatment of this syndrome.
Some surgeons focus on the external elements of the inguinal canal and repair the external oblique fascia or enforce the groin with the rectus abdominis. Other surgeons perform an inguinal hernia repair procedure, either with sutures or synthetic mesh, performed by an open approach or laparoscopically. Some researchers believe that the problem is in the lower abdominal muscles, or is caused by nerve entrapment, and treat it accordingly. Recent authors compared an open technique (Bassini) and neurotomy of the ileoinguinal nerve applied to patients with a positive herniogram and/or positive nerve block test with athletes who were treated conservatively [15]. Some authors recommend that, in cases where PWD or tear of the posterior inguinal wall are clearly diagnosed, routine inguinal hernia repair should be done without unnecessary delay $[17,42,46]$.

Basically, a number of reports have been published that describe different repairs of the posterior inguinal wall deficiency as the main approach for sportman's hernias with excellent results $[19,22]$. During the operation, the inguinal canal should be thoroughly explored to find the different entities that could be detected during surgery, such us a true inguinal hernia, wide internal ring and peritoneal dimple [57], hernia femoralis [35], preperitoneal lipoma [59], hernia obturatoria [35], prevascular hernia [3], obvious musculotendinous tear [50], muscle asymmetry [50], or a significant bulge in the posterior wall [40]. Even if no clear pathology is identified, reinforcement of the wall using a mesh offers good clinical results for athletes with idiopathic groin pain [60], although other authors have recommended not using the mesh in these cases [33]. The most common finding in athletes with chronic groin pain was a deficiency of the posterior wall of the inguinal canal [52]. Some authors believe that ilioinguinal nerve resection may be beneficial for patients $[7,15,30,37,52,66]$, but the overall quality of most of the studies is low [31].

When the surgical option is selected, either the open or the laparoscopic approach can provide good results [9, 23, 28]. The endoscopic preperitoneal approach the technique was used more during the past year [50, 55, 57,60], although other authors consider an open hernia repair using mesh, performed as an outpatient procedure with local anesthesia and sedation as the optimal treatment [32]. Ingoldby [28] performed a comparative nonrandomized study that compared the open and the laparoscopic approach, which showed that the endoscopic repair permits an early return to activity.

A wide variety of open repair techniques are described with mesh [1, 5, 24, 56, 59] or without [15, 20-22, 42, 52], including repair of a "thin" or damaged insertion of the tendon of the rectus abdominis onto the pubic crest [44, 45], but there are no data allowing a comparison between these techniques [9, 31]. One author reported good preliminary results for using fibrin glue to secure the mesh and 
achieve tension-free open inguinal hernia repair in soccer athletes with chronic pain [8].

The laparoscopic approach may provide better posterior inguinal wall exposure, enabling easier bilateral reinforcement [19] and allow a quicker recovery time than open surgery $[9,23,28,58]$. Two types of laparoscopic surgery are successfully applied: the transabdominal preperitoneal patch plasty (TAPP) $[19,28,35,65]$, and the total extraperitoneal preperitoneal patch plasty $[12,51,55,57,60]$. No studies have shown the true efficacy of these different techniques, thus a recommendation for one or the other method cannot be given and depends on the skill and personal preference of the surgeon involved. Well-designed prospective, randomized, controlled studies are greatly needed for more clarity and more reliable recommendations. The same is true with respect to postsurgical rehabilitation programs. Until now, there has been no general agreement about the best postoperative physical training programme to enable the athletes to return to full sports activity in the shortest time [24, 60]. Valuable studies that have a high level of evidence are urgently needed.

References (in parentheses graduation of evidence)

1. Ahumada LA, Ashruf S, Espinosa-de-los-Monteros A, Long JN, de la Torre JI, Garth WP, Vasconez LO (2005) Athletic pubalgia: definition and surgical treatment. Ann Plast Surg 55:393-396. (4)

2. Akita K, Niga S, Yamato Y, Muneta T, Sato T (1999) Anatomic basis of chronic groin pain with special reference to sports hernia. Surg Radiol Anat 21: $1-5 .(4)$

3. Aldridge AJ, Packham IM, Nash AG (2001) Prevascular hernia: a rare cause of chronic obscure groin pain after inguinal hernia repair. Hernia 5(1):53-55. (4)

4. Azurin DJ, Go LS, Schuricht A, McShane J, Bartolozzi A (1997) Endoscopic preperitoneal herniorrhaphy in professional athletes with groin pain. J Laparoendosc Adv Surg Tech A 7:7-12. (4)

5. Brannigan AE, Kerin MJ, McEntee GP (2000) Gilmore's groin repair in athletes. J Orthop Sports Phys Ther 30:329-332. (4)

6. Barile A, Erriquez D, Cacchio A, De Paulis F, Di Cesare E, Masciocchi C (2000) Groin pain in athletes: role of magnetic resonance. Radiol Med (Torino 100(4):216-222. (4)

7. Brown RA, Mascia A, Kinnear DG, Lacroix V, Feldman L, Mulder DS (2008) An 18-year review of sports groin injuries in the elite hockey player: clinical presentation, new diagnostic imaging, treatment, and results. Clin J Sport Med 18:221-226. (4)

8. Canonico S, Benevento R, Della Corte A, Fattopace A, Canonico R (2007) Sutureless tension-free hernia repair with human fibrin glue (tissucol) in soccer players with chronic inguinal pain: initial experience. Int J Sports Med 28:873-876. (4)

9. Caudill P, Nyland J, Smith C, Yerasimides J, Lach J (2008) Sports hernias: a systematic literature review. Br J Sports Med 42:954-964. (3)

10. Daigeler A, Belyaev O, Werner H et al. (2007) MRI findings do not correlate with outcome in athletes with chronic groin pain. J Sports Sci Med 6: 71-76. (4)

11. Depasquale R, Landes C, Doyle G (2009) Audit of ultrasound and decision to operate in groin pain of unknown aetiology with ultrasound technique explained. Clin Radiol 64(6):608-614. (4)

12. Edelman DS, Selesnick H (2006) "Sports" hernia: treatment with biologic mesh (Surgisis): a preliminary study. Surg Endosc 20:971-973. (4)

13. Ekberg O, Persson NH, Abrahamsson PA, Westlin NE, Lilja B (1988) Longstanding groin pain in athletes. A multidisciplinary approach. Sports Med 6(1):56-61. (4)

14. Ekstrand J, Hilding J (1999) The incidence and differential diagnosis of acute groin injuries in male soccer players. Scand J Med Sci Sports 9:98-103. (4)

15. Ekstrand J, Ringborg S (2001) Surgery versus conservative treatment in soccer players with chronic groin pain: a prospective randomized study in soccer players. Eur J Sports Traumatol Rel Res 23:141-145. (2B)

16. Falvey EC, Franklyn-Miller A, McCrory PR (2009) The groin triangle: a patho-anatomical approach to the diagnosis of chronic groin pain in athletes. $\mathrm{Br} \mathrm{J}$ Sports Med 43:213-220. (5)

17. Farber AJ, Wilckens JH (2007) Sports hernia: diagnosis and therapeutic approach. J Am Acad Orthop Surg 15:507-514. (5)

18. Fon LJ, Spence RA (2000) Sportsman's hernia. Br J Surg 87:545-552. (3)

19. Genitsaris M, Goulimaris I, Sikas N (2004) Laparoscopic repair of groin pain in athletes. Am J Sports Med 32:1238-1242. (4)

20. Gilmore OJA (1991) Gilmore's groin: 10 years experience with groin disruption - a previously unsolved problem in sportsman. Sports Soft Med Tissue Trauma 3:12-14. (4)

21. Gilmore OJA (1995) Gilmore's groin. Physiother Sport 18:14-15. (4)

22. Hackney RG (1993) The sports hernia: a cause of chronic groin pain. Br J Sports Med 27:58-62. (4)

23. Harmon KG (2007) Evaluation of groin pain in athletes. Curr Sports Med Rep 6:354-361. (4)

24. Hemingway AE, Herrington L, Blower AL (2003) Changes in muscle strength and pain in response to surgical repair of posterior abdominal wall disruption 
followed by rehabilitation. $\mathrm{Br} \mathrm{J}$ Sports Med 37:54-58. (4)

25. Holmich P, Dienst M (2006) Differential diagnosis of hip and groin pain. Symptoms and technique for physical examination. Orthopade 35:10-15. (5)

26. Hölmich P, Hölmich LR, Bjerg AM (2004) Clinical examination of athletes with groin pain: an intraobserver and interobserver reliability study. Br J Sports Med 38:446-451. (2b)

27. Hölmich P, Uhrskou P, Ulnits L et al. (1999) Effectiveness of active physical training as treatment for long-standing adductor-related groin pain in athletes: randomised trial. Lancet 353:439-443. (1B)

28. Ingoldby CJ (1997) Laparoscopic and conventional repair of groin disruption in sportsmen. Br J Surg 84:1171-1172. (3)

29. Inklaar H, Bol E, Schmikli SL, Mosterd WL (1996) Injuries in male soccer players: team risk analysis. Int J Sport Med 17:229-234. (3)

30. Irshad K, Feldman LS, Lavoie C, Lacroix VJ, Mulder DS, Brown RA (2001) Operative management of "hockey groin syndrome": 12 years of experience in National Hockey League players. Surgery 130: 759-764. (4)

31. Jansen JA, Mens JM, Backx FJ, Kolfschoten N, Stam HJ (2008) Treatment of longstanding groin pain in athletes: a systematic review. Scand J Med Sci Sports 18:263-274. (3)

32. Joesting DR (2002) Diagnosis and treatment of sportsman's hernia. Curr Sports Med Rep 1: 121-124. (5)

33. Kaplan O, Arbel R (2005) Sportsman's hernia-a plea for conservative therapeutical approach. Harefuah 144:351-356, 381. (5)

34. Kidron A (2001) Groin pain in sport Harefuah. 140:1095-1099, 1115. (5)

35. Kluin J, den Hoed PT, van Linschoten R, Ijzerman JC, van Steensel CJ (2004) Endoscopic evaluation and treatment of groin pain in athletes. Am J Sports Med 32:944-948. (4)

36. Kumar A, Doran J, Batt ME, Nguyen-Van-Tam JS, Beckingham IJ (2002) Results of inguinal canal repair in athlete $\mathrm{s}$ with sports hernia. R Coll Surg Edinb 47:561-565. (4)

37. Lacroix VJ, Kinnear DG, Mulder DS, Brown RA (1998) Lower abdominal pain syndrome in national hockey league players: a report of 11 cases. Clin J Sport Med 8:5-9. (4)

38. Lilly MC, Arregui ME (2002) Ultrasound of the inguinal floor for evaluation of hernias. Surg Endosc 16:659-662. (3)

39. LeBlanc KE, LeBlanc KA (2003) Groin pain in athletes. Hernia 7:68-71. (5)
40. Lorenzini C, Sofia L, Pergolizzi FP, Trovato M (2008) The value of diagnostic ultrasound for detecting occult inguinal hernia in patients with groin pain. Chir Ital 60(6):813-817. (3)

41. Lynch SA, Renström PA (1999) Groin injuries in sport: treatment strategies. Sports Med 28:137-144. (5)

42. Malycha P, Lovell G (1992) Inguinal surgery in athletes with chronic groin pain: the 'sportsman's' hernia. Aust N Z J Surg 62:123-125. (4)

43. McCrory P, Bell S (1999) Nerve entrapment syndromes as a cause of pain in the hip, groin and buttock. Sports Med 27:261-274. (4)

44. Meyers WC, Foley DO, Garrett WE et al. (2000) Management of severe lower abdominal or inguinal pain in high-performance athletes. Performing athletes with abdominal or inguinal neuromuscular pain study group (PAIN). Am J Sports Med 28:2-8. (4)

45. Meyers WC, McKechnie A, Philippon MJ, Horner MA, Zoga AC, Devon ON (2008) Experience with "sports hernia" spanning two decades. Ann Surg 248:656-665. (4)

46. Moeller JL (2007) Sportsman's hernia.. Curr Sports Med Rep 6(2):111-114. (5)

47. Morelli V, Smith V (2001) Groin injuries in athletes. Am Fam Physc 15:1405-1414. (5)

48. Omar IM, Zoga AC, Kavanagh EC, Koulouris G, Bergin D, Gopez AG, Morrison WB, Meyers WC (2008) Athletic pubalgia and "sports hernia": optimal MR imaging technique and findings. Radiographics 28:1415-438. (4)

49. Orchard JW, Read JW, Neophyton J, Garlick D (1998) Groin pain associated with ultrasound finding of inguinal canal posterior wall deficiency in Australian Rules footballers. Br J Sports Med 32:134-139. (4)

50. Paajanen H, Hermunen H, Karonen J (2008) Pubic magnetic resonance imaging findings in surgically and conservatively treated athletes with osteitis pubis compared with asymptomatic athletes during heavy training. Am J Sports Med 36(1):117-121. (3)

51. Paajanen H, Syvähuoko I, Finland AI (2004) Totally extraperitoneal endoscopic (TEP) treatment of sportsman's hernia. Surg Laparosc Endosc Percutan Tech 14:215-218. (4)

52. Polglase AL, Frydman GM, Framer KC (1991) Inguinal surgery for debilitating chronic groin pain in athletes. Med J Aust 155:674-677. (4)

53. Renstroem AF (1997) Groin injuries: a true challenge in orthopaedic sports medicine. Sports Med Arthroscopy Rev 5:247-251. (4)

54. Schilders E, Bismil Q, Robinson P, O'Connor PJ, Gibbon WW, Talbot JC (2007) Adductor-related groin pain in competitive athletes. Role of adductor enthesis, magnetic resonance imaging, and entheseal 
pubic cleft injections. J Bone Joint Surg Am 89(10):2173-2178. (3)

55. Srinivasan A, Schuricht A (2002) Long-term followup of laparoscopic preperitoneal hernia repair in professional athletes. J Laparoendosc Adv Surg Tech A 12:101-106. (4)

56. Steele P, Annear P, Grove JR. Surgery for posterior inguinal wall deficiency in athletes. J Sci Med Sport. 2004; 7: 415-421. (4)

57. Susmallian S, Ezri T, Elis M, Warters R, Charuzi I, Muggia-Sullam M (2004) Laparoscopic repair of "sportsman's hernia" in soccer players as treatment of chronic inguinal pain. Med Sci Monit 10:52-54. (4)

58. Swan KG Jr, Wolcott M (2007) The athletic hernia: a systematic review. Clin Orthop Relat Res 455:78-87. (3)

59. Taylor DC, Meyers WC, Moylan JA, Lohnes J, Bassett FH, Garrett WE Jr (1991) Abdominal musculature abnormalities as a cause of groin pain in athletes. Inguinal hernias and pubalgia. Am J Sports Med 19:239-242. (4)

60. van Veen RN, de Baat P, Heijboer MP, Kazemier G, Punt BJ, Dwarkasing RS, Bonjer HJ, van Eijck CH (2007) Successful endoscopic treatment of chronic groin pain in athletes. Surg Endosc 21:189-193. (4)

61. Verrall GM, Slavotinek JP, Fon GT et al. (2007) Outcome of conservative management of athletic chronic groin injury diagnosed as pubic bone stress injury. Am J Sports Med 35:467-474. (4)

62. Verrall GM, Slavotinek JP, Fon GT (2001) Incidence of pubic bone marrow oedema in Australian rules football players: relation to groin pain. $\mathrm{Br} \mathrm{J}$ Sports Med 35:28-33. (4)

63. Westlin N (1997) Groin pain in athletes from Southern Sweden. Sports Med Athrosc Rev 5:280-284. (4)

64. Yilmazlar T, Kizil A, Zorluoglu A, Ozgüç H (1996) The value of herniography in football players with obscure groin pain. Acta Chir Belg 96:115-118. (4)

65. Ziprin P, Prabhudesai SG, Abrahams S, Chadwick SJ (2008) Transabdominal preperitoneal laparoscopic approach for the treatment of sportsman's hernia. J Laparoendosc Adv Surg Tech A 18:669-672. (4)

66. Ziprin P, Williams P, Foster E (1999) External oblique aponeurosis nerve entrapment as a cause of groin pain in the athlete. Br J Surg 86:566-568. (4)

\section{Remarks on costs}

Some readers of the Guidelines will miss a chapter on costs. We discussed this topic several times but decided against a chapter on this subject. Without any question, costs are an important issue. Several studies attempted to measure the costs of hernia surgery but with doubtful results. It is an extremely difficult task to perform a reliable analysis of costs (for hospital and society), which might be useful for the surgical community. When calculating costs, one key point is that payroll and operating room costs crucially depend on the kind of hospital in which the operation takes place. Furthermore, these costs are predicated on the hospital's location, the town, region, country, and continent, and last but not least on the surgeon's skills. To make it simple, there should be the following basic rules (Level 5) to make aiming costs as low as possible: (1) use the equipment (video tower) for other laparoscopic procedures; (2) use nondisposable trocars and instruments; (3) use a cost-effective mesh (see Chapter "Selection of mesh materials"); (4) perform a lot of operations; (5) perform in a high-quality; and (6) do it in a reasonable time.

In conclusion, a strictly standardized technique and perioperative management according to the presented Guidelines of the International Endohernia Society (IEHS) are indispensable requirements for performing a cost-efficient laparoscopic hernia repair.

\section{Guidelines Committee Members}

Maurice Arregui, Department Chair, General Surgery, St. Vincent Hospital, Indianapolis, Indiana, USA.

Rene Fortelny, Univ.-Lector. Chief Resident, 2nd Department of Surgery, Wilhelminenspital, Vienna, Austria.

Uwe Klinge, Institut for Applied Medical Engineering AME Helmholtz, Aachen, Germany.

Davide Lomanto, Director of the Minimally Invasive Surgical Center; Director of the KTP Advanced Surgical Training Center; YYL School of Medicine, National University of Singapore.

Jacob Rosenberg, Chief Surgeon, Department of Surgery D, Herlev Hospital, University of Copenhagen, Denmark.

Stefan Sauerland, Head of the Department of Non-Drug Interventions, Institute for Quality and Efficiency in Healthcare, Cologne, Germany.

Christine Schug-Pass, Department for Surgery, Center for Minimally Invasive Surgery, Vivantes Klinikum Spandau, Berlin, Germany.

Michael Timoney, Attending Surgeon/Director of Quality Assurance, Lutherian Medical Center, Brooklyn, NY, USA.

Acknowledgment We are very grateful to Max Healthcare Institute Ltd., Saket, New Delhi (India) for supporting open access to this publication.

Open Access This article is distributed under the terms of the Creative Commons Attribution Noncommercial License which permits any noncommercial use, distribution, and reproduction in any medium, provided the original author(s) and source are credited. 